\title{
Biomimetic Total Synthesis and Antimicrobial Evaluation of Anachelin
}

\section{SUPPORTING INFORMATION}

Karl Gademann*,†,, Yann Bethuel, $\ddagger$ Hans H. Locher, $\S$ and Christian Hubschwerlen, $\S$

Chemical Synthesis Laboratory, Swiss Federal Institute of Technology (EPFL), SB-ISIC-

LSYNC, CH-1015 Lausanne, Switzerland, and Laboratorium für Organische Chemie, Swiss

Federal Institute of Technology (ETH), CH-8093 Zürich, Switzerland and Actelion

Pharmaceuticals, Gewerbestrasse 16, CH-4123 Allschwil, Switzerland.

karl.gademann@epfl.ch

$\dagger$ EPFL

†TH Zürich

$\S$ Actelion 
Table of Contents

$\begin{array}{ll}\text { Experimental } & \text { S-3 }\end{array}$

$\begin{array}{ll}\text { General } & \text { S-3 }\end{array}$

$\begin{array}{ll}\text { Procedures and characterization data } & \text { S-4 }\end{array}$

$\begin{array}{ll}\text { Antimcrobial evaluation } & \text { S-36 }\end{array}$

$\begin{array}{ll}\text { References } & \text { S-36 }\end{array}$

$\begin{array}{ll}\text { NMR spectra } & \text { S-37 }\end{array}$ 
Experimental. - Abbreviations. Boc = tert-butoxycarbonyl; $\mathrm{CDI}=$ Carbonyldiimidazole; DMAP $=N, N$-Dimethylaminopyridine $;$ EDC $=$ ethyl- $(N, N$-dimethylaminopropyl $)$ carbodiimide; ether refers to diethylether; $\mathrm{FC}=$ Flashchromatography; $\mathrm{HOBt}=1$-hydroxybenzotriazole; NMM $=\mathrm{N}$-methyl-morpholine; $\mathrm{RT}=$ room temperature; $\mathrm{TBS}=$ tert -Butyl-dimethylsilyl; $\mathrm{THF}=$ tetrahydrofuran; THQ = 3-Amino-6,7-dihydroxy-1,1-dimethyl-1,2,3,4-tetrahydro-quinolinium; Z $=$ Benzyloxycarbonyl.

\section{General.}

Reactions were run under an atmosphere of Ar in dry glassware (at least $24 \mathrm{~h}$ in an oven at 140 ${ }^{\circ} \mathrm{C}$, followed by heating with a heat gun under high vacuum). Analytical thin layer chromatograpy (TLC) was performed on silica gel plates $(0.25 \mathrm{~mm}$ thickness) precoated with a fluorescent indicator. The developed plates were examined under UV light and stained with ceric ammonium molybdate (CAM) stain or $\mathrm{KMnO}_{4}$ stain followed by heating. Flash chromatography was performed using silica gel 60 (230-400 mesh). All ${ }^{1} \mathrm{H}$ and ${ }^{13} \mathrm{C}$ NMR spectra were recorded at ambient temperature, chemical shifts $\delta$ are given in ppm, coupling constants $J$ are in Hz. IR spectra were recorded as $\mathrm{CHCl}_{3}$ solution, absorptions are given in $\mathrm{cm}^{-1}$. Optical rotations were measured using a $1 \mathrm{ml}$ cell with a $1 \mathrm{dm}$ path length, the concentration $c$ is given in $\mathrm{g} / 100 \mathrm{~mL}$. In massspectroscopy, fragment ions are given in $\mathrm{m} / \mathrm{z}$ with relative intensities (\%) in parentheses. Nomenclature is according to Autonom 2.0, Beilstein Informationssysteme GmbH. 
(4S)-5-Benzyloxy-4-benzyloxycarbonylamino-3-oxo-pentanoic acid methyl ester (8). $\mathrm{MgCl}_{2}$ $(15.2 \mathrm{~g}, 0.16 \mathrm{~mol})$ was suspended in THF $(300 \mathrm{ml})$ in a 11 flask, $\mathrm{KO}_{2} \mathrm{CCH}_{2} \mathrm{CO}_{2} \mathrm{Me}(31.5 \mathrm{~g}, 0.202$ mol) was added in one portion and the resulting suspension heated to reflux for $5 \mathrm{~h}$. The suspension was then cooled with an ice bath. In the meantime, Z-L-Ser(OBn)-OH (7) (42.5 g, $0.125 \mathrm{~mol})$ was dissolved in THF $(300 \mathrm{ml})$ in a $11 \mathrm{flask}$. The solution was cooled in an ice bath, and CDI (22.3 g, $0.1375 \mathrm{~mol}, 1.1 \mathrm{eq})$ was added in portions. After 1 minute, gas evolution started and the solution was stirred $1 \mathrm{~h}$ at $0{ }^{\circ} \mathrm{C}$ and $1 \mathrm{~h}$ at RT. This solution containing the activated amino acid was then added dropwise to the $\mathrm{K}-\mathrm{Mg}$-enolate suspension via addition funnel at $0{ }^{\circ} \mathrm{C}$. The resulting suspension was warmed up to RT and was stirred for $16 \mathrm{~h}$ at RT. The solvent was evaporated, the residue taken up in EtOAc and $1 \mathrm{M} \mathrm{HCl}$ solution was added. The mixture was stirred for 10 minutes resulting in a yellowish solution. The layers were separated and the aq. layer extracted $3 \mathrm{x}$ with EtOAc. The combined org. layers were then washed $2 \mathrm{x}$ with $1 \mathrm{~N} \mathrm{HCl}$ soln, $2 \mathrm{x}$ with satd. $\mathrm{NaHCO}_{3}$ solution and $2 \mathrm{x}$ with brine. The org. layer was dried $\left(\mathrm{Na}_{2} \mathrm{SO}_{4}\right)$, filtered and the solvent was evaporated. FC (EtOAc/Hexane 1:4) gave the title compound 8 (34.2 g, $89 \mathrm{mmol}, 71 \%)$. Colorless oil. $\mathrm{R}_{\mathrm{f}}=0.15\left(\right.$ EtOAc/Hexane 1:2.5). $[\alpha]_{\mathrm{D}}=$ $+0.6\left(\mathrm{c}=0.75, \mathrm{CHCl}_{3}\right) .{ }^{1} \mathrm{H}-\mathrm{NMR}\left(\mathrm{CDCl}_{3}, 300 \mathrm{MHz}\right) 3.68(\mathrm{~s}, 2 \mathrm{H}), 3.70-3.74(\mathrm{~m}, 4 \mathrm{H}), 3.93(\mathrm{dd}, 1$ $\left.\mathrm{H}, J_{1}=9.7, J_{2}=3.7\right), 4.49(\mathrm{~d}, 2 \mathrm{H}, J=4.1), 4.56-4.61(\mathrm{~m}, 1 \mathrm{H}), 5.12(\mathrm{~s}, 2 \mathrm{H}), 5.81(\mathrm{~d}, 1 \mathrm{H}, J=$ 7.5), 7.24-7.37 (m, 10H). ${ }^{13} \mathrm{C}-\mathrm{NMR}\left(\mathrm{CDCl}_{3}, 75 \mathrm{MHz}\right)$ 46.7, 52.7, 60.5, 67.4, 69.4, 73.7, 128.0, $128.3,128.4,128.5,128.77,128.81,136.3,137.3,156.2,167.3,200.4$. IR 3019s, 2977m, $1721 m$. MS $408.1\left(65,[\mathrm{M}+\mathrm{Na}]^{+}\right), 376.1\left(100,\left[\mathrm{M}+\mathrm{Na}-\mathrm{CH}_{3} \mathrm{OH}\right]^{+}\right)$. HRMS calcd. for $\mathrm{C}_{21} \mathrm{H}_{23} \mathrm{NO}_{6} \mathrm{Na}$ $(\mathrm{M}+\mathrm{Na})^{+}:$408.1418, found: 408.1422. 


\section{(3R, 4S)-5-Benzyloxy-4-benzyloxycarbonylamino-3-hydroxy-pentanoic acid methyl ester}

(9). (4S)-5-Benzyloxy-4-benzyloxycarbonylamino-3-oxo-pentanoic acid methyl ester (8) (1.70 g, $4.41 \mathrm{mmol})$ was dissolved in $\mathrm{MeOH}(40 \mathrm{ml}) / \mathrm{Et}_{2} \mathrm{O}(5 \mathrm{ml})$ and cooled to $-60{ }^{\circ} \mathrm{C}\left(\mathrm{CHCl}_{3} / \mathrm{dry}\right.$ ice bath). $\mathrm{NaBH}_{4}(183.5 \mathrm{mg}, 4.85 \mathrm{mmol})$ was added in one portion, stirring was continued for $6 \mathrm{~h}$, and the reaction mixture was poured into a stirring solution of $10 \%$ citric acid/EtOAc $(100 \mathrm{ml}$, 1:1 v/v). After 20 min., the layers were separated and the aq. layer was $2 \mathrm{x}$ extracted with EtOAc. The comb. organic layers were washed $2 \mathrm{x}$ with brine, dried $\left(\mathrm{MgSO}_{4}\right)$, filtered and the solvent evaporated. FC (EtOAc/Hexane 1:1) gave the title compounds 9 and $\mathbf{1 0}$ (1.538 g, 3.97 mmol, 90\%) as a mixture of 2 diastereoisomers $\left(\mathrm{dr}=2.4: 1\right.$ according to ${ }^{1} \mathrm{H}-\mathrm{NMR}$ analysis of the crude reaction mixture). Recrystallization from EtOAc/Hexane (1:2.5) gave the diastereomerically pure title compound $9(821 \mathrm{mg}, 2.12 \mathrm{mmol}, 48 \%)$. Colorless crystalline solid. $\mathrm{Mp}=80-82{ }^{\circ} \mathrm{C} . \mathrm{R}_{\mathrm{f}}=0.41\left(\right.$ EtOAc/Hexane 1:1). $[\alpha]_{\mathrm{D}}=+0.03\left(\mathrm{c}=0.56, \mathrm{CHCl}_{3}\right) .{ }^{1} \mathrm{H}-\mathrm{NMR}$ $\left(\mathrm{CDCl}_{3}, 300 \mathrm{MHz}\right)$ 2.51-2.67 (m, 2H), $3.39(\mathrm{~d}, 1 \mathrm{H}, J=5.9), 3.59-3.62(\mathrm{~m}, 1 \mathrm{H}), 3.69(\mathrm{~s}, 3 \mathrm{H})$, 3.82-3.84 (m, 2H), 4.11-4.17 (m, 1H), $4.51(\mathrm{~s}, 2 \mathrm{H}), 5.10(\mathrm{~s}, 2 \mathrm{H}, J=7.5), 5.39(\mathrm{~d}, 1 \mathrm{H}, J=8.1)$, 7.26-7.35 (m, 10H). ${ }^{13} \mathrm{C}-\mathrm{NMR}\left(\mathrm{CDCl}_{3}, 75 \mathrm{MHz}\right)$ 38.5, 51.9, 54.0, 67.0, 68.9, 69.0, 73.5, 127.6, 127.8, 128.0, 128.1, 128.39, 128.44, 136.1, 137.4, 156.1, 172.7. IR 3437w, 3020s, 1720s, $1508 m$. MS $410.2\left(100,[\mathrm{M}+\mathrm{Na}]^{+}\right), 344.2\left(89,\left[\mathrm{M}+\mathrm{Na}-\mathrm{CH}_{3} \mathrm{OH}\right]^{+}\right)$. HRMS calcd. for $\mathrm{C}_{21} \mathrm{H}_{25} \mathrm{NO}_{6} \mathrm{Na}$ $(\mathrm{M}+\mathrm{Na})^{+}:$410.1574, found: 410.1570. Anal. calcd. for $\mathrm{C}_{21} \mathrm{H}_{25} \mathrm{NO}_{6}(387.43): \mathrm{C} 65.10, \mathrm{H} 6.50, \mathrm{~N}$ 3.62; found: C 64.94, H 6.34, N 3.63. 


\section{(3R, 4S)-5-Benzyloxy-4-benzyloxycarbonylamino-3-(tert-butyl-dimethyl-silanoxy)-}

pentanoic acid methyl ester (9a). (3R, 4S)-5-Benzyloxy-4-benzyloxycarbonylamino-3hydroxy-pentanoic acid methyl ester (9) (1.0455 g, $2.698 \mathrm{mmol}$ ) was dissolved in $\mathrm{CH}_{2} \mathrm{Cl}_{2}$ and the solution was cooled to $-20{ }^{\circ} \mathrm{C} .2,6$-Lutidine $(0.63 \mathrm{ml}, 5.396 \mathrm{mmol})$ was added dropwise, followed by the dropwise addition of TBSOTf $(0.93 \mathrm{ml}, 4.05 \mathrm{mmol})$. The reaction was allowed to stir at $-20{ }^{\circ} \mathrm{C}$ for $30 \mathrm{~min}$. and $15 \mathrm{~min}$. at $\mathrm{RT}$, after which the reaction mixture was diluted with $\mathrm{CH}_{2} \mathrm{Cl}_{2}$. The organic layer was washed $3 \mathrm{x}$ using $10 \%$ citric acid solution, $1 \mathrm{x}$ with $\mathrm{H}_{2} \mathrm{O}$, dried $\left(\mathrm{MgSO}_{4}\right)$ and the solvent evaporated. FC (EtOAc/Hexane 1:6) followed by FC (EtOAc/Hexane 1:7) gave the title compound (9a) $(1.057 \mathrm{~g}, 2.109 \mathrm{mmol}, 78 \%)$. Colorless oil. $\mathrm{R}_{\mathrm{f}}=0.16$ (EtOAc/Hexane 1:7). $[\boldsymbol{\alpha}]_{\mathrm{D}}=+0.15\left(\mathrm{c}=1.14, \mathrm{CHCl}_{3}\right) .{ }^{1} \mathrm{H}-\mathrm{NMR}\left(\mathrm{CDCl}_{3}, 300 \mathrm{MHz}\right) 0.03(\mathrm{~s}, 3 \mathrm{H})$, $0.05(\mathrm{~s}, 3 \mathrm{H}), 0.85(\mathrm{~s}, 9 \mathrm{H}), 2.48\left(\mathrm{dd}, 1 \mathrm{H}, J_{1}=15.9, J_{2}=6.2\right), 2.64\left(\mathrm{dd}, 1 \mathrm{H}, J_{1}=15.9, J_{2}=5.9\right)$, $3.50\left(\mathrm{dd}, 1 \mathrm{H}, J_{1}=9.4, J_{2}=4.4\right), 3.61(\mathrm{~s}, 3 \mathrm{H}), 3.70\left(\mathrm{dd}, 1 \mathrm{H}, J_{1}=9.4, J_{2}=3.7\right), 3.84-3.88(\mathrm{~m}, 1 \mathrm{H})$, 4.33-4.36 (m, 1H), $4.44(\mathrm{~d}, 1 \mathrm{H}, J=11.8), 4.51(\mathrm{~d}, 1 \mathrm{H}, J=11.8), 5.05-5.19(\mathrm{~m}, 3 \mathrm{H}), 7.28-7.36$ $(\mathrm{m}, 10 \mathrm{H}) .{ }^{13} \mathrm{C}-\mathrm{NMR}\left(\mathrm{CDCl}_{3}, 75 \mathrm{MHz}\right)-4.9,-4.6,18.0,25.8,40.1,51.6,55.4,66.8,68.3$, 69.0, 73.1, 127.6 (2 C), 128.0 (2 C), 128.3, 128.4, 136.4, 137.7, 155.9, 171.8. IR 3028w, 1728s, 1508m. MS $524.2\left(100,[\mathrm{M}+\mathrm{Na}]^{+}\right), 458.3(11), 394.2$ (17). HRMS calcd. for $\mathrm{C}_{27} \mathrm{H}_{39} \mathrm{NO}_{6} \mathrm{SiNa}$ $(\mathrm{M}+\mathrm{Na})^{+}:$524.2439, found: 524.2434. 


\section{(3R, 4S)-5-Benzyloxy-4-benzyloxycarbonylamino-3-(tert-butyl-dimethyl-silanoxy)-}

pentanoic acid (9b). (3R, 4S)-5-Benzyloxy-4-benzyloxycarbonylamino-3-(tert-butyl-dimethylsilanoxy)-pentanoic acid methyl ester (9a) $(7.8 \mathrm{~g}, 15.5 \mathrm{mmol})$ was dissolved in THF (150 ml) / $\mathrm{MeOH}(75 \mathrm{ml})$ and cooled with an ice-bath. A solution of $1 \mathrm{~N} \mathrm{NaOH}(75 \mathrm{ml})$ was added dropwise over 15 minutes and the reaction was allowed to stir at $0{ }^{\circ} \mathrm{C}$ for $1 \mathrm{~h}$ and at $\mathrm{RT}$ for $3 \mathrm{~h}$. The reaction mixture was then acidified to $\mathrm{pH}=7$ with $10 \%$ citric acid solution and the organic solvent removed. The $\mathrm{pH}$ of the aqueous layer was adjusted to $\mathrm{pH}=1-2$ with $1 \mathrm{~N} \mathrm{HCl}$ solution and followed by extraction of the aqueous layer $3 \mathrm{x}$ with EtOAc. The comb. organic layers were washed with $2 \times \mathrm{NaCl}$ soln., dried $\left(\mathrm{MgSO}_{4}\right)$, filtered and the solvent evaporated. FC (EtOAc/Hexane 1:1) and subsequent drying under high vacuum $\left(3 \times 10^{-2}\right.$ mbar at $\left.65^{\circ} \mathrm{C}\right)$ gave the title compound (9b) (4.05 g, $8.3 \mathrm{mmol}, 54 \%)$. Colorless oil. $\mathrm{R}_{\mathrm{f}}=0.45($ EtOAc/Hexane 1:1). $[\alpha]_{\mathrm{D}}=+0.24\left(\mathrm{c}=0.67, \mathrm{CHCl}_{3}\right) .{ }^{1} \mathrm{H}-\mathrm{NMR}\left(\mathrm{CDCl}_{3}, 300 \mathrm{MHz}\right) 0.10(\mathrm{~s}, 6 \mathrm{H}), 0.91(\mathrm{~s}, 9 \mathrm{H}), 2.57(\mathrm{dd}$, $\left.1 \mathrm{H}, J_{1}=15.9, J_{2}=6.2\right), 2.72\left(\mathrm{dd}, 1 \mathrm{H}, J_{1}=15.9, J_{2}=4.7\right), 3.56\left(\mathrm{dd}, 1 \mathrm{H}, J_{1}=9.7, J_{2}=4.4\right), 3.65-$ $3.76(\mathrm{~m}, 1 \mathrm{H}), 3.95-4.00(\mathrm{~m}, 1 \mathrm{H}), 4.38-4.39(\mathrm{~m}, 1 \mathrm{H}), 4.49(\mathrm{~d}, 1 \mathrm{H}, J=11.8), 4.56(\mathrm{~d}, 1 \mathrm{H}, J=$ 11.8), 5.15-5.2 (m, 2H), 5.28 (d, $1 \mathrm{H}, J=9.0), 7.29-7.39(\mathrm{~m}, 10 \mathrm{H}) .{ }^{13} \mathrm{C}-\mathrm{NMR}\left(\mathrm{CDCl}_{3}, 75 \mathrm{MHz}\right)-$ $4.8,-4.4,18.1,25.9,40.1,55.2,67.0,68.2,69.0,73.2,127.7,128.0,128.3(2 \mathrm{C}), 128.4(2 \mathrm{C})$, 136.3, 137.6, 156.2, 176.7. IR 3021w, 1720s, 1510m. MS $510.2\left(100,[\mathrm{M}+\mathrm{Na}]^{+}\right), 444.3(25)$. HRMS calcd. for $\mathrm{C}_{26} \mathrm{H}_{37} \mathrm{NO}_{6} \mathrm{SiNa}(\mathrm{M}+\mathrm{Na})^{+}: 510.2282$, found: 510.2278. 


\section{(5R, 6S)-7-Benzyloxy-6-benzyloxycarbonylamino-5-hydroxy-3-oxo-heptanoic acid methyl}

ester (11). $\mathrm{MgCl}_{2}(1.27 \mathrm{~g}, 13.3 \mathrm{mmol})$ was dissolved in THF $(60 \mathrm{ml}), \mathrm{KO}_{2} \mathrm{CCCH}_{2} \mathrm{CO}_{2} \mathrm{Me}(2.85$ $\mathrm{g}, 18.26 \mathrm{mmol}$ ) was added and the resulting suspension stirred at reflux for $5 \mathrm{~h}$. In the meantime in another flask, (3R, 4S)-5-Benzyloxy-4-benzyloxycarbonylamino-3-(tert-butyl-dimethylsilanoxy)-pentanoic acid (9b) $(4.05 \mathrm{~g}, 8.30 \mathrm{mmol})$ was dissolved in $\mathrm{THF}(60 \mathrm{ml})$, cooled to $0{ }^{\circ} \mathrm{C}$, CDI (1.48 g, $9.13 \mathrm{mmol}$ ) added and the resulting solution was stirred for $1 \mathrm{~h}$ at $0{ }^{\circ} \mathrm{C}$. The suspension containing the $\mathrm{Mg}-\mathrm{K}$-enolate was cooled to $\mathrm{RT}$ and added dropwise via addition funnel to the cooled solution of the activated amino acid. The reaction mixture was allowed to warm to RT and stirred for $16 \mathrm{~h}$. The solvent was evaporated and the residue was taken up in 100 $\mathrm{ml} 10 \%$ citric acid solution/100 ml EtOAc and stirred for 20 minutes after which the suspension turned clear. The layers were separated and the aqueous layer was extracted $3 \mathrm{x}$ with EtOAc. The combined organic layers were washed $3 \mathrm{x}$ with satd. $\mathrm{NaHCO}_{3}$ solution, $3 \mathrm{x}$ with $10 \%$ citric acid solution and $3 \mathrm{x}$ with brine. The organic layer was dried $\left(\mathrm{MgSO}_{4}\right)$, filtered and the solvent removed under reduced pressure. FC (EtOAc/Hexane 1:5, $\left.\mathrm{R}_{\mathrm{f}}=0.21\right)$ gave $3.38 \mathrm{~g}(6.21 \mathrm{mmol}$, $75 \%)$ of $(5 R, 6 S)-7-B e n z y l o x y-6-$ benzyloxycarbonylamino-5-(tert-butyl-dimethyl-silanoxy)-3oxo-heptanoic acid methyl ester (9c).

(5R,6S)-7-Benzyloxy-6-benzyloxycarbonylamino-5-(tert-butyl-dimethyl-sila-noxy)-3-oxoheptanoic acid methyl ester $(\mathbf{9 c})(2.72 \mathrm{~g}, 5.0 \mathrm{mmol})$ was dissolved in THF $(50 \mathrm{ml})$ and the solution was cooled with an ice bath. TBAF (12.5 ml, $1 \mathrm{M}$ in THF) was added dropwise via syringe and the resulting solution was stirred at $0{ }^{\circ} \mathrm{C}$ for $1 \mathrm{~h}$ and at $\mathrm{RT}$ for $2.5 \mathrm{~h}$. The reaction was quenched with saturated $\mathrm{NaHCO}_{3}$ solution and the layers were separated. The aqueous layer was extracted $4 \mathrm{x}$ with EtOAc, the organic layers were combined and washed $3 \mathrm{x}$ with brine. After drying with $\mathrm{MgSO}_{4}$, the solvent was evaporated. FC (EtOAc/Hexane 1:1) gave the title compound $11(1.28 \mathrm{~g}, 3.0 \mathrm{mmol}, 60 \%)$. Colorless needles. $\mathrm{Mp}=81-83{ }^{\circ} \mathrm{C} . \quad \mathrm{R}_{\mathrm{f}}=0.26$ $\left(\right.$ EtOAc/Hexane 1:1). $[\alpha]_{\mathrm{D}}=+0.25\left(\mathrm{c}=0.5, \mathrm{CHCl}_{3}\right) .{ }^{1} \mathrm{H}-\mathrm{NMR}\left(\mathrm{CDCl}_{3}, 300 \mathrm{MHz}\right) 2.78(\mathrm{~d}, 2 \mathrm{H}, J$ 
$=5.6), 3.40-3.44(\mathrm{~m}, 3 \mathrm{H}), 3.56-3.59(\mathrm{~m}, 1 \mathrm{H}), 3.70(\mathrm{~m}, 3 \mathrm{H}), 3.71-3.81(\mathrm{~m}, 2 \mathrm{H}), 4.15-4.19(\mathrm{~m}$, $1 \mathrm{H}), 4.50(\mathrm{~s}, 2 \mathrm{H}), 5.01(\mathrm{~s}, 2 \mathrm{H}), 5.45(\mathrm{~d}, 1 \mathrm{H}, J=8.4), 7.25-7.35(\mathrm{~m}, 10 \mathrm{H}) .{ }^{13} \mathrm{C}-\mathrm{NMR}\left(\mathrm{CDCl}_{3}, 75\right.$ MHz) 46.6, 49.6, 52.4, 54.1, 67.0, 68.2, 68.8, 73.4, 127.6, 127.8, 128.0, 128.1, 128.4, 128.5, 136.2, 137.5, 156.2, 167.2, 202.9. IR 3435w, 3022m, 1716s (shoulder 1737m), 1508m. MS 452.2 $\left(100,[\mathrm{M}+\mathrm{Na}]^{+}\right), 420.1(54), 368.2(63)$. HRMS calcd. for $\mathrm{C}_{23} \mathrm{H}_{27} \mathrm{NO}_{7} \mathrm{Na}(\mathrm{M}+\mathrm{Na})^{+}: 452.1680$, found: 452.1688. Anal. calcd. for $\mathrm{C}_{23} \mathrm{H}_{27} \mathrm{NO}_{7}$ (429.47): C 64.32, H 6.34, N 3.26; found: C 64.48, H 6.19, N 3.21. 


\section{7-Benzyloxy-(6S)-6-benzyloxycarbonylamino-(3S, 5R)-3,5-bis-(tert-butyl-dimethyl-}

silanyloxy)-heptanoic acid methyl ester (12). A solution of $\mathrm{Et}_{3} \mathrm{~B}(1.08 \mathrm{~mL}, 1.08 \mathrm{mmol}, 1.5 \mathrm{eq}$, $1 \mathrm{M}$ sol. in hexane) and pivalic acid (3.7 mg, $36 \mu \mathrm{mol}, 0.05 \mathrm{eq})$ dissolved in dry THF $(0.5 \mathrm{~mL})$ and $\mathrm{MeOH}(1.5 \mathrm{~mL})$ was stirred at $\mathrm{RT}$ for 1 hour and was then cooled to $-70{ }^{\circ} \mathrm{C}$. 7 -Benzyloxy(6S)-6-benzyloxycarbonylamino-(5R)-5-hydroxy-3-oxo-heptanoic acid methyl ester (11) (300 $\mathrm{mg}, 0.72 \mathrm{mmol})$ in dry THF $(2.2 \mathrm{~mL})$ was added dropwise followed by $\mathrm{NaBH}_{4}(82 \mathrm{mg}, 2.16$ mmol, 3 eq) and the reaction mixture was stirred at $-70{ }^{\circ} \mathrm{C}$ for 4 hours. $\mathrm{H}_{2} \mathrm{O}_{2}(3 \mathrm{~mL})$ and $\mathrm{H}_{2} \mathrm{O}(5$ $\mathrm{mL}$ ) were then added at $-70{ }^{\circ} \mathrm{C}$ and the reaction was allowed to warm to $\mathrm{RT}$. Then $\mathrm{CHCl}_{3}$ and $\mathrm{H}_{2} \mathrm{O}$ were added and the aqueous phase extracted with chloroform. The combined organic layers were washed with $5 \mathrm{x} \mathrm{H}_{2} \mathrm{O}$, dried over $\mathrm{Na}_{2} \mathrm{SO}_{4}$, filtered and evaporated under reduced pressure. The residue was directly introduced in the next step.

The residue was dissolved in dry $\mathrm{CH}_{2} \mathrm{Cl}_{2}(1.5 \mathrm{~mL})$ and cooled to $-20{ }^{\circ} \mathrm{C}$. Then 2,6 -lutidine (0.335 mL, $2.88 \mathrm{mmol}, 4 \mathrm{eq})$ and TBSOTf (496 $\mu \mathrm{l}, 2.16 \mathrm{mmol}, 3 \mathrm{eq})$ were added dropwise and the reaction mixture stirred at this temperature for 3 hours. The mixture was washed $3 \mathrm{x}$ with citric acid (10\%), 2x with $\mathrm{H}_{2} \mathrm{O}$, filtered and evaporated under reduced pressure. FC (hexane/EtOAc 9:1) gave the title compound 12 (395 mg, $0.6 \mathrm{mmol}, 85 \%) . \mathrm{R}_{\mathrm{f}}=0.64$ $\left(\right.$ EtOAc/hexane 2:8). $[\alpha]_{\mathrm{D}}=-24.9\left(\mathrm{C}=0.9, \mathrm{CHCl}_{3}, \mathrm{~T}=30.1{ }^{\circ} \mathrm{C}\right) .{ }^{1} \mathrm{H}-\mathrm{NMR}\left(\mathrm{CDCl}_{3}, 300 \mathrm{MHz}\right) \delta$ $0.015(\mathrm{~s}, 3 \mathrm{H}), 0.03(\mathrm{~s}, 3 \mathrm{H}), 0.07(\mathrm{~s}, 3 \mathrm{H}), 0.099(\mathrm{~s}, 3 \mathrm{H}), 0.84(\mathrm{~s}, 9 \mathrm{H}), 0.86(\mathrm{~s}, 9 \mathrm{H}), 1.67-1.8(\mathrm{~m}$, 2H), 2.35-2.45 (m, 1H), 2.48-2.55 (m, 1H), $3.57(\mathrm{~d}, 1 \mathrm{H}, J=5.2), 3.63(\mathrm{~s}, 3 \mathrm{H}), 3.9-4.01(\mathrm{~m}, 2 \mathrm{H})$, 4.2-4.28 (m, 1H), $4.5(\mathrm{~s}, 2 \mathrm{H}), 4.92-5(\mathrm{~m}, 1 \mathrm{H}), 5.1(\mathrm{~s}, 2 \mathrm{H}), 7.2-7.4(\mathrm{~m}, 10 \mathrm{H})$. IR $1735 \mathrm{~m}, 1501 w$. MS $682.4\left(100,[\mathrm{M}+\mathrm{Na}]^{+}\right)$. HRMS calcd. for $\mathrm{C}_{35} \mathrm{H}_{57} \mathrm{NO}_{7} \mathrm{Si}_{2} \mathrm{Na}(\mathrm{M}+\mathrm{Na})^{+}:$682.3566, found: 682.3558 


\section{(6S)-6-(2-benzyloxy-benzoylamino)-(3S,5R)-3,5,7-tris-(tert-butyl-dimethyl-silanyloxy)-}

heptanoic acid methyl ester (13). To a solution of 7-Benzyloxy-(6S)-6benzyloxycarbonylamino-(3S， 5R)-3,5-bis-(tert-butyl-dimethyl-silanyloxy)-heptanoic acid methyl ester (12) $(58 \mathrm{mg}, 88 \mu \mathrm{mol})$ in $\mathrm{MeOH}(1 \mathrm{~mL})$ previously $3 \mathrm{x}$ flushed with argon was added $\mathrm{Pd} / \mathrm{C}$. Then it was flushed with $\mathrm{H}_{2}$ and it was stirred at RT for 4 hours. $\mathrm{Pd} / \mathrm{C}$ was filtered over celite and the solvent was removed under reduced pressure. This product was added to a solution of $O$-Bn-salicylic acid $(20 \mathrm{mg}, 88 \mu \mathrm{mol}, 1 \mathrm{eq})$ dissolved in dry $\mathrm{CH}_{2} \mathrm{Cl}_{2}(1 \mathrm{~mL})$ with EDC.HCl (17 mg, $88 \mu \mathrm{mol}, 1 \mathrm{eq})$, HOBt (13.5 mg, $88 \mu \mathrm{mol}, 1 \mathrm{eq})$ and NMM (29 $\mu \mathrm{L}, 264 \mu \mathrm{mol}$, 3 eq). The reaction mixture was stirred at RT for 20 hours. The solvent was then removed under reduced pressure and the residue taken up with EtOAc. The organic layer was washed 3x with citric acid $(10 \%)$ and $3 \mathrm{x}$ with satd. $\mathrm{NaHCO}_{3}$. The organic phase was dried over $\mathrm{MgSO}_{4}$, filtered and the solvent evaporated under reduced pressure. The residue was dissolved in $\mathrm{CH}_{2} \mathrm{Cl}_{2}(1 \mathrm{~mL})$ and cooled to $-20^{\circ} \mathrm{C}$. Then TBSOTf (44.5 $\mu 1,194 \mu$ mol, 2.2 eq) and 2,6-lutidine $(22.5 \mu 1,194$ $\mu$ mol, 2.2 eq) were added dropwise. The reaction mixture was stirred at $-20{ }^{\circ} \mathrm{C}$ for 3 hours. It was washed $2 \mathrm{x}$ with citric acid, dried over $\mathrm{Na}_{2} \mathrm{SO}_{4}$, filtered and evaporated under reduced pressure. FC (EtOAc/hexane 1:7) gave $13(44 \mathrm{mg}, 58 \mu \mathrm{mol}, 66 \%) . \mathrm{R}_{\mathrm{f}}=0.33($ EtOAc/hexane 1:7). $[\alpha]_{\mathrm{D}}=-0.90\left(\mathrm{C}=1.56, \mathrm{CHCl}_{3}, \mathrm{~T}=25^{\circ} \mathrm{C}\right) .{ }^{1} \mathrm{H}-\mathrm{NMR}\left(\mathrm{CDCl}_{3}, 300 \mathrm{MHz}\right) \delta-0.042(\mathrm{~s}, 3 \mathrm{H}),-$ $0.037(\mathrm{~s}, 3 \mathrm{H}), 0.001(\mathrm{~s}, 6 \mathrm{H}), 0.024(\mathrm{~s}, 3 \mathrm{H}), 0.05(\mathrm{~s}, 3 \mathrm{H}), 0.80(\mathrm{~s}, 9 \mathrm{H}), 0.83(\mathrm{~s}, 9 \mathrm{H}), 0.84(\mathrm{~s}, 9 \mathrm{H})$, $1.55-1.61(\mathrm{~m}, 2 \mathrm{H}), 2.29\left(\mathrm{dd}, 1 \mathrm{H}, J_{1}=9.03, J_{2}=14.63\right), 2.57\left(\mathrm{dd}, J_{1}=3.11, J_{2}=14.63\right), 3.5-3.6$ $(\mathrm{m}, 1 \mathrm{H}), 3.64(\mathrm{~s}, 3 \mathrm{H}), 3.64-3.73(\mathrm{~m}, 1 \mathrm{H}), 3.84-3.91(\mathrm{~m}, 1 \mathrm{H}), 5.18(\mathrm{~s}, 2 \mathrm{H}), 7.0(\mathrm{~d}, 1 \mathrm{H}, J=7.8)$, $7.08\left(\mathrm{td}, J_{1}=0.93, J_{2}=7.8\right), 7.35-7.47(\mathrm{~m}, 5 \mathrm{H}), 7.9(\mathrm{~d}, 1 \mathrm{H}, J=8.09), 8.23\left(\mathrm{dd}, 1 \mathrm{H}, J_{1}=1.87, J_{2}\right.$ = 7.8). ${ }^{13} \mathrm{C}-\mathrm{NMR}\left(\mathrm{CDCl}_{3}, 75 \mathrm{MHz}\right)-5.26,-5.14,-4.95,-4.35,-4.15,18.0,25.8,26.0,41.2,42.9$, $51.4,55.3,61.2,67.0,68.4,71.2,112.5,121.451,121.945,127.7,128.5,128.8,132.5,135.5$, 156.5, 164.6, 171.9. IR 3392w, 1739m, 1656m. MS $760\left(100,[\mathrm{M}+\mathrm{H}]^{+}\right)$. 
$(3 R, 5 R, 6 S)$-7-Benzyloxy-6-benzyloxycarbonylamino-3,5-bis-(tert-butyl-dimethyl-silanoxy)heptanoic acid methyl ester (14). (5R, 6S)-7-Benzyloxy-6-benzyloxycarbonylamino-5hydroxy-3-oxo-heptanoic acid methyl ester (11) (144.6 $\mathrm{mg}, 0.336 \mathrm{mmol}$ ) was dissolved in $\mathrm{CH}_{3} \mathrm{CN}(1.5 \mathrm{ml})$ and cooled to $-40{ }^{\circ} \mathrm{C}$. $\mathrm{Me}_{4} \mathrm{NBH}(\mathrm{OAc})_{3}(612 \mathrm{mg}, 2.3 \mathrm{mmol})$ was dissolved in $\mathrm{CH}_{3} \mathrm{CN} / \mathrm{AcOH}$ 1:1 $(1.5 \mathrm{ml})$ and stirred at RT for 30 minutes. This solution was then added dropwise to the $-40{ }^{\circ} \mathrm{C}$ solution of the substrate. The reaction mixture was stirred for $64 \mathrm{~h}$ at -37 ${ }^{\circ} \mathrm{C}$ (bath temp) and was then allowed to warm up to $0{ }^{\circ} \mathrm{C}$. Saturated Na-K-tartrate solution $(5 \mathrm{ml})$ was added, the suspension was stirred for $4 \mathrm{~h}$ at $0^{\circ} \mathrm{C}$. The layers were separated and the aqueous layer was $3 \mathrm{x}$ extracted with EtOAc. The combined organic layers were washed $3 \mathrm{x}$ with brine, dried $\left(\mathrm{MgSO}_{4}\right)$, filtered and the solvent evaporated. The diastereomeric ratio of the reaction was measured by ${ }^{1} \mathrm{H}-\mathrm{NMR}$ analysis of the crude reaction product to be $\mathrm{dr}>96: 4$. This intermediate was used without further purification.

The resulting dihydroxyester was dissolved in $\mathrm{CH}_{2} \mathrm{Cl}_{2}(0.6 \mathrm{ml})$ and cooled to $-20{ }^{\circ} \mathrm{C}$. 2,6Lutidine (156 ul, $1.34 \mathrm{mmol}$ ) was added dropwise followed by the dropwise addition of TBSOTf (232 ul, $1.0 \mathrm{mmol}$ ). The reaction was stirred at $-20^{\circ} \mathrm{C}$ for $1.5 \mathrm{~h}$ and was then diluted with $\mathrm{CH}_{2} \mathrm{Cl}_{2}(5 \mathrm{ml})$. The organic layer was washed with $3 \times 10 \%$ citric acid solution and $2 \times$ with $\mathrm{H}_{2} \mathrm{O}$. The solution was dried $\left(\mathrm{MgSO}_{4}\right)$, filtered and the solvent was evaporated. FC (EtOAc/Hexane 1:1) gave the title compound 14 (166.8 mg, $0.252 \mathrm{mmol}, 75 \%)$. Colorless oil. $\mathrm{R}_{\mathrm{f}}=0.72\left(\right.$ EtOAc/Hexane 1:1). $[\alpha]_{\mathrm{D}}=+0.5\left(\mathrm{c}=0.83, \mathrm{CHCl}_{3}\right) .{ }^{1} \mathrm{H}-\mathrm{NMR}\left(\mathrm{CDCl}_{3}, 300 \mathrm{MHz}\right) 0.04-$ $0.10(\mathrm{~m}, 12 \mathrm{H}), 0.86(\mathrm{~s}, 9 \mathrm{H}), 0.87(\mathrm{~s}, 9 \mathrm{H}), 1.62-1.71(\mathrm{~m}, 1 \mathrm{H}), 1.80-1.88(\mathrm{~m}, 1 \mathrm{H}), 2.46-2.58(\mathrm{~m}$, 2H), 3.55-3.60 (m, 2H), $3.65(\mathrm{~s}, 3 \mathrm{H}), 3.84-3.89(\mathrm{~m}, 1 \mathrm{H}), 4.01-4.03(\mathrm{~m}, 1 \mathrm{H}), 4.21-4.26(\mathrm{~m}, 1 \mathrm{H})$, $4.50(\mathrm{~s}, 2 \mathrm{H}), 5.07-5.16(\mathrm{~m}, 3 \mathrm{H}), 7.29-7.36(\mathrm{~m}, 10 \mathrm{H}) .{ }^{13} \mathrm{C}-\mathrm{NMR}\left(\mathrm{CDCl}_{3}, 75 \mathrm{MHz}\right) .-4.44,-4.40$, $4.09,-4.04,18.0,18.1,25.8,25.9,26.0,42.4,43.0,51.5,54.8,66.6,67.3,68.1,69.8,73.1,127.6$ (2 C), 128.0, 128.3 (2 C), 128.4, 136.5, 137.9, 156.0, 171.3. IR 2955w, 1722s, 1508m. MS 682.4 $\left(100,[\mathrm{M}+\mathrm{Na}]^{+}\right)$. HRMS calcd. for $\mathrm{C}_{35} \mathrm{H}_{57} \mathrm{NO}_{7} \mathrm{Si}_{2} \mathrm{Na}(\mathrm{M}+\mathrm{Na})^{+}: 682.3566$, found: 682.3561 . 


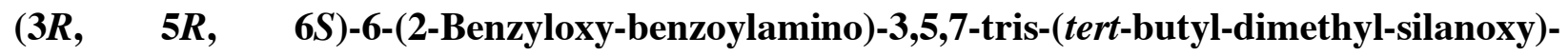
heptanoic acid methyl ester (15). (3R, 5R, 6S)-7-Benzyloxy-6-benzyloxycarbonylamino-3,5bis-(tert-butyl-dimethyl-silanoxy)-heptanoic acid methyl ester (14) (169.8 mg, $0.257 \mathrm{mmol}$ ) was dissolved in $\mathrm{CH}_{3} \mathrm{OH}(2 \mathrm{ml})$, the flask was flushed $3 \mathrm{x}$ with $\mathrm{Ar}$, and 2 small spatula of $\mathrm{Pd} / \mathrm{C}(10 \%)$ were added. The flask was flushed $3 \mathrm{x}$ with $\mathrm{H}_{2}$, and the black suspension was vigorously stirred for $4 \mathrm{~h}$ at RT. The suspension was filtered over Celite, and the solvent evaporated. ${ }^{1} \mathrm{H}-\mathrm{NMR}$ analysis showed complete deprotection. This intermediate was used without further purification. The intermediate amino ester was suspended in $\mathrm{CHCl}_{3}$, hydroxybenzotriazole (47.2 mg, 0.308 mmol), 2-BnO-salicylic acid (70.4 mg, $0.309 \mathrm{mmol}), N$-methylmorpholine $(84.7 \quad 1,0.771$ mmol) and EDC (59.1 mg, $0.308 \mathrm{mmol})$ were added. The resulting solution was stirred for $3 \mathrm{~d}$ at RT and was then diluted with $\mathrm{CHCl}_{3}$. The organic layer was washed 3 x with $10 \%$ citric acid solution, $3 \mathrm{x}$ with saturated $\mathrm{NaHCO}_{3}$ solution and $1 \mathrm{x}$ with $\mathrm{H}_{2} \mathrm{O}$. The organic layer was dried $\left(\mathrm{MgSO}_{4}\right)$, filtered and the solvent evaporated. This intermediate was used without further purification.

The hydroxy amino ester was dissolved in DMF $(0.5 \mathrm{ml})$ and the solution was cooled with an ice-bath. TBSCl (42.6 mg, $0.282 \mathrm{mmol})$, Imidazole (21.0 mg, $0.308 \mathrm{mmol})$ and DMAP (3.0 mg, $0.025 \mathrm{mmol}$ ) were added, the reaction mixture was allowed to warm up to RT and stirred for 16 h. After this time, additional $\mathrm{TBSCl}(20 \mathrm{mg})$ and imidazole $(10 \mathrm{mg})$ were added and stirred for another $24 \mathrm{~h}$ at RT. DMF was then removed under high vacuum. FC (EtOAc/Hexane 1:7) gave the title compound (15) $(137.0 \mathrm{mg}, 0.180 \mathrm{mmol}, 70 \%)$. Colorless oil. $\mathrm{R}_{\mathrm{f}}=0.3(\mathrm{EtOAc} / \mathrm{Hexane}$ 1:7). $[\boldsymbol{\alpha}]_{\mathrm{D}}=+0.16\left(\mathrm{c}=2.49, \mathrm{CHCl}_{3}\right) .{ }^{1} \mathrm{H}-\mathrm{NMR}\left(\mathrm{CDCl}_{3}, 300 \mathrm{MHz}\right) \quad-0.02(\mathrm{~s}, 3 \mathrm{H}), 0.03(\mathrm{~s}, 3 \mathrm{H})$, $0.038(\mathrm{~s}, 3 \mathrm{H}), 0.043(\mathrm{~s}, 3 \mathrm{H}), 0.06(\mathrm{~s}, 3 \mathrm{H}), 0.07$ (s, 3H), $0.80(\mathrm{~s}, 9 \mathrm{H}), 0.85$ (s, 9H), 0.86 (s, 9H), $1.48-1.56(\mathrm{~m}, 1 \mathrm{H}), 1.68-1.74(\mathrm{~m}, 1 \mathrm{H}), 2.39\left(\mathrm{dd}, 1 \mathrm{H}, J_{1}=14.6, J_{2}=7.8\right), 2.62\left(\mathrm{dd}, J_{1}=14.3, J_{2}=\right.$ $4.4,1 \mathrm{H}), 3.58(\mathrm{~s}, 3 \mathrm{H}), 3.59-3.64(\mathrm{~m}, 1 \mathrm{H}), 3.76\left(\mathrm{dd}, J_{1}=10.6, J_{2}=6.2,1 \mathrm{H}\right), 4.06-4.12(\mathrm{~m}, 1 \mathrm{H})$, 
4.18-4.25 (m, 2H), $5.23(\mathrm{~s}, 2 \mathrm{H}), 6.97(\mathrm{~d}, J=8.4,1 \mathrm{H}), 7.07(\mathrm{t}, J=6.5,1 \mathrm{H}), 7.34-7.45(\mathrm{~m}, 6 \mathrm{H})$, $8.05(\mathrm{~d}, J=7.47,1 \mathrm{H}), 8.23(\mathrm{~d}, J=8.0,1 \mathrm{H}) .{ }^{13} \mathrm{C}-\mathrm{NMR}\left(\mathrm{CDCl}_{3}, 75 \mathrm{MHz}\right)-5.2,-5.1,-4.5,-4.3,-$ $4.2,-3.9,18.0,18.3,25.8,25.9,26.0,41.5,43.2,51.3,55.7,61.1,67.4,69.0,71.0,112.7,121.3$, $121.8,127.3,128.4,128.7,132.3,132.4,135.7,156.5,164.9,171.5$. IR $2955 m, 1734 m, 1648 m$. MS $782.4\left(59,[\mathrm{M}+\mathrm{Na}]^{+}\right), 760.5\left(13,[\mathrm{M}+\mathrm{H}]^{+}\right), 628.4\left(100,[\mathrm{M}-\mathrm{Boc}+\mathrm{Na}]^{+}\right) . \quad$ HRMS calcd. for $\mathrm{C}_{40} \mathrm{H}_{69} \mathrm{NO}_{7} \mathrm{Si}_{3} \mathrm{Na}(\mathrm{M}+\mathrm{Na})^{+}:$782.4274, found: 782.4282 .

\section{[1-(tert-Butyl-dimethyl-silanyloxymethyl)-3-(2,2-dimethyl-6-oxo-6H-[1,3]dioxin-4-yl)-((3S)-}

2-hydroxy-propyl]-(2S)carbamic acid benzyl ester (16a). Following a modified literature procedure $^{21}$, a solution of [1-(tert-Butyl-dimethyl-silanyloxymethyl)-(2S)-2-oxo-ethyl]-carbamic acid benzyl ester (16) $(298 \mathrm{mg}, 0.89 \mathrm{mmol})$ in dry $\mathrm{CH}_{2} \mathrm{Cl}_{2}(1 \mathrm{~mL})$ was cooled to $0{ }^{\circ} \mathrm{C}$ and $\mathrm{Eu}(\mathrm{fod})_{3}(185 \mathrm{mg}, 0.178 \mathrm{mmol}, 0.2 \mathrm{eq})$ was added. After 10 minutes (2,2-dimethyl-6-methylene6H-[1,3]dioxin-4-yloxy)-trimethyl-silane (190 mg, $0.89 \mathrm{mmol}, 1 \mathrm{eq})$ dissolved in $\mathrm{CH}_{2} \mathrm{Cl}_{2}(1 \mathrm{~mL})$ was added dropwise. The reaction mixture was then stirred overnight reaching RT gradually. $\mathrm{CH}_{2} \mathrm{Cl}_{2}$ was removed under reduced pressure and the residue was taken up with EtOAc. It was washed $3 x$ with citric acid $(10 \%)$ and $3 x$ with satd. $\mathrm{NaHCO}_{3}$. The organic phase was dried over $\mathrm{Na}_{2} \mathrm{SO}_{4}$, filtered and evaporated under reduced pressure. FC (EtOAc/Hexane 3:7) gave the title compound 16a (199 mg, $0.41 \mathrm{mmol}, 47 \%$ ). White solid. $\mathrm{M}_{\mathrm{p}}=60-63{ }^{\circ} \mathrm{C} . \mathrm{R}_{\mathrm{f}}=0.21$ (EtOAc/Hexane 3:7). $[\alpha]_{\mathrm{D}}=-1.07\left(\mathrm{C}=3.2, \mathrm{CHCl}_{3}, \mathrm{~T}=26{ }^{\circ} \mathrm{C}\right) .{ }^{1} \mathrm{H}-\mathrm{NMR}\left(\mathrm{CDCl}_{3}, 300 \mathrm{MHz}\right) \delta$ $0.056(\mathrm{~s}, 3 \mathrm{H}), 0.071(\mathrm{~s}, 3 \mathrm{H}), 0.88(\mathrm{~s}, 9 \mathrm{H}), 2.34\left(\mathrm{dd}, 1 \mathrm{H}, J_{1}=4.67, J_{2}=14.95\right), 2.44\left(\mathrm{dd}, 1 \mathrm{H}, J_{1}=\right.$ $\left.8.5, J_{2}=14.95\right), 3.33(\mathrm{~s}, 1 \mathrm{H}), 3.63-3.66(\mathrm{~m}, 1 \mathrm{H}), 3.86(\mathrm{~d}, 2 \mathrm{H}, J=3.42), 4.26-4.29(\mathrm{~m}, 1 \mathrm{H}), 5.12$ $(\mathrm{s}, 2 \mathrm{H}), 5.33(\mathrm{~s}, 1 \mathrm{H}), 5.41(\mathrm{br} . \mathrm{d}, 1 \mathrm{H}, J=9.03), 7.32-7.37(\mathrm{~m}, 5 \mathrm{H}) .{ }^{13} \mathrm{C}-\mathrm{NMR}\left(\mathrm{CDCl}_{3}, 75 \mathrm{MHz}\right)$ $-5.5,18.2,24.8,25.4,25.8,38.6,54.1,66.0,67.0,69.9,95.3,106.2,128.0,128.2,128.5,136.1$, $156.2,160.8,168.1$ 
(6S)-6-Benzyloxycarbonylamino-7-(tert-butyl-dimethyl-silanyloxy)-(3R,5S)-4,5-hydroxy-3-

oxo-heptanoic acid methyl ester (18a). A solution of $\mathrm{Et}_{3} \mathrm{~B}(750 \mu \mathrm{l}, 0.75 \mathrm{mmol}, 1.5 \mathrm{eq}, 1 \mathrm{M}$ sol. in hexane) and pivalic acid (2.5 mg, $25 \mu \mathrm{mol}, 0.05 \mathrm{eq})$ dissolved in dry THF $(0.5 \mathrm{~mL})$ and $\mathrm{MeOH}(1 \mathrm{~mL})$ was stirred at RT for 1 hour and was then cooled to $-70{ }^{\circ} \mathrm{C}$. (6S)-6Benzyloxycarbonylamino-7-(tert-butyl-dimethyl-silanyloxy)-(5S)-5-hydroxy-3-oxo-heptanoic acid methyl ester (18) $(0.225 \mathrm{~g}, 0.50 \mathrm{mmol})$ in dry THF (1 mL) was added dropwise followed by $\mathrm{NaBH}_{4}(57 \mathrm{mg}, 1.5 \mathrm{mmol}, 3 \mathrm{eq})$ and it was stirred at $-70{ }^{\circ} \mathrm{C}$ for 4 hours. $\mathrm{H}_{2} \mathrm{O}_{2}(3 \mathrm{~mL})$ and $\mathrm{H}_{2} \mathrm{O}(5$ $\mathrm{mL}$ ) were then added at $-70{ }^{\circ} \mathrm{C}$ and the reaction allowed to warm until RT. Then $\mathrm{CHCl}_{3}$ and $\mathrm{H}_{2} \mathrm{O}$ were added and the aqueous phase extracted with chloroform. The combined organic layers were washed with $5 \mathrm{x} \mathrm{H}_{2} \mathrm{O}$, dried over $\mathrm{Na}_{2} \mathrm{SO}_{4}$, filtered and evaporated under reduced pressure. FC (Hexane/EtOAc 5.5:4.5) gave the title compound 18a $(155.8 \mathrm{mg}, 0.34 \mu \mathrm{mol}, 69 \%) . \mathrm{R}_{\mathrm{f}}=0.31$ (EtOAc/Hexane 3.5:6.5). $[\alpha]_{\mathrm{D}}=+10.6\left(\mathrm{C}=0.95, \mathrm{CHCl}_{3}, \mathrm{~T}=30.7{ }^{\circ} \mathrm{C}\right) .{ }^{1} \mathrm{H}-\mathrm{NMR}\left(\mathrm{CDCl}_{3}, 300\right.$ $\mathrm{MHz}) \delta 0.055(\mathrm{~s}, 3 \mathrm{H}), 0.063(\mathrm{~s}, 3 \mathrm{H}), 0.88(\mathrm{~s}, 9 \mathrm{H}), 1.5-1.6(\mathrm{~m}, 1 \mathrm{H}), 1.67-1.82(\mathrm{~m}, 1 \mathrm{H}), 2.44-2.51$ (m, 2H), 3.57-3.65 (m, 1H), $3.7(\mathrm{~s}, 3 \mathrm{H}), 3.72-3.77$ (br. s, 1H), 3.78-3.82 (m, 1H), 3.87-3.92 (br. $\mathrm{s}, 1 \mathrm{H}), 5.1(\mathrm{~s}, 2 \mathrm{H}), 5.38(\mathrm{~d}, 1 \mathrm{H}, J=9.03), 7.31-7.37(\mathrm{~m}, 5 \mathrm{H}) .{ }^{13} \mathrm{C}-\mathrm{NMR}\left(\mathrm{CDCl}_{3}, 75 \mathrm{MHz}\right)-5.4$, $18.3,25.9,39.4,41.5,51.9,55.0,65.2,66.9,68.2,72.0,128.0,128.1,128.4,136.3,156.3,172.6$. IR 3611-3144m, 1721s, 1510m. MS $478.2\left(100,[\mathrm{M}+\mathrm{Na}]^{+}\right)$. HRMS calcd. for $\mathrm{C}_{22} \mathrm{H}_{37} \mathrm{NO}_{7} \mathrm{SiNa}$ $(\mathrm{M}+\mathrm{Na})^{+}:$478.2232, found: 478.2224.

S(6S)-6-Benzyloxycarbonylamino-7-(tert-butyl-dimethyl-silanyloxy)-(3S,5S)-4,5-hydroxy-3oxo-heptanoic acid methyl ester (18b). A solution of (6S)-6-Benzyloxycarbonylamino-7-(tertbutyl-dimethyl-silanyloxy)-(5S)-5-hydroxy-3-oxo-heptanoic acid methyl ester (18) (80 mg, 0.18 mmol) in $\mathrm{CH}_{3} \mathrm{CN}(0.5 \mathrm{~mL})$ was cooled to $-35{ }^{\circ} \mathrm{C}$ and $\mathrm{Me}_{4} \mathrm{~N}(\mathrm{OAc}){ }_{3} \mathrm{BH}(331 \mathrm{mg}, 1.26 \mathrm{mmol}, 7$ eq) dissolved in $\mathrm{CH}_{3} \mathrm{CN} / \mathrm{AcOH}(0.5 \mathrm{~mL} / 0.5 \mathrm{~mL})$ was added. The reaction mixture was stirred at this temperature for 62 hours. It was then allowed to reach $0{ }^{\circ} \mathrm{C}$ and a saturated solution of Na- 
K-tartrate was added. The solution was stirred at this temperature for 4 hours. The phases were separated and the aqueous phase extracted 3x with EtOAc. The combined organic layers were washed with brine, dried over $\mathrm{Na}_{2} \mathrm{SO}_{4}$, filtered and evaporated under reduced pressure. The NMR of this compound showed a pure compound (d.r. = $97: 3$ ) which was directly used in the next step. 


\section{(6S)-6-Benzyloxycarbonylamino-(3S,5S)-3,5,7-tris-(tert-butyl-dimethyl-silanyloxy)-}

heptanoic acid methyl ester (20). A solution of (6S)-6-Benzyloxycarbonylamino-7-(tert-butyldimethyl-silanyloxy)-(3S,5S)-4,5-hydroxy-3-oxo-heptanoic acid methyl ester (18b) (80.0 mg, $0.18 \mathrm{mmol})$ was dissolved in dry $\mathrm{CH}_{2} \mathrm{Cl}_{2}(0.8 \mathrm{~mL})$ and cooled to $-20{ }^{\circ} \mathrm{C} .2,6$ lutidine $(84 \mu \mathrm{l}, 0.72$ mmol, 4 eq) was added dropwise followed by the dropwise addition of TBSOTf (124 $\mu 1,0.54$ mmol, 3 eq). The reaction mixture was stirred at $-20{ }^{\circ} \mathrm{C}$ for $1 \mathrm{~h} 30$. It was diluted with $\mathrm{CH}_{2} \mathrm{Cl}_{2}(3$ $\mathrm{mL}$ ), washed $3 \mathrm{x}$ with citric acid (10\%) and $2 \mathrm{x}$ with $\mathrm{H}_{2} \mathrm{O}$. It was dried over $\mathrm{MgSO}_{4}$, filtered and evaporated under reduced pressure. FC (EtOAc/hexane 5/95) gave 20 (62.0 mg, 0.09 mmol, 52 $\%$ over 2 steps). $\mathrm{R}_{\mathrm{f}}=0.53($ EtOAc/hexane $1: 9) .[\alpha]_{\mathrm{D}}=+8.3\left(\mathrm{C}=3.1, \mathrm{CHCl}_{3}, \mathrm{~T}=24.7{ }^{\circ} \mathrm{C}\right) .{ }^{1} \mathrm{H}-$ $\operatorname{NMR}\left(\mathrm{CDCl}_{3}, 300 \mathrm{MHz}\right) \delta 0.024(\mathrm{~s}, 3 \mathrm{H}), 0.033(\mathrm{~s}, 3 \mathrm{H}), 0.054(\mathrm{~s}, 3 \mathrm{H}), 0.066(\mathrm{~s}, 3 \mathrm{H}), 0.077$ (s, 3H), 0.089 (s, 3H), 0.102 (s, 3H), 0.84 (s, 9H), 0.88 (s, 18H), 1.58-1.68 (m, 1H), 1.85 (ddd, 1H, $\left.J_{1}=4.98, J_{2}=9.34, J_{3}=13.39\right), 2.37\left(\mathrm{dd}, 1 \mathrm{H}, J_{1}=7.78, J_{2}=14\right), 2.49\left(\mathrm{dd}, 1 \mathrm{H}, J_{1}=4.36, J_{2}=\right.$ 14), 3.45-3.48 (m, 1H), 3.59-3.62 (m, 1H), $3.65(\mathrm{~s}, 3 \mathrm{H}), 4.02-4.09(\mathrm{~m}, 1 \mathrm{H}), 4.10-4.16(\mathrm{~m}, 1 \mathrm{H})$, 5.02 (br. d, $1 \mathrm{H}, \mathrm{J}=8.09), 5.09(\mathrm{~s}, 2 \mathrm{H}), 7.31-7.39(\mathrm{~m}, 5 \mathrm{H}) .{ }^{13} \mathrm{C}-\mathrm{NMR}\left(\mathrm{CDCl}_{3}, 75 \mathrm{MHz}\right)-5.3$, $5.2,-4.8,-4.7,-4.4,-4.1,18.0,18.1,25.8,25.9,26.0,128.1,128.2,128.4,155.9,171.2$. IR 2254m, 1719s. MS $706\left(100,[\mathrm{M}+\mathrm{Na}]^{+}\right)$. HRMS calcd. for $\mathrm{C}_{34} \mathrm{H}_{65} \mathrm{NO}_{7} \mathrm{Si}_{3} \mathrm{Na}(\mathrm{M}+\mathrm{Na})^{+}:$706.3961, found: 706.3954 .

(6S)-6-(2-benzyloxy-benzoylamino)-(3R,5S)-3,5,7-tris-(tert-butyl-dimethyl-silanyloxy)heptanoic acid methyl ester (21). To a solution of (6S)-6-Benzyloxycarbonylamino-(3R,5S)3,5,7-tris-(tert-butyl-dimethyl-silanyloxy)-heptanoic acid methyl ester (19) (70 mg, $102 \mu \mathrm{mol})$ in $\mathrm{MeOH}(1 \mathrm{~mL})$ previously $3 \mathrm{x}$ flushed with argon was added $\mathrm{Pd} / \mathrm{C}$. Then it was flushed with $\mathrm{H}_{2}$ and it was stirred at RT for 4 hours. $\mathrm{Pd} / \mathrm{C}$ was filtered over celite and the solvent was removed 
under reduced pressure. This product was added to a solution of $O$-Bn-salicylic acid $(27.9 \mathrm{mg}$, $122 \mu \mathrm{mol}, 1.2 \mathrm{eq})$ dissolved in dry $\mathrm{CHCl}_{3}(1.5 \mathrm{~mL})$ with $\mathrm{EDC} . \mathrm{HCl}(23.4 \mathrm{mg}, 122 \mu \mathrm{mol}, 1.2 \mathrm{eq})$, HOBt (18.9 mg, $122 \mu \mathrm{mol}, 1.2 \mathrm{eq})$ and NMM (34 $\mu \mathrm{L}, 306 \mu \mathrm{mol}, 3 \mathrm{eq})$. The reaction mixture was stirred at RT for 20 hours. The solvent was then removed under reduced pressure and the residue taken up with EtOAc. It was washed 3x with citric acid (10\%) and 3x with satd. $\mathrm{NaHCO}_{3}$. The organic phase was dried over $\mathrm{MgSO}_{4}$, filtered and evaporated under reduced pressure. FC (EtOAc/Hexane 1:9) gave 21 (45 mg, $59 \mu \mathrm{mol}, 58 \%) . \mathrm{R}_{\mathrm{f}}=0.43($ EtOAc/Hexane 2:8). $[\alpha]_{\mathrm{D}}=-4.2\left(\mathrm{C}=2.235, \mathrm{CHCl}_{3}, \mathrm{~T}=26.5^{\circ} \mathrm{C}\right) .{ }^{1} \mathrm{H}-\mathrm{NMR}\left(\mathrm{CDCl}_{3}, 300 \mathrm{MHz}\right) \delta 0.061(\mathrm{~s}, 6 \mathrm{H})$, $0.071(\mathrm{~s}, 3 \mathrm{H}), 0.091(\mathrm{~s}, 3 \mathrm{H}), 0.094(\mathrm{~s}, 3 \mathrm{H}), 0.105(\mathrm{~s}, 3 \mathrm{H}), 0.84(\mathrm{~s}, 9 \mathrm{H}), 0.86(\mathrm{~s}, 9 \mathrm{H}), 0.89$ (s, 9H), $1.67-1.78(\mathrm{~m}, 2 \mathrm{H}), 2.35-2.48(\mathrm{~m}, 2 \mathrm{H}), 3.49(\mathrm{~s}, 3 \mathrm{H}), 3.6\left(\mathrm{dd}, 1 \mathrm{H}, J_{1}=8.4, J_{2}=9.33\right), 3.71(\mathrm{dd}$, $\left.1 \mathrm{H}, J_{1}=5.6, J_{2}=9.6\right), 4.1-4.21(\mathrm{~m}, 2 \mathrm{H}), 4.23-4.28(\mathrm{~m}, 1 \mathrm{H}), 5.29(\mathrm{~s}, 2 \mathrm{H}), 6.91\left(\mathrm{dd}, 1 \mathrm{H}, J_{1}=0.6\right.$, $\left.J_{2}=8.4\right), 7.0-7.1(\mathrm{~m}, 1 \mathrm{H}), 7.28-7.37(\mathrm{~m}, 6 \mathrm{H}), 8.0(\mathrm{~d}, 1 \mathrm{H}, J=8.4), 8.16\left(\mathrm{dd}, 1 \mathrm{H}, J_{1}=1.87, J_{2}=\right.$ 7.8). ${ }^{13} \mathrm{C}-\mathrm{NMR}\left(\mathrm{CDCl}_{3}, 75 \mathrm{MHz}\right)-5.1,-4.5,-4.2,-4.0,17.9,18.1,18.5,25.9,26.0,26.1,42.1$, $43.2,51.4,53.8,61.2,66.5,67.1,70.7,113.2,121.3,122.3,126.7,128.1,128.7,132.2,132.3$, 135.9, 156.3, 164.9, 171.3. IR 2953m, 2928m, 2856m, 1740m, 1654m. MS $760\left(100,[\mathrm{M}+\mathrm{H}]^{+}\right)$. HRMS calcd. for $\mathrm{C}_{40} \mathrm{H}_{69} \mathrm{NO}_{7} \mathrm{Si}_{3} \mathrm{Na}(\mathrm{M}+\mathrm{Na})^{+}:$782.4274, found: 782.4285 . 
(6S)-6-(2-benzyloxy-benzoylamino)-(3S,5S)-3,5,7-tris-(tert-butyl-dimethyl-silanyloxy)-

heptanoic acid methyl ester (22). To a solution of (6S)-6-Benzyloxycarbonylamino-(3S,5S)3,5,7-tris-(tert-butyl-dimethyl-silanyloxy)-heptanoic acid methyl ester (20) (59 mg, $86 \mu \mathrm{mol})$ in $\mathrm{MeOH}(0.7 \mathrm{~mL})$ previously 3x flushed with argon was added $\mathrm{Pd} / \mathrm{C}(1 \mathrm{mg}, 10 \%)$. Then it was flushed with $\mathrm{H}_{2}$ and it was stirred at RT for 4 hours. Pd/C was filtered over celite and the solvent was removed under reduced pressure. This product was added to a solution of $O$-Bn-salicylic acid $(19.6 \mathrm{mg}, 86 \mu \mathrm{mol}, 1 \mathrm{eq})$ dissolved in dry $\mathrm{CH}_{2} \mathrm{Cl}_{2}(1 \mathrm{~mL})$ with EDC.HCl $(16.5 \mathrm{mg}, 86$ $\mu \mathrm{mol}, 1 \mathrm{eq})$, HOBt $(13 \mathrm{mg}, 86 \mu \mathrm{mol}, 1 \mathrm{eq})$ and NMM $(28 \mu \mathrm{L}, 258 \mu \mathrm{mol}, 3 \mathrm{eq})$. The reaction mixture was stirred at RT for 20 hours. The solvent was then removed under reduced pressure and the residue taken up with EtOAc. It was washed 3x with citric acid (10\%) and 3x with satd. $\mathrm{NaHCO}_{3}$. The organic phase was dried over $\mathrm{MgSO}_{4}$, filtered and evaporated under reduced pressure. FC (EtOAc/hexane 1:9) gave $22(24 \mathrm{mg}, 32 \mu \mathrm{mol}, 70 \%) . \mathrm{R}_{\mathrm{f}}=0.55($ EtOAc/hexane 2:8). $[\alpha]_{\mathrm{D}}=+26.3\left(\mathrm{C}=0.9, \mathrm{CHCl}_{3}, \mathrm{~T}=22.2{ }^{\circ} \mathrm{C}\right) .{ }^{1} \mathrm{H}-\mathrm{NMR}\left(\mathrm{CDCl}_{3}, 300 \mathrm{MHz}\right) \delta-0.06(\mathrm{~s}, 3 \mathrm{H}),-$ $0.01(\mathrm{~s}, 3 \mathrm{H}), 0.06(\mathrm{~s}, 6 \mathrm{H}), 0.07(\mathrm{~s}, 3 \mathrm{H}), 0.1(\mathrm{~s}, 3 \mathrm{H}), 0.8(\mathrm{~s}, 9 \mathrm{H}), 0.81(\mathrm{~s}, 9 \mathrm{H}), 0.9(\mathrm{~s}, 9 \mathrm{H}), 1.65$ $\left(\mathrm{ddd}, 1 \mathrm{H}, J_{1}=4.67, J_{2}=9.03, J_{3}=13.69\right), 1.89\left(\mathrm{ddd}, 1 \mathrm{H}, J_{1}=4.67, J_{2}=9.34, J_{3}=13.7\right), 2.36$ $\left(\mathrm{dd}, 1 \mathrm{H}, J_{1}=8.09, J_{2}=14.01\right), 2.52\left(\mathrm{dd}, 1 \mathrm{H}, J_{1}=4.05, J_{2}=14.01\right), 3.50(\mathrm{t}, 1 \mathrm{H}, J=9.34), 3.64(\mathrm{~s}$, $3 \mathrm{H}), 3.67\left(\mathrm{dd}, J_{1}=4.98, J_{2}=9.34\right), 4.11-4.24(\mathrm{~m}, 3 \mathrm{H}), 5.3(\mathrm{~s}, 2 \mathrm{H}), 6.90\left(\mathrm{dd}, 1 \mathrm{H}, J_{1}=0.62, J_{2}=\right.$ 8.4), $7.03\left(\mathrm{td}, 1 \mathrm{H}, J_{1}=0.93, J_{2}=7.78\right), 7.29-7.36(\mathrm{~m}, 5 \mathrm{H}), 8.0($ br. $\mathrm{d}, J=8.4), 8.16\left(\mathrm{dd}, 1 \mathrm{H}, J_{1}=\right.$ $\left.1.87, J_{2}=7.78\right) .{ }^{13} \mathrm{C}-\mathrm{NMR}\left(\mathrm{CDCl}_{3}, 75 \mathrm{MHz}\right)-5.2,-5.0,-4.8,-4.6,-4.3,-4.1,18.0,18.2,18.3$, 25.9, 26.1, 42.4, 42.5, 51.6, 53.6, 60.7, 66.8, 67.0, 71.0, 113.5, 121.6, 122.7, 126.9, 128.4, 129.0, 132.7, 136.4, 156.7, 165.4, 171.7. IR 3399s, 1735m, 1647m. MS $782\left(100,[\mathrm{M}+\mathrm{Na}]^{+}\right)$. HRMS calcd. for $\mathrm{C}_{40} \mathrm{H}_{69} \mathrm{NO}_{7} \mathrm{Si}_{3} \mathrm{Na}(\mathrm{M}+\mathrm{Na})^{+}:$782.4274, found: 782.4285 . 
(2S)-[2-(3,4-Bis-benzyloxy-phenyl)-1-dimethylcarbamoyl-ethyl]-carbamic acid tert-butyl

ester (24). (S)-[2-(3,4-Dihydroxy-phenyl)-1-dimethylcarbamoyl-ethyl]-carbamic acid tert-butyl ester (23) (6.48 g, $20 \mathrm{mmol})$ was dissolved in acetone $(150 \mathrm{~mL})$ and $\mathrm{Cs}_{2} \mathrm{CO}_{3}(19.55 \mathrm{~g}, 60 \mathrm{mmol}$, 3 eq) was added. The reaction mixture was stirred at this temperature for 15 minutes and the color turned red. Then benzyl bromide $(7.13 \mathrm{~mL}, 60 \mathrm{mmol}, 3 \mathrm{eq})$ was added and the reaction mixture was refluxed for 4 hours. The solvent was evaporated under reduced pressure and the residue taken up in EtOAc. It was washed 3x with citric acid, 3x with satd. $\mathrm{NaHCO}_{3}$ soln., $2 \mathrm{x}$ with $\mathrm{H}_{2} \mathrm{O}$ and $2 \mathrm{x}$ with brine. The organic phase was dried over $\mathrm{MgSO}_{4}$, filtered and evaporated under reduced pressure. The obtained solid was recrystallised from EtOAc/hexane 1:5 to give the title compound. FC (Hexane / EtOAc 1:1) of the evaporated mother liquor gave another $2 \mathrm{~g}$ to finally yield $24(9.6 \mathrm{~g}, 19 \mathrm{mmol}, 95 \%)$. White solid. $\mathrm{M}_{\mathrm{p}}=85-88^{\circ} \mathrm{C} . \mathrm{R}_{\mathrm{f}}=0.3(\mathrm{EtOAc} / \mathrm{Hexane}$ 1:1). $[\alpha]_{\mathrm{D}}=+27.5\left(\mathrm{C}=1.05, \mathrm{CHCl}_{3}, \mathrm{~T}=28.5^{\circ} \mathrm{C}\right) .{ }^{1} \mathrm{H}-\mathrm{NMR}\left(\mathrm{CDCl}_{3}, 300 \mathrm{MHz}\right) \delta 1.42(\mathrm{~s}, 9 \mathrm{H})$, $2.46(\mathrm{~s}, 3 \mathrm{H}), 2.76(\mathrm{~s}, 3 \mathrm{H}), 2.81\left(\mathrm{dd}, 1 \mathrm{H}, J_{1}=9.33, J_{2}=13.07\right), 2.91\left(\mathrm{dd}, 1 \mathrm{H}, J_{1}=5.6, J_{2}=13.07\right)$, 4.69-4.79 (m, 1H), $5.11(\mathrm{~s}, 4 \mathrm{H}), 5.52(\mathrm{~d}, 1 \mathrm{H}, J=8.4), 6.68\left(\mathrm{dd}, 1 \mathrm{H}, J_{1}=1.56, J_{2}=8.41\right), 6.82$ (m, 2H), 7.24-7.48 (m, 10H). ${ }^{13} \mathrm{C}-\mathrm{NMR}\left(\mathrm{CDCl}_{3}, 75 \mathrm{MHz}\right)$ 28.5, 35.5, 36.8, 40.0, 51.4, 71.2, 71.3, $76.8,79.5,115.2,116.0,122.2,127.3,127.69,127.75,128.3,128.4,129.9,137.1,137.2,147.6$, 148.7, 155.0, 171.4. IR 3293w, 1704s, 1641s, 1509s. MS $527\left(100,[\mathrm{M}+\mathrm{Na}]^{+}\right)$.

\section{(2S)-[2-(3,4-Bis-benzyloxy-phenyl)-1-dimethylaminomethyl-ethyl]-carbamic acid tert-butyl}

ester (25). (2S)-[2-(3,4-Bis-benzyloxy-phenyl)-1-dimethylcarbamoyl-ethyl]-carbamic acid tertbutyl ester (24) (7.6 g, $14.8 \mathrm{mmol})$ was dissolved in $\mathrm{CH}_{2} \mathrm{Cl}_{2}(60 \mathrm{~mL})$ and cooled to $0{ }^{\circ} \mathrm{C}$. Then TFA $(60 \mathrm{~mL})$ was added and the reaction mixture was stirred for 1 hour at this temperature and 
for 1 hour at RT. It was then neutralized by the addition of $\mathrm{NaOH}(1 \mathrm{M})$ and extracted $3 \mathrm{x}$ with EtOAc. The combined organic phases were dried over $\mathrm{MgSO}_{4}$, filtered and evaporated under reduced pressure. It was directly used without further purification in the next step.

The deprotected amine was dissolved in THF $(40 \mathrm{~mL})$ and cooled to $0{ }^{\circ} \mathrm{C}$. Then $\mathrm{BH}_{3} \mathrm{THF}(1 \mathrm{M})$ (44.4 $\mathrm{mL}, 44.4 \mathrm{mmol}, 3 \mathrm{eq}$ ) was added dropwise and the reaction mixture was refluxed over night. It was cooled to $0{ }^{\circ} \mathrm{C}$ and $\mathrm{HCl}(12 \mathrm{~N})$ was added until $\mathrm{pH}$ reached 2-3. THF was evaporated under reduced pressure and $\mathrm{NaOH}(6 \mathrm{~N})$ was added until $\mathrm{pH}=14$. It was extracted $3 \mathrm{x}$ with EtOAc and the combined organic phases were dried over $\mathrm{MgSO}_{4}$, filtered and evaporated under reduced pressure. It was used in the next step without further purification.

The diamine was dissolved in a mixture of dioxane/water $20 \mathrm{~mL}: 20 \mathrm{~mL}$ and $\mathrm{NaOH}(1 \mathrm{M}, 15.54$ mmol, $15.54 \mathrm{~mL}, 1.05 \mathrm{eq})$ was added. $\mathrm{Boc}_{2} \mathrm{O}(3.88 \mathrm{~g}, 17.76 \mathrm{mmol}, 1.2 \mathrm{eq})$ were added and the reaction mixture was stirred at RT over night. Dioxane was removed and the residual water extracted with 3x EtOAc. The combined organic phases were dried over $\mathrm{MgSO}_{4}$, filtered and evaporated under reduced pressure. FC (EtOAc/Hexane 8:2) gave 25 (3.8 g, 7.8 mmol, 53\%). Colorless oil. $\mathrm{R}_{\mathrm{f}}=0.4\left(\mathrm{CH}_{2} \mathrm{Cl}_{2} / \mathrm{MeOH} 9: 1\right) .[\alpha]_{\mathrm{D}}=+19.95\left(\mathrm{C}=2.05, \mathrm{CHCl}_{3}, \mathrm{~T}=27.1{ }^{\circ} \mathrm{C}\right) .{ }^{1} \mathrm{H}-$ $\operatorname{NMR}\left(\mathrm{CDCl}_{3}, 300 \mathrm{MHz}\right) \delta 1.44(\mathrm{~s}, 9 \mathrm{H}), 2.06-2.16(\mathrm{~m}, 2 \mathrm{H}), 2.18(\mathrm{~s}, 6 \mathrm{H}), 2.71\left(\mathrm{dd}, 1 \mathrm{H}, J_{1}=6.54\right.$, $\left.J_{2}=13.7\right), 2.84\left(\mathrm{dd}, 1 \mathrm{H}, J_{1}=4.05, J_{2}=13.7\right), 3.78-3.81(\mathrm{~m}, 1 \mathrm{H}), 4.61-4.69(\mathrm{~m}, 1 \mathrm{H}), 5.13(\mathrm{~s}, 2 \mathrm{H})$, $5.15(\mathrm{~s}, 2 \mathrm{H}), 6.69\left(\mathrm{dd}, 1 \mathrm{H}, J_{1}=1.86, J_{2}=8.09\right), 6.82(\mathrm{~d}, 1 \mathrm{H}, J=1.86), 6.87(\mathrm{~d}, 1 \mathrm{H}, J=8.4)$, 7.23-7.5 (m, 10H). ${ }^{13} \mathrm{C}-\mathrm{NMR}\left(\mathrm{CDCl}_{3}, 75 \mathrm{MHz}\right)$ 28.5, 38.4, 45.6, 61.7, 71.3, 71.4, 79.1, 115, $116.6,122.5,127.2,127.3,127.6,127.7,128.3,131.1,137.2,137.3,147.4,148.5,155.6$. IR $3365 w, 2971 w, 2768 w, 1682 s, 1523 s . M S 391.2\left(48,[\mathrm{M}-\mathrm{Boc}]^{+}\right)$. HRMS calcd. for $\mathrm{C}_{25} \mathrm{H}_{31} \mathrm{~N}_{2} \mathrm{O}_{2}$ $(\text { M-Boc) })^{+}:$391.2380, found: 391.2377. 


\section{(S)-[1-(3,4-Dihydroxy-benzyl)-2-dimethylamino-ethyl]-carbamic acid tert-butyl ester (26)}

Boc-L-DOPA-dimethylamide (1.2785 g, $3.94 \mathrm{mmol})$ was suspended in $\mathrm{CH}_{2} \mathrm{Cl}_{2}$ (4 ml) and cooled under Ar to $0{ }^{\circ} \mathrm{C}$. Trifluoroacetic acid $(4 \mathrm{ml})$ was added dropwise and the resulting solution was stirred for $1 \mathrm{~h}$ at $0{ }^{\circ} \mathrm{C}$ and for $1 \mathrm{~h}$ at room temperature. The solvent was removed under reduced pressure, and the residue was twice dissolved in toluene and the solvent removed under reduced pressure. The residue was dried under high vacuum and used without further purification.

The residue was dissolved in THF $(8 \mathrm{ml})$, cooled under Ar to $0{ }^{\circ} \mathrm{C}$ and $\mathrm{BH} 3 *$ THF complex $(1$ $\mathrm{M}$ in THF, $20 \mathrm{ml}$ ) was added dropwise (gas evolution). The solution was stirred at $0{ }^{\circ} \mathrm{C}$ for $2 \mathrm{~h}$, warmed to room temperature and stirred overnight. The reaction mixture was cooled to $0{ }^{\circ} \mathrm{C}, 6 \mathrm{~N}$ $\mathrm{HCl}(3 \mathrm{ml})$ was added dropwise (gas evolution), and stirred at $0{ }^{\circ} \mathrm{C}$ for $3 \mathrm{~h}$. The solvent was removed under reduced pressure. The resulting diamine hydrochloride was used without further purification.

The oily residue was dissolved in dioxane $(4 \mathrm{ml}), \mathrm{H}_{2} \mathrm{O}(1 \mathrm{ml})$ and the $\mathrm{pH}$ was adjusted to $\sim 9-10$ by the addition of $1 \mathrm{~N} \mathrm{NaOH}$ solution. $\mathrm{Boc}_{2} \mathrm{O}(860 \mathrm{mg}, 3.94 \mathrm{mmol})$ was dissolved in dioxane (1 $\mathrm{ml}$ ) and added to the reaction mixture. Gas evolution started and the $\mathrm{pH}$ was controlled and adjusted to $\sim 9-10$ by the addition of $1 \mathrm{~N} \mathrm{NaOH}$ solution every $30 \mathrm{~min}$ for $4 \mathrm{~h}$. The reaction mixture was then stirred overnight at room temperature. The solvent was removed under reduced pressure, the residue partitioned between EtOAc and satd. $\mathrm{NaHCO}_{3}$ solution. The layers were separated and the aqueous layer was three times extracted with EtOAc. The combined organic layers were dried $\left(\mathrm{MgSO}_{4}\right)$, filtered, and the solvent was removed under reduced pressure. FC (10 $\mathrm{g} \mathrm{SiO}_{2}, \mathrm{CH}_{2} \mathrm{Cl}_{2} / \mathrm{MeOH}$ 7:1 -> 1:1) gave the title compound (194.8 mg, $0.63 \mathrm{mmol}, 16 \%$ ). Colorless oil. $\mathrm{R}_{\mathrm{f}}=0.05\left(\mathrm{CH}_{2} \mathrm{Cl}_{2} / \mathrm{MeOH} 7: 1\right) \cdot[\boldsymbol{\alpha}]_{\mathrm{D}}=-4.2(c=1, \mathrm{MeOH}) .{ }^{1} \mathrm{H}-\mathrm{NMR}\left(\mathrm{CD}_{3} \mathrm{OD}, 300\right.$ MHz) 1.37, 1.40 (s, $9 \mathrm{H}$, Boc-rotamers), $2.20(\mathrm{~s}, 6 \mathrm{H}), 2.25\left(\mathrm{dd}, J_{1}=12.4, J_{2}=5.0,1 \mathrm{H}\right), 2.39$ $\left(\mathrm{dd}, J_{1}=12.4, J_{2}=8.7,1 \mathrm{H}\right), 2.46$ (br. $\left.\mathrm{m}, 2 \mathrm{H}\right), 3.80$ (br. m, $\left.1 \mathrm{H}\right), 6.48-6.56(\mathrm{~m}, 2 \mathrm{H}), 6.63-6.65$ (m, 1H). ${ }^{13} \mathrm{C}-\mathrm{NMR}\left(\mathrm{CD}_{3} \mathrm{OD}, 75 \mathrm{MHz}\right)$ 28.0, 28.5 (Boc-rotamers), 40.2, 45.4, 51.0, 63.3, 79.5, 115.7, 
117.1, 121.3, 130.7, 144.4, 145.7, 157.4. IR 3432w, 3019m, 1766w, 1700s, 1492s, 1368s. MS $643.4\left(72,[2 \mathrm{M}+\mathrm{Na}]^{+}\right), 333.2\left(40,[\mathrm{M}+\mathrm{Na}]^{+}\right), 311.2\left(100,[\mathrm{M}+\mathrm{H}]^{+}\right), . \quad$ HRMS calcd. for $\mathrm{C}_{16} \mathrm{H}_{27} \mathrm{~N}_{2} \mathrm{O}_{4}(\mathrm{M}+\mathrm{H})^{+}:$311.1965, found: 311.1967.

\section{(3S)-6,7-Bis-benzyloxy-3-tert-butoxycarbonylamino-1,1-dimethyl-1,2,3,4-tetrahydro-}

quinolinium; chloride (27). (2S)-[2-(3,4-Bis-benzyloxy-phenyl)-1-dimethylaminomethylethyl]-carbamic acid tert-butyl ester (25) (1.6 g, $3.26 \mathrm{mmol}$ ) was dissolved in $\mathrm{MeOH}$ (30 mL), and $\mathrm{AcOH}(300 \mu \mathrm{l})$. The reaction mixture was flushed 3x with argon and $\mathrm{Pd} / \mathrm{C}(10 \%, 350 \mathrm{mg})$ was added. Then it was flushed with $\mathrm{H}_{2}$ and stirred at RT for 4 hours. $\mathrm{Pd} / \mathrm{C}$ was filtered over Celite and the solvent evaporated under reduced pressure to give 26, which was used in the next step.

Compound 26 was dissolved in $\mathrm{CH}_{2} \mathrm{Cl}_{2}(33 \mathrm{~mL})$ and dianisyltelluriumoxide (1.28 g, $3.59 \mathrm{mmol}$, 1.1 eq) was added. After 20 minutes the color turned red, and the reaction mixture was stirred for another 3 hours at RT. The organic phase was extracted $3 \mathrm{x}$ with water and the water phases washed $5 \mathrm{x}$ with $\mathrm{CH}_{2} \mathrm{Cl}_{2}$. Lyophilization gave the cyclized product that was directly introduced in the next step.

The compound was dissolved in dry aceton $(30 \mathrm{~mL})$ and $\mathrm{Cs}_{2} \mathrm{CO}_{3}(3.19 \mathrm{~g}, 9.78 \mathrm{mmol}, 3 \mathrm{eq})$ was added. After addition of $\mathrm{BnBr}(3.27 \mathrm{~mL}, 9.78 \mathrm{mmol}, 3 \mathrm{eq})$, the reaction mixture was refluxed for 4 hours and the solvent then evaporated under reduced pressure. The residue was taken up in EtOAc and washed $3 \mathrm{x}$ with $\mathrm{H}_{2} \mathrm{O}$. The organic phase was dried over $\mathrm{Na}_{2} \mathrm{SO}_{4}$, filtered and evaporated under reduced pressure. $\mathrm{FC}\left(\mathrm{CH}_{2} \mathrm{Cl}_{2} / \mathrm{MeOH}\right.$ 9:1) gave 27 (630 mg, 1.3 mmol, 40\%). Off-white solid. $\mathrm{R}_{\mathrm{f}}=0.5\left(\mathrm{CH}_{2} \mathrm{Cl}_{2} / \mathrm{MeOH} 9: 1\right) .[\alpha]_{\mathrm{D}}=+8.16\left(\mathrm{C}=1, \mathrm{CHCl}_{3}, \mathrm{~T}=25.6{ }^{\circ} \mathrm{C}\right) .{ }^{1} \mathrm{H}-$ NMR $\left(\mathrm{CDCl}_{3}, 300 \mathrm{MHz}\right) \delta 1.39$ (s, 9H), 2.1-2.16 (m, 2H), 3.0 (br. d, 1H), 3.15 (br. dd, 1H), 3.73 (s, 3H), 3.95-4.05 (m, 1H), 4.1-4.3 (m, 2H), $5.1(\mathrm{~s}, 2 \mathrm{H}), 5.35$ (s, 2H), 6.6 (br. s, 2H), 7.25-7.38 $(\mathrm{m}, 7 \mathrm{H}), 7.49(\mathrm{~d}, 1 \mathrm{H}, J=7.16), 7.61(\mathrm{~s}, 1 \mathrm{H}) .{ }^{13} \mathrm{C}-\mathrm{NMR}\left(\mathrm{CDCl}_{3}, 75 \mathrm{MHz}\right)$ 28.4, 33.1, 41.2, 58.7, 
$66.4,71.0,72.1,107.8,114.5,127.0,127.7,127.9,128.1,128.4,128.6,135.9,136.3,148.5$, 149.9, 194.1. IR 3686-3107w, 1700m, 1518m. MS 433.2 (100, [M-tBu] $\left.]^{+}\right), 489.3\left(46, \mathrm{M}^{+}\right)$. HRMS calcd. for $\mathrm{C}_{30} \mathrm{H}_{37} \mathrm{~N}_{2} \mathrm{O}_{4}(\mathrm{M})^{+}$: 489.2748, found: 489.2742 .

Boc-L-Thr(OBn)-L-Ser(OBn)-L-Ser(OBn)-(3S)-THQ(OBn) (28a). The Boc-Ser(OBn)THQ(OBn) (28) $(4.6 \mathrm{mg}, 0.007 \mathrm{mmol})$ was dissolved in $\mathrm{CH}_{2} \mathrm{Cl}_{2}(0.1 \mathrm{ml})$, and cooled to $0{ }^{\circ} \mathrm{C}$ under Ar. Trifluoroacetic acid $(0.1 \mathrm{ml})$ was added dropwise and the resulting solution was stirred for $1 \mathrm{~h}$ at $0{ }^{\circ} \mathrm{C}$ and for $1 \mathrm{~h}$ at room temperature. The solvent was removed under reduced pressure, and the residue was twice dissolved in toluene and the solvent removed under reduced pressure. The residue was dried under high vacuum and used without further purification. The residue was dissolved in $\mathrm{CHCl}_{3}(0.25 \mathrm{ml}), \mathrm{NMM}(2.3 \mathrm{ml}, 0.021 \mathrm{mmol}), \mathrm{HOBt}(1.2 \mathrm{mg}, 0.008$ mmol), Boc-L-Thr(OBn)-D-Ser(OBn)-OH (3.8 mg, $0.008 \mathrm{mmol}$ and EDC (1.5 mg, $0.008 \mathrm{mmol})$ were added to the solution. The reaction was stirred overnight under Ar. The reaction mixture was then diluted with $\mathrm{CHCl}_{3}(2 \mathrm{ml})$ and three times washed with $1 \mathrm{~N} \mathrm{HCl}$ solution, three times with $1 \mathrm{~N} \mathrm{NaOH}$ solution, and three times with $\mathrm{H}_{2} \mathrm{O}$. The organic phase was dried $\left(\mathrm{MgSO}_{4}\right)$, filtered and the solvent was removed under reduced pressure. $\mathrm{FC}\left(\mathrm{CH}_{2} \mathrm{Cl}_{2} / \mathrm{MeOH} 10: 1\right)$ gave the title compound (28a) $(5.3 \mathrm{mg}, 5.1 \mathrm{mmol}, 73 \%) . \mathrm{R}_{\mathrm{f}}=0.23\left(\mathrm{CH}_{2} \mathrm{Cl}_{2} / \mathrm{MeOH} 10: 1\right) .{ }^{1} \mathrm{H}-\mathrm{NMR}$ $\left(\mathrm{CD}_{3} \mathrm{OD}, 300 \mathrm{MHz}\right.$, Rotamers of Boc-Thr) 1.15-1.18 (br. 3H), 1.42/1.43 (s, 9H), 3.00 (d, J = 8.1, 2H), 3.52-3.60 (m, 7H), 3.68-3.73 (m, 3H), 3.86-3.90 (m, 2H), 4.24 (br. s, $1 \mathrm{H}), 4.40-4.56(\mathrm{~m}$, 14H), $5.17(\mathrm{~s}, 2 \mathrm{H}), 5.20(\mathrm{~s}, 2 \mathrm{H}), 6.89(\mathrm{~s}, 1 \mathrm{H}), 7.22-7.47$ (m, $26 \mathrm{H})$.

Boc-L-Thr(OBn)-D-Ser(OBn)-L-Ser(OBn)-(3S)-THQ(OBn); chloride (28a). (3S)-6,7-Bisbenzyloxy-3-tert-butoxycarbonylamino-1,1-dimethyl-1,2,3,4-tetrahydro-quinolinium chloride (27) $(50 \mathrm{mg}, 95.3 \mu \mathrm{mol})$ was dissolved in dioxane $(1 \mathrm{~mL})$, cooled to $0{ }^{\circ} \mathrm{C}$ and 
HCl.dioxane $(4 \mathrm{M})(0.48 \mathrm{mmol}, 480 \mu \mathrm{l}, 5 \mathrm{eq})$ was added. The reaction mixture was stirred at $0{ }^{\circ} \mathrm{C}$ for 1 hour and 3 hours at RT. Then the solvent was removed under reduced pressure and the product dried under high vacuum overnight.

Boc-L-Ser(OBn) (1.2 eq) was dissolved in DMF (1 mL) with iBuOCOCl (15 $\mu 1,150 \mu$ mol 1.2 eq) and NMM (21 $\mu \mathrm{l}, 191 \mu \mathrm{mol}, 2$ eq) and cooled to $-18{ }^{\circ} \mathrm{C}$. The reaction mixture was stirred for $30 \mathrm{~min}$ and the amine salt dissolved in DMF (0.5 mL), NMM (21 $\mu 1,191 \mu \mathrm{mol}, 2$ eq) was added dropwise. It was allowed to reach RT gradually overnight. Then the solvent was evaporated under reduced pressure and the residue taken up in EtOAc. It was washed 3xwith $\mathrm{H}_{2} \mathrm{O}$ and the combined water phases $3 x$ extracted with EtOAc. The combined organic phases were dried over $\mathrm{Na}_{2} \mathrm{SO}_{4}$, filtered and evaporated under reduced pressure. $\mathrm{FC}\left(\mathrm{CH}_{2} \mathrm{Cl}_{2} / \mathrm{MeOH}\right.$ 90:10) gave the expected product (28) (47.4 mg, $67.7 \mu \mathrm{mol}, 71 \%)$.

It was dissolved in dioxane $(1 \mathrm{~mL})$, cooled to $0{ }^{\circ} \mathrm{C}$ and $\mathrm{HCl}$.dioxane $(4 \mathrm{M}, 85 \mu \mathrm{l}, 338 \mu \mathrm{mol}, 5 \mathrm{eq})$ was added. The reaction mixture was stirred for 1 hour at $0{ }^{\circ} \mathrm{C}$ and 3 hours at RT. Then the solvent was evaporated under reduced pressure and the product dried under high vacuum overnight.

Boc-L-Thr(OBn)-D-Ser(OBn) (40 mg, $81.2 \mu \mathrm{mol}, 1.2 \mathrm{eq})$ was dissolved in DMF (1 mL) with iBuOCOCl (10.6 $\mu \mathrm{l}, 81.2 \mu \mathrm{mol}, 1.2 \mathrm{eq})$ and NMM (15 $\mu \mathrm{l}, 135 \mu \mathrm{mol}, 2 \mathrm{eq})$ and cooled to $-18{ }^{\circ} \mathrm{C}$. The reaction mixture was stirred for $30 \mathrm{~min}$ and the amine salt dissolved in DMF $(0.5 \mathrm{~mL})$, NMM (15 $\mu$ l, $135 \mu \mathrm{mol}, 2$ eq) was added dropwise. It was allowed to reach RT gradually over night. Then the solvent was evaporated under reduced pressure and the residue taken up in EtOAc. It was washed 3 times with $\mathrm{H}_{2} \mathrm{O}$ and the combined water phases $3 x$ extracted with EtOAc. The combined organic phases were dried over $\mathrm{Na}_{2} \mathrm{SO}_{4}$, filtered and evaporated under reduced pressure. $\mathrm{FC}\left(\mathrm{CH}_{2} \mathrm{Cl}_{2} / \mathrm{MeOH}\right.$ 90:10) gave the title compound 28a (34 mg, $33.1 \mu \mathrm{mol}$, 49\%). Colorless oil. $\mathrm{R}_{\mathrm{f}}=0.33\left(\mathrm{CH}_{2} \mathrm{Cl}_{2} / \mathrm{MeOH} 90: 10\right) .[\alpha]_{\mathrm{D}}=+4.36\left(\mathrm{C}=1.825, \mathrm{CHCl}_{3}, \mathrm{~T}=25.1\right.$ $\left.{ }^{\circ} \mathrm{C}\right) .{ }^{1} \mathrm{H}-\mathrm{NMR}\left(\mathrm{CDCl}_{3}, 300 \mathrm{MHz}\right) \delta 1.19(\mathrm{~d}, 3 \mathrm{H}, J=6.23), 1.33(\mathrm{~s}, 9 \mathrm{H}), 2.80-2.90(\mathrm{~m}, 2 \mathrm{H}), 3.15-$ 
$3.3(\mathrm{~m}, 1 \mathrm{H}), 3.45(\mathrm{~s}, 6 \mathrm{H}), 3.6-3.75(\mathrm{~m}, 4 \mathrm{H}), 3.9-4.0(\mathrm{~m}, 2 \mathrm{H}), 4.05-4.2(\mathrm{~m}, 1 \mathrm{H}), 4.3-4.45(\mathrm{~m}, 1 \mathrm{H})$, $4.43(\mathrm{~s}, 2 \mathrm{H}), 4.47(\mathrm{~s}, 2 \mathrm{H}), 4.48(\mathrm{~s}, 2 \mathrm{H}), 4.6-4.7(\mathrm{~m}, 1 \mathrm{H}), 4.75-4.82(\mathrm{~m}, 1 \mathrm{H}), 5.1(\mathrm{~d}, 2 \mathrm{H}, J=3.11)$, $5.31(\mathrm{~s}, 2 \mathrm{H}), 5.63(\mathrm{~d}, 1 \mathrm{H}, J=7.47), 6.55(\mathrm{~s}, 1 \mathrm{H}), 7.02-7.41(\mathrm{~m}, 25 \mathrm{H}), 7.82(\mathrm{~d}, 1 \mathrm{H}, J=7.78), 8.51$ (d, $1 \mathrm{H}, J=5.92), 8.68(\mathrm{~d}, 1 \mathrm{H}, J=6.53)$. IR $3317 w, 1705 w, 1664 m, 1518 m$. MS $1034.5(100$, $\left.[\mathrm{M}]^{+}\right)$. HRMS calcd. for $\mathrm{C}_{61} \mathrm{H}_{72} \mathrm{~N}_{5} \mathrm{O}_{10}(\mathrm{M})^{+}:$1034.5274, found: 1034.5264 . 


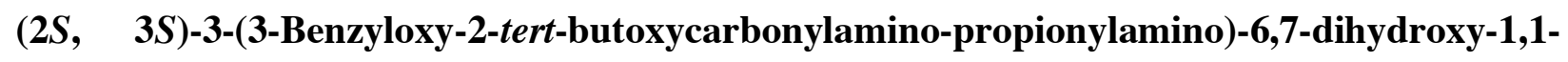

dimethyl-1,2,3,4-tetrahydro-quinolinium (30a). $\quad(S, S)$-\{2-Benzyloxy-1-[1-(3,4-dihydroxybenzyl)-2-dimethylamino-ethylcarba-moyl]-ethyl\}-carbamic acid tert-butyl ester (30) (61.3 mg, $0.125 \mathrm{mmol})$ was dissolved in $\mathrm{CH}_{2} \mathrm{Cl}_{2}(1.25 \mathrm{ml})$ under Ar. Dianisyltellurium oxide (49.2 mg, $0.1375 \mathrm{mmol}$ ) was added in one portion, and the resulting solution was stirred for $2 \mathrm{~h}$ at room temperature. The solvent was removed under reduced pressure and the residue was dissolved in $\mathrm{CHCl}_{3}(1 \mathrm{ml})$. The organic layer was three times extracted with $\mathrm{H}_{2} \mathrm{O}$ and the aqueous layers combined. Lyophilization gave the title compound (30a) (48 mg, $0.1 \mathrm{mmol}, 80 \%$ ). Colorless fluffy powder. ${ }^{1} \mathrm{H}-\mathrm{NMR}\left(\mathrm{CD}_{3} \mathrm{OD}, 300 \mathrm{MHz}\right) 1.44(\mathrm{~s}, 9 \mathrm{H}), 2.88\left(\mathrm{dd}, J_{1}=16.2, J_{2}=10.6,1 \mathrm{H}\right)$, $3.03\left(\mathrm{dd}, J_{1}=16.2, J_{2}=5.6,1 \mathrm{H}\right), 3.54(\mathrm{~s}, 6 \mathrm{H}), 3.57-3.81(\mathrm{~m}, 2 \mathrm{H}), 4.28(\mathrm{t}, J=5.3,1 \mathrm{H}), 4.53(\mathrm{~s}$, $2 \mathrm{H}), 4.53-4.60(\mathrm{~m}, 1 \mathrm{H}), 6.64(\mathrm{~s}, 1 \mathrm{H}), 7.16(\mathrm{~s}, 1 \mathrm{H}), 7.26-7.36(\mathrm{~m}, 5 \mathrm{H}) .{ }^{13} \mathrm{C}-\mathrm{NMR}\left(\mathrm{CD}_{3} \mathrm{OD}, 75\right.$ MHz) 28.4, 32.0, 41.3, 55.8, 58.4, 58.9, 66.1, 70.7, 73.9, 80.6, 107.8, 116.3, 119.8, 128.4, 128.5, 129.0, 133.7, 138.8, 146.8, 148.2, 172.8. MS 486.2 $\left(100, \mathrm{M}^{+}\right), 430.2\left(74,[\mathrm{M}-t \mathrm{Bu}+\mathrm{H}]^{+}\right), 386.2$ $\left(16,[\mathrm{M}-\mathrm{Boc}]^{+}\right)$. HRMS calcd. for $\mathrm{C}_{26} \mathrm{H}_{36} \mathrm{~N}_{3} \mathrm{O}_{6}\left(\mathrm{M}^{+}\right)$: 486.2599, found: 486.2595 . 
(5S, 6S)-7-Benzyloxy-6-benzyloxycarbonylamino-5-hydroxy-3-oxo-heptanoic acid tert-butyl

ester (32). To a solution of ${ }^{\mathrm{i}} \mathrm{Pr}_{2} \mathrm{NH}(691 \mu \mathrm{L}, 4.9 \mathrm{mmol}, 6.4 \mathrm{eq})$ in dry $\mathrm{THF}(2 \mathrm{~mL})$ at $0{ }^{\circ} \mathrm{C}$ was added $\mathrm{BuLi}$ ( $1.6 \mathrm{M}$ in hexan) ( $2.9 \mathrm{~mL}, 4.6 \mathrm{mmol}, 6 \mathrm{eq})$ dropwise. The reaction mixture was stirred at this temperature for 10 minutes and cooled to $-78^{\circ} \mathrm{C}$. Then $\mathrm{AcO}{ }^{\mathrm{t}} \mathrm{Bu}(623 \mu \mathrm{L}, 4.6 \mathrm{mmol}$, 6 eq) was added dropwise and it was stirred at this temperature for 1 hour. The enolate was cannulated into a solution of $(3 S, 4 S)$-5-Benzyloxy-4-benzyloxycarbonylamino-3-(tert-butyldimethyl-silanoxy)-pentanoic acid methyl ester (10) $(300 \mathrm{mg}, 775 \mu \mathrm{mol})$ in dry THF (2 mL) at $0^{\circ} \mathrm{C}$. It was stirred 1 hour at $0^{\circ} \mathrm{C}$ and 30 minutes at RT. The reaction mixture was quenched with saturated $\mathrm{NH}_{4} \mathrm{Cl}$ and the THF was evaporated. A mixture of $\mathrm{NH}_{4} \mathrm{Cl} / \mathrm{H}_{2} \mathrm{O}(1: 1)$ was added and the solution 3 times extracted with EtOAc. The combined organic layers were washed with saturated $\mathrm{NH}_{4} \mathrm{Cl}$, dried over $\mathrm{Na}_{2} \mathrm{SO}_{4}$, filtered and evaporated under reduced pressure. FC (Hexan/EtOAc 7:1) gave the expected product $32(274 \mathrm{mg}, 75 \%) . \mathrm{R}_{\mathrm{f}}=0.34($ EtOAc/Hexane 4:6). $[\alpha]_{\mathrm{D}}=+0.24\left(\mathrm{C}=5.22, \mathrm{CHCl}_{3}, \mathrm{~T}=27^{\circ} \mathrm{C}\right) .{ }^{1} \mathrm{H}-\mathrm{NMR}\left(\mathrm{CDCl}_{3}, 300 \mathrm{MHz}\right) \delta 1.45(\mathrm{~s}, 9 \mathrm{H})$, $2.65\left(\mathrm{dd}, 1 \mathrm{H}, J_{1}=4.04, J_{2}=17.74\right), 2.79\left(\mathrm{dd}, 1 \mathrm{H}, J_{1}=8.72, J_{2}=17.43\right), 3.33\left(\mathrm{dd}, 1 \mathrm{H}, J_{1}=2.49\right.$, $\left.J_{2}=10.3\right), 3.35(\mathrm{~s}, 2 \mathrm{H}), 3.64(\mathrm{~d}, 2 \mathrm{H}, J=4.98), 3.76-3.86(\mathrm{~m}, 1 \mathrm{H}), 4.4-4.48(\mathrm{~m}, 1 \mathrm{H}), 4.51(\mathrm{~s}, 2 \mathrm{H})$, $5.11(\mathrm{~s}, 2 \mathrm{H}), 5.39(\mathrm{~d}, J=9.34), 7.28-7.36(\mathrm{~m}, 10 \mathrm{H}) .{ }^{13} \mathrm{C}-\mathrm{NMR}\left(\mathrm{CDCl}_{3}, 75 \mathrm{MHz}\right)$ 28.0, 28.1, 46.6, $51.1,53.3,53.6,66.9,67.3,67.4,71.0,73.5,82.2,127.5,127.8,128.3,128.6,136.2,137.4$, 156.3, 165.9, 203.0. IR 3606-3187w, 2977w, 1744m, 1712s. MS 494.2 (17, [M+Na $\left.]^{+}\right), 394.2(81$, $\left[\mathrm{M}-\mathrm{CO}_{2}{ }^{t} \mathrm{Bu}+\mathrm{Na}\right]^{+}$. HRMS calcd. for $\mathrm{C}_{26} \mathrm{H}_{33} \mathrm{NO}_{7} \mathrm{Na}(\mathrm{M}+\mathrm{Na})^{+}$: 494.2149, found: 494.2141. 


\section{$(3 R, 5 S, 6 S)$-7-Benzyloxy-6-benzyloxycarbonylamino-3,5-dihydroxy-heptanoic acid tert-}

butyl ester (32a). A solution of $\mathrm{Et}_{3} \mathrm{~B}(1.5 \mathrm{eq}, 1 \mathrm{M}$ sol. in hexane) and pivalic acid (0.05 eq) dissolved in dry THF $(1.5 \mathrm{~mL})$ and $\mathrm{MeOH}(1 \mathrm{~mL})$ was stirred at RT for 1hour and was then cooled to $-70^{\circ} \mathrm{C} .32(0.115 \mathrm{~g}, 0.25 \mathrm{mmol})$ in dry THF $(1 \mathrm{~mL})$ was added dropwise followed by $\mathrm{NaBH}_{4}(3 \mathrm{eq})$ and it was stirred at $-70^{\circ} \mathrm{C}$ for 4hours. $\mathrm{H}_{2} \mathrm{O}_{2}(3 \mathrm{~mL})$ and $\mathrm{H}_{2} \mathrm{O}(5 \mathrm{~mL})$ were then added at $-70^{\circ} \mathrm{C}$ and the reaction allowed to warm until RT. Then $\mathrm{CHCl}_{3}$ and $\mathrm{H}_{2} \mathrm{O}$ were added and the aqueous phase extracted with chloroform. The combined organic layers were washed with $5 \mathrm{x} \mathrm{H}_{2} \mathrm{O}$, dried over $\mathrm{Na}_{2} \mathrm{SO}_{4}$, filtered and evaporated under reduced pressure. FC (Hexane/EtOAc 6:4) gave the 3,5-syn-compound (32a) (90 mg, $0.19 \mathrm{mmol}, 78 \%) . \mathrm{R}_{\mathrm{f}}=0.38$ $\left(\right.$ EtOAc/Hexane 1:1). $[\alpha]_{\mathrm{D}}=+0.35\left(\mathrm{C}=0.86, \mathrm{CHCl}_{3}, \mathrm{~T}=36^{\circ} \mathrm{C}\right) .{ }^{1} \mathrm{H}-\mathrm{NMR}\left(\mathrm{CDCl}_{3}, 300 \mathrm{MHz}\right) \delta$ $1.46(\mathrm{~s}, 9 \mathrm{H}), 1.45-1.58(\mathrm{~m}, 1 \mathrm{H}), 1.64-1.78(\mathrm{~m}, 1 \mathrm{H}), 2.32-2.42(\mathrm{~m}, 2 \mathrm{H}), 3.52-3.68(\mathrm{~m}, 2 \mathrm{H}), 3.74-$ $3.86(\mathrm{~m}, 1 \mathrm{H}), 3.92-4.08(\mathrm{~m}, 2 \mathrm{H}), 4.12-4.3(\mathrm{~m}, 2 \mathrm{H}), 4.51(\mathrm{~d}, 2 \mathrm{H}, J=4.36), 4.1(\mathrm{~d}, 2 \mathrm{H}, J=1.87)$, $5.53(\mathrm{~d}, 1 \mathrm{H}, J=9.34), 7.26-7.35(\mathrm{~m}, 10 \mathrm{H}) .{ }^{13} \mathrm{C}-\mathrm{NMR}\left(\mathrm{CDCl}_{3}, 75 \mathrm{MHz}\right) 28.2,39.3,42.7,54.1$, $66.8,68.4,70.9,71.0,73.4,76.8,81.3,136.4,137.6,156.4,171.7$. IR 3602-3142w, 2977w, 1720s. MS $496.2\left(14,[\mathrm{M}+\mathrm{Na}]^{+}\right), 440.2\left(100,\left[\mathrm{M}-2 \mathrm{H}_{2} \mathrm{O}+\mathrm{H}\right]^{+}\right)$. HRMS calcd. for $\mathrm{C}_{26} \mathrm{H}_{35} \mathrm{NO}_{7} \mathrm{Na}$ $(\mathrm{M}+\mathrm{Na})^{+}:$496.2306, found: 496.2298. 
$(3 R, 5 S, 6 S)$-7-Benzyloxy-6-benzyloxycarbonylamino-3,5-bis-(tert-butyl-dimethyl-silanoxy)heptanoic acid tert-butyl ester (33). A solution of 32a $(22.0 \mathrm{mg}, 46.5 \mu \mathrm{mol})$ in $\operatorname{dry} \mathrm{CH}_{2} \mathrm{Cl}_{2}(0.5$ $\mathrm{mL}$ ) was cooled to $-20^{\circ} \mathrm{C}$ and 2,6 lutidine (4 eq) was added dropwise followed by TBSOTf (3 eq). The reaction mixture was stirred at $-20^{\circ} \mathrm{C}$ for $1 \mathrm{~h} 15$. Then $\mathrm{CH}_{2} \mathrm{Cl}_{2}$ was added and the organic phase was washed $3 \mathrm{x}$ with citric acid $(10 \%)$ and $2 \mathrm{x}$ with $\mathrm{H}_{2} \mathrm{O}$, dried over $\mathrm{Na}_{2} \mathrm{SO}_{4}$, filtered and evaporated under reduced pressure. FC (EtOAc/Hexane 1:9) gave 33 (31.0 mg, $44.2 \mu \mathrm{mol}, 94$ \%). $\mathrm{R}_{\mathrm{f}}=0.24\left(\right.$ EtOAc/Hexane 1:9). $[\alpha]_{\mathrm{D}}=-0.83\left(\mathrm{C}=0.35, \mathrm{CHCl}_{3}, \mathrm{~T}=25^{\circ} \mathrm{C}\right) .{ }^{1} \mathrm{H}-\mathrm{NMR}\left(\mathrm{CDCl}_{3}\right.$, $300 \mathrm{MHz}) \delta 0.06(\mathrm{~s}, 3 \mathrm{H}), 0.07$ (s, 3H), 0.09 (s, 3H), $0.11(\mathrm{~s}, 3 \mathrm{H}), 0.84(\mathrm{~s}, 9 \mathrm{H}), 0.89$ (s, 9H), 1.45 $(\mathrm{s}, 9 \mathrm{H}), 1.7(\mathrm{~m}, 1 \mathrm{H}), 1.8(\mathrm{~m}, 1 \mathrm{H}), 2.36(\mathrm{~m}, 1 \mathrm{H}), 3.44(\mathrm{t}, 1 \mathrm{H}, J=8.41), 3.55\left(\mathrm{dd}, 1 \mathrm{H}, J_{1}=5.3, J_{2}=\right.$ 8.72), 3.92-4.04 (m, 1H), 4.05-4.17 (m, 2H), 4.44-4.54 (m, 1H), 4.49 (d, 1H, J= 4.05), 5.04-5.18 (m, 3H), 7.25-7.38 (m, 10H). ${ }^{13} \mathrm{C}-\mathrm{NMR}\left(\mathrm{CDCl}_{3}, 75 \mathrm{MHz}\right)-4.7,-4.5,-4.1,-3.4,-2.8,17.9,18.06$, $18.1,18.2,19.8,25.8,25.9,26.0,28.1,41.4,44.6,52.4,66.3,66.8,67.4,69.0,73.2,76.7,80.3$, $124.5,127.5,127.6,127.7,127.9,128.0,128.1,128.14,128.4,136.4,137.8,156.1,169.9$. IR 2957m, 2929m, 2852m, 1727s. MS $724.4\left(58,[\mathrm{M}+\mathrm{Na}]^{+}\right), 646.4\left(100,[\mathrm{M}-\mathrm{tBu}]^{+}\right), 602.4(77$, $\left.[\mathrm{M}+\mathrm{H}]^{+}\right)$. HRMS calcd. for $\mathrm{C}_{38} \mathrm{H}_{63} \mathrm{NO}_{7} \mathrm{Si}_{2} \mathrm{Na}(\mathrm{M}+\mathrm{Na})^{+}:$: 724.4035, found: 724.4022 .

\section{$(3 R, \quad 5 S, \quad 6 S)-6-(2-B e n z y l o x y-b e n z o y l a m i n o)-3,5-b i s-(t e r t-b u t y l-d i m e t h y l-s i l a n o x y)-7-$}

hydroxy-heptanoic acid tert-butyl ester (33a). 33 (40 mg, $0.057 \mathrm{mmol}$ ) was dissolved in $\mathrm{CH}_{3} \mathrm{OH}(0.5 \mathrm{ml})$, the flask was flushed $3 \mathrm{x}$ with $\mathrm{Ar}$, and 2 small spatula of $\mathrm{Pd} / \mathrm{C}(10 \%)$ were added. The flask was flushed $3 \mathrm{x}$ with $\mathrm{H}_{2}$, and the black suspension was vigorously stirred for $4 \mathrm{~h}$ at RT. The suspension was filtered over Celite, and the solvent evaporated. ${ }^{1} \mathrm{H}-\mathrm{NMR}$ analysis showed complete deprotection. This intermediate was used without further purification.

The intermediate amino ester was suspended in $\mathrm{CH}_{2} \mathrm{Cl}_{2}(1.2 \mathrm{~mL})$, hydroxybenzotriazole (10 $\mathrm{mg}$, $0.068 \mathrm{mmol}), 2-\mathrm{BnO}$-salicylic acid $(16 \mathrm{mg}, 0.068 \mathrm{mmol}), N$-methylmorpholine $(19 \quad 1,0.171$ 
mmol) and EDC (13 mg, $0.068 \mathrm{mmol})$ were added. The resulting solution was stirred over night at RT and was then diluted with $\mathrm{CHCl}_{3}$. The organic layer was washed $3 \mathrm{x}$ with $10 \%$ citric acid solution, $3 \mathrm{x}$ with saturated $\mathrm{NaHCO}_{3}$ solution and $1 \mathrm{x}$ with $\mathrm{H}_{2} \mathrm{O}$. The organic layer was dried $\left(\mathrm{MgSO}_{4}\right)$, filtered and the solvent evaporated. FC (EtOAc/cyclohexne 4:6) gave the title compound 33a $(27 \mathrm{mg}, 0.039 \mathrm{mmol}, 70 \%)$. Colorless oil. $\mathrm{R}_{\mathrm{f}}=0.57$ (EtOAc/Cyclohexane 4:6). $[\alpha]_{\mathrm{D}}=0.95\left(\mathrm{C}=1.35, \mathrm{CHCl}_{3}, \mathrm{~T}=24^{\circ} \mathrm{C}\right) .{ }^{1} \mathrm{H}-\mathrm{NMR}\left(\mathrm{CDCl}_{3}, 300 \mathrm{MHz}\right) \delta 0.075(\mathrm{~s}, 3 \mathrm{H}), 0.09(\mathrm{~s}$, $3 \mathrm{H}), 0.10(\mathrm{~s}, 3 \mathrm{H}), 0.12(\mathrm{~s}, 3 \mathrm{H}), 0.83(\mathrm{~s}, 9 \mathrm{H}), 0.89(\mathrm{~s}, 9 \mathrm{H}), 1.31(\mathrm{~s}, 9 \mathrm{H}), 1.62-1.80(\mathrm{~m}, 2 \mathrm{H}), 2.28-$ $2.34\left(\mathrm{dd}, J_{1}=4.05, J_{2}=6.54,1 \mathrm{H}\right), 2.77(\mathrm{t}, 1 \mathrm{H}, J=4.67), 3.74-3.80(\mathrm{~m}, 2 \mathrm{H}), 4.06-4.16(\mathrm{~m}, 2 \mathrm{H})$, $4.28-4.38(\mathrm{~m}, 1 \mathrm{H}), 5.28(\mathrm{~s}, 2 \mathrm{H}), 6.92\left(\mathrm{dd}, 1 \mathrm{H}, J_{1}=0.63, J_{2}=8.41\right), 7.04\left(\mathrm{td}, 1 \mathrm{H}, J_{1}=0.93, J_{2}=\right.$ 7.93), 7.3-7.4 (m, 5H), $8.17\left(\mathrm{dd}, 1 \mathrm{H}, J_{1}=1.87, J_{2}=7.78\right), 8.31(\mathrm{~d}, 1 \mathrm{H}, J=7.78) .{ }^{13} \mathrm{C}-\mathrm{NMR}$ $\left(\mathrm{CDCl}_{3}, 75 \mathrm{MHz}\right)-4.7,-4.4,-4.3,-4.2,18.0,25.9,27.0,28.0,28.2,41.4,44.6,54.2,65.0,66.4$, 69.0, 70.9, 76.6, 80.3, 113.0, 121.3, 126.9, 128.2, 128.7, 132.3, 132.6, 135.8, 156.5, 169.8. IR $3558-3234 w, 2950 m, 2921 m, 2842 m, 1729 m, 1636 m$. MS $710.4\left(52,\left[\mathrm{M}+\mathrm{Na}^{+}\right]^{+}\right)$. HRMS (MALDI) calcd. for for $\mathrm{C}_{37} \mathrm{H}_{61} \mathrm{NO}_{7} \mathrm{Si}_{2} \mathrm{Na}, 710.3879$; found, 710.3866 . 
$(3 R, \quad 5 S, \quad 6 S)-6-(2-B e n z y l o x y-b e n z o y l a m i n o)-3,5,7-t r i s-(t e r t-b u t y l-d i m e t h y l-s i l a n o x y)-$ heptanoic acid tert-butyl ester (33b). 33a (177 mg, $257 \mu \mathrm{mol})$ was dissolved in DMF (1.5 ml) and the solution was cooled with an ice-bath. TBSCl (31 mg, $0.205 \mathrm{mmol})$, Imidazole (12 mg, $0.205 \mathrm{mmol}$ ) and DMAP (3 $\mathrm{mg}, 0.026 \mathrm{mmol}$ ) were added, the reaction mixture was allowed to warm up to RT and stirred overnight. DMF was then removed under high vacuum. FC (EtOAc/cyclohexane 1:7) gave the title compound (33b) $(137.0 \mathrm{mg}, 0.180 \mathrm{mmol}, 70 \%)$. Colorless oil. $\mathrm{R}_{\mathrm{f}}=0.35\left(\right.$ EtOAc/cyclohexane 1:8). $[\alpha]_{\mathrm{D}}=-0.39\left(\mathrm{C}=0.7, \mathrm{CHCl}_{3}, \mathrm{~T}=24^{\circ} \mathrm{C}\right) .{ }^{1} \mathrm{H}-$ NMR $\left(\mathrm{CDCl}_{3}, 300 \mathrm{MHz}\right) \delta 0.06$ (s, 3H), 0.07 (s, 3H), 0.085 (s, 3H), 0.093 (s, 3H), 0,1 (s, 3H), $0.11(\mathrm{~s}, 3 \mathrm{H}), 0.84(\mathrm{~s}, 9 \mathrm{H}), 0.87(\mathrm{~s}, 9 \mathrm{H}), 0.90(\mathrm{~s}, 9 \mathrm{H}), 1.33(\mathrm{~s}, 9 \mathrm{H}), 1.66-1.82(\mathrm{~m}, 2 \mathrm{H}), 2.32(\mathrm{t}, 1 \mathrm{H}$, $J=5.77), 3.6\left(\mathrm{dd}, J_{1}=8.24, J_{2}=9.62\right), 3.72\left(\mathrm{dd}, 1 \mathrm{H}, J_{1}=5.5, J_{2}=9.62\right), 4.18(\mathrm{~m}, 3 \mathrm{H}), 5.29(\mathrm{~s}$, $2 \mathrm{H}), 6.9(\mathrm{~d}, 1 \mathrm{H}, J=8.24), 7.03\left(\mathrm{td}, 1 \mathrm{H}, J_{1}=1.1, J_{2}=7.97\right), 7.28-7.4(\mathrm{~m}, 5 \mathrm{H}), 8.04(\mathrm{~d}, 1 \mathrm{H}, J=$ 8.25), $8.17\left(\mathrm{dd}, 1 \mathrm{H}, J_{1}=1.92, J_{2}=7.69\right) .{ }^{13} \mathrm{C}-\mathrm{NMR}\left(\mathrm{CDCl}_{3}, 75 \mathrm{MHz}\right)-5.1,-4.5,-4.4,-4.1,-4.0$, $17.96,18.04,18.5,26.0,26.2,28.1,41.9,44.3,54.0,61.2,66.6,67.2,70.8,80.1,113.2,121.2$, $122.5,126.7,128.0,128.6,132.2,132.3,136.0,156.3,165.0,170.0$. IR 2958m, 2922m, 2859m, $1731 s, 1654 m . \mathrm{MS} 824.5\left(24,[\mathrm{M}+\mathrm{Na}]^{+}\right), 802.5\left(30,[\mathrm{M}+\mathrm{H}]^{+}\right), 746.4\left(100,[\mathrm{M}-\mathrm{tBu}]^{+}\right), 614.3(93$, [M-tBuOH-TBS] $]^{+}$. HRMS calcd. for $\mathrm{C}_{43} \mathrm{H}_{76} \mathrm{NO}_{7} \mathrm{Si}_{3}(\mathrm{M}+\mathrm{H})^{+}: 802.4930$ found: 802.4909 .

\section{(6S)-6-(2-benzyloxy-benzoylamino)-(3R,5S)-3,5,7-tris-(tert-butyl-dimethyl-silanyloxy)-}

heptanoic acid (34). Compound 33b (16.0 mg, $20.0 \mu \mathrm{mol}, 1.00$ equiv) was dissolved in dry $\mathrm{CH}_{2} \mathrm{Cl}_{2}(0.500 \mathrm{~mL})$ and cooled to $-18{ }^{\circ} \mathrm{C}$. Molecular sieves (4 A) were added and $\mathrm{TMSBr}(7.90$ $\mu \mathrm{L}, 60.0 \mu \mathrm{mol}, 3.00$ equiv) was added at this temperature. The reaction was stirred for $2.5 \mathrm{~h}$ at $18{ }^{\circ} \mathrm{C}$. It was neutralized with saturated aqueous $\mathrm{NaHCO}_{3}$ and the two phases separated. The organic phase was washed 2 x with $\mathrm{H}_{2} \mathrm{O}$ and dried over $\mathrm{MgSO}_{4}$. The solvent was evaporated under reduced pressure and the expected product $\mathbf{3 4}$ was introduced directly in the next step without further purification. For analytical purposes, a sample was derivatized to the methylester 
using diazomethane, and the resulting proton and carbon NMR spectra proved to be identical to compound 21. 


\section{(S)-tert-butyl 1-(dimethylamino)-3-(4-hydroxyphenyl)-1-oxopropan-2-ylcarbamate}

Boc-L-Tyr-OH (5 g, $17.7 \mathrm{mmol})$ was dissolved in THF (40 mL) and cooled to $-46^{\circ} \mathrm{C}$ (dry ice/acetonitrile bath). NMM (2.05 mL, $18.7 \mathrm{mmol})$ and then isobutylchloroformate $(2.53 \mathrm{~mL}$, $18.7 \mathrm{mmol}$ ) were added via syringe. The reaction mixture was stirred for 30 minutes at this temperature, and then dimethylamine $(26.5 \mathrm{~mL}, 2 \mathrm{M}$ in THF) were added via syringe. The reaction was allowed to warm to $\mathrm{RT}$ and then stirred for additional $16 \mathrm{~h}$. The solvent of the colorless suspension was removed under reduced pressure and the residue was partitioned in EtOAc $(200 \mathrm{~mL})$ and citric acid soln. $(10 \%, 15 \mathrm{~mL})$. The organic layer was washed three times each with citric acid soln. $(10 \%, 15 \mathrm{~mL})$, satd. $\mathrm{NaHCO}_{3}$ soln. $(15 \mathrm{~mL})$ and brine $(15 \mathrm{~mL})$. The organic layer was dried $\left(\mathrm{MgSO}_{4}\right)$ and the solvent removed under reduced pressure. FC (EtOAC/cyclohexane 1:1) gave the title compound (3.6 g, $11.6 \mathrm{mmol}, 66 \%$ ). Colorless crystalline solid. $R_{f}=0.15\left(\right.$ EtOAc/cyclohexane 1:1). M.p $=126-127{ }^{\circ} \mathrm{C} .[\alpha]_{D}=+51(\mathrm{C}=1.04$, $\left.\mathrm{CHCl}_{3}\right) .{ }^{1} \mathrm{H}-\mathrm{NMR}\left(\mathrm{CDCl}_{3}, 300 \mathrm{MHz}\right) \delta 1.39(\mathrm{~s}, 9 \mathrm{H}), 2.61(\mathrm{~s}, 3 \mathrm{H}), 2.83-2.85(\mathrm{~m}, 5 \mathrm{H}), 4.75(\mathrm{q}, J=$ $6.8,1 \mathrm{H}), 5.48(\mathrm{~d}, J=8.7,1 \mathrm{H}), 6.72(\mathrm{~d}, J=8.2,2 \mathrm{H}), 6.96(\mathrm{~d}, J=8.2,2 \mathrm{H}), 8.00-8.20$ (br. s, $1 \mathrm{H})$. ${ }^{13} \mathrm{C}-\mathrm{NMR}\left(\mathrm{CDCl}_{3}, 75 \mathrm{MHz}\right)$ 28.4, 35.8, 37.0, 39.2, 51.6, 80.0, 115.3, 127.0, 130. 2, 155.2, 155.6, 171.9. IR $3337 w, 2978 w, 2935 w, 1698 m, 1681 s, 1635 s, 1615 m, 1596 w, 1512 s$. MS 331 (26, $\left.[\mathrm{M}+\mathrm{Na}]^{+}\right), 309\left(21,[\mathrm{M}+\mathrm{H}]^{+}\right), 209\left(100,[\mathrm{M}-\mathrm{Boc}]^{+}\right)$. HRMS calcd. for $\mathrm{C}_{16} \mathrm{H}_{25} \mathrm{~N}_{2} \mathrm{O}_{4}(\mathrm{M}+\mathrm{H})^{+}$: 309.1814, found: 309.1808 . 


\section{(S)-tert-butyl 1-(dimethylamino)-3-(4-hydroxyphenyl)propan-2-ylcarbamate (36)}

(S)-tert-butyl 1-(dimethylamino)-3-(4-hydroxyphenyl)-1-oxopropan-2-ylcarbamate $\quad(2.088 \mathrm{~g}$, $6.78 \mathrm{mmol})$ was dissolved at $0^{\circ} \mathrm{C}$ in dioxane $(12 \mathrm{~mL})$ and $\mathrm{HCl} /$ dioxane $(4 \mathrm{M}, 17 \mathrm{~mL})$ was added via syringe. The reaction mixture was stirred at $0^{\circ} \mathrm{C}$ for $1 \mathrm{~h}$ and at $\mathrm{RT}$ for $1 \mathrm{~h}$. The solvent was removed under reduced pressure and the resulting $\mathrm{HCl}$ salt was used without further purification. The residue was dissolved in THF $(17 \mathrm{~mL})$, the reaction mixture was cooled to $0^{\circ} \mathrm{C}$, and $\mathrm{BH}_{3} *$ THF (1 M, $20.3 \mathrm{~mL})$ was slowly added via syringe. The reaction mixture was allowed to warm to RT and stirred for $16 \mathrm{~h}$ at this temperature. Finally, the reaction mixture was heated to reflux for $5 \mathrm{~h}$. The reaction mixture was then cooled in an ice bath and $\mathrm{HCl}$ soln $(5 \mathrm{M})$ was added until the $\mathrm{pH}$ of the resulting soln. was around 1. The reaction mixture was then stirred for $2 \mathrm{~h}$ at $\mathrm{RT}$ and then the $\mathrm{pH}$ was adjusted to 10 by the addn. of $\mathrm{NaOH}$ soln (2M). The organic solvent was removed under reduced pressure and then dioxane $(25 \mathrm{~mL})$ was added. $\mathrm{Boc}_{2} \mathrm{O}(2.0 \mathrm{~mL}, 8.8$ mmol) was added, and the reaction was stirred at $\mathrm{RT}$ for $16 \mathrm{~h}$. The $\mathrm{pH}$ of the reaction mixture was regularly controlled and adjusted to 10 by the addn. of $\mathrm{NaOH}$ soln $(1 \mathrm{M})$, if necessary. The solvent was removed under reduced pressure. The residue was purified by FC (EtOAC, $1 \%$ $\left.\mathrm{Et}(\mathrm{Me})_{2} \mathrm{~N}\right)$ and then by recrystallization from EtOAc/hexane to give the title compound $(1.41 \mathrm{~g}$, 4.80 mmol, $71 \%$ ). Colorless crystalline solid. $R_{f}=0.14$ (EtOAc). M.p $=156-157^{\circ} \mathrm{C} \cdot[\alpha]_{D}=+21$ $\left(\mathrm{C}=1.07, \mathrm{CHCl}_{3}\right) .{ }^{1} \mathrm{H}-\mathrm{NMR}\left(\mathrm{CD}_{3} \mathrm{OD}, 300 \mathrm{MHz}\right) \delta 1.36(\mathrm{~s}, 9 \mathrm{H}), 2.22(\mathrm{~s}, 6 \mathrm{H}), 2.22-2.42(\mathrm{~m}, 2 \mathrm{H})$, 2.54-2.70 (m, 2H), 3.79-3.81 (br. m, $1 \mathrm{H}), 6.68(\mathrm{~d}, \mathrm{~J}=8.2,2 \mathrm{H}), 7.01(\mathrm{~d}, \mathrm{~J}=8.2,2 \mathrm{H}) .{ }^{13} \mathrm{C}-\mathrm{NMR}$ $\left(\mathrm{CD}_{3} \mathrm{OD}, 75 \mathrm{MHz}\right) 28.5,39.8,45.4,51.0,63.4,79.5,115.6,130.0,156.4,157.3$. IR 2974w, 1678s, 1612m, 1514s. MS $295\left(100,[\mathrm{M}+\mathrm{H}]^{+}\right), 239(58), 195\left([\mathrm{M}-\mathrm{Boc}]^{+}\right)$. HRMS calcd. for $\mathrm{C}_{16} \mathrm{H}_{27} \mathrm{~N}_{2} \mathrm{O}_{3}(\mathrm{M}+\mathrm{H})^{+}:$295.2022, found: 295.2015. Anal. calcd. for $\mathrm{C}_{16} \mathrm{H}_{26} \mathrm{~N}_{2} \mathrm{O}_{3}$ (295.40): C 65.28, H 8.90, N 9.52; found: C 65.28, H 9.07, N 9.27. 


\section{Antimicrobial evaluation}

Minimal inhibitory concentrations (MICs) were determined by a microdilution method following generally the CLSI guidelines. The test medium was cation-adjusted Mueller-Hinton broth, pH 7.2-7.4, which was supplemented accordingly for fastidious organisms (1). Serial dilutions in 96well plates were prepared with the help of a Biomek 2000 robot. The bacterial strains used were from our in-house strain collection. Clinical isolates have been originally obtained from the Kantonsspital Basel, Switzerland, and from other European and US hospitals. Reference strains were obtained from the American Type Culture Collection (ATCC). For some strains MICs were also determined in defined, iron deficient medium (M9 medium). Activity against Helicobacter pylori ATCC 43504 was tested by disk test on blood agar. Disks were loaded with $50 \mu \mathrm{g}$ of compound and the zone of inhibition was recorded after $48 \mathrm{~h}$ incubation under microaerophilic conditions.

\section{References:}

[1] Clinical and Laboratory Standards Institute. Methods for Dilution Antimicrobial Susceptibility Tests for Bacteria that Grow Aerobically, 4th ed.; Approved standard: NCCLS Document M7-A4; National Committee for Clinical Laboratory Standards: Villanova, PA, USA 1997. 
Spectral data 


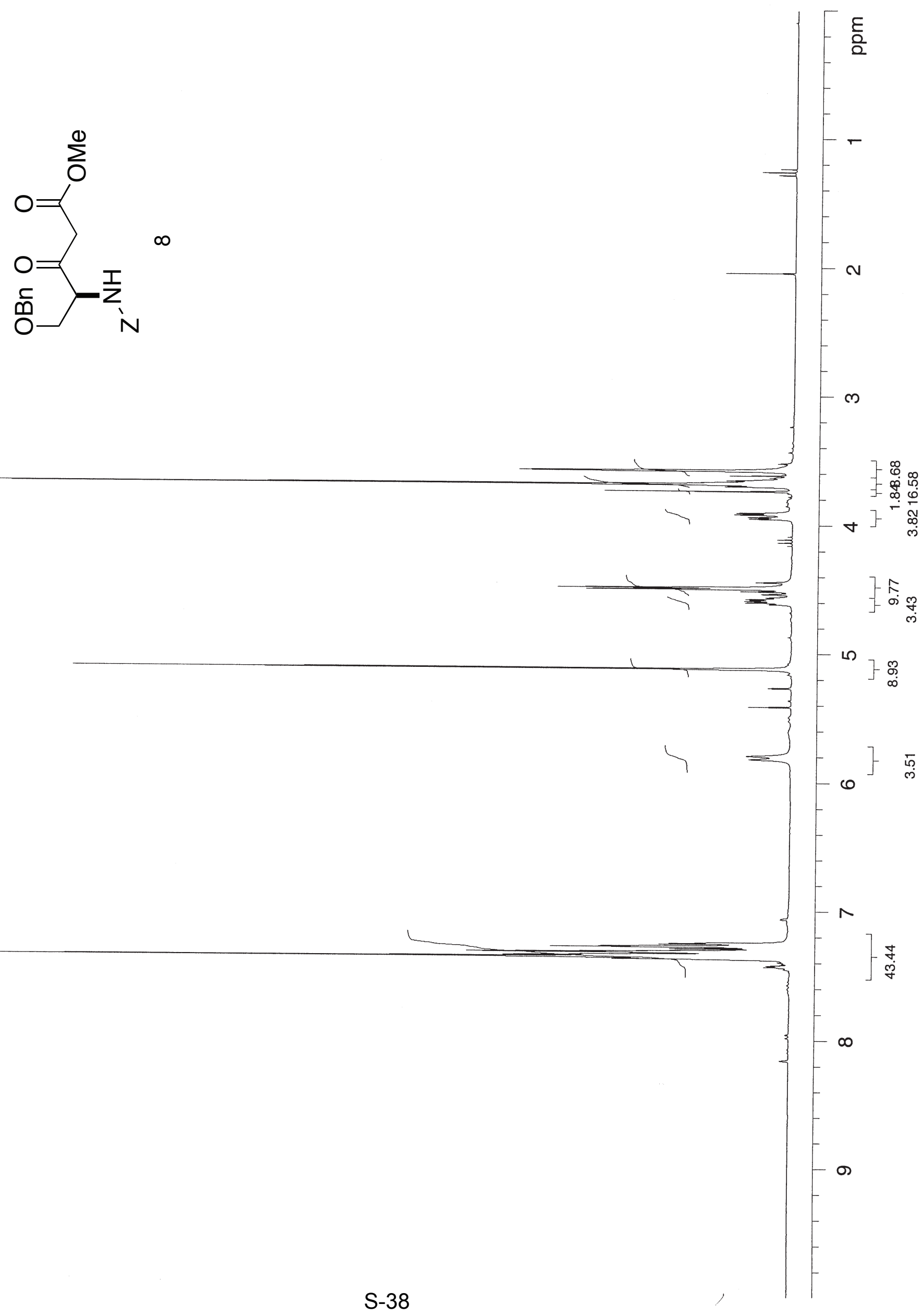




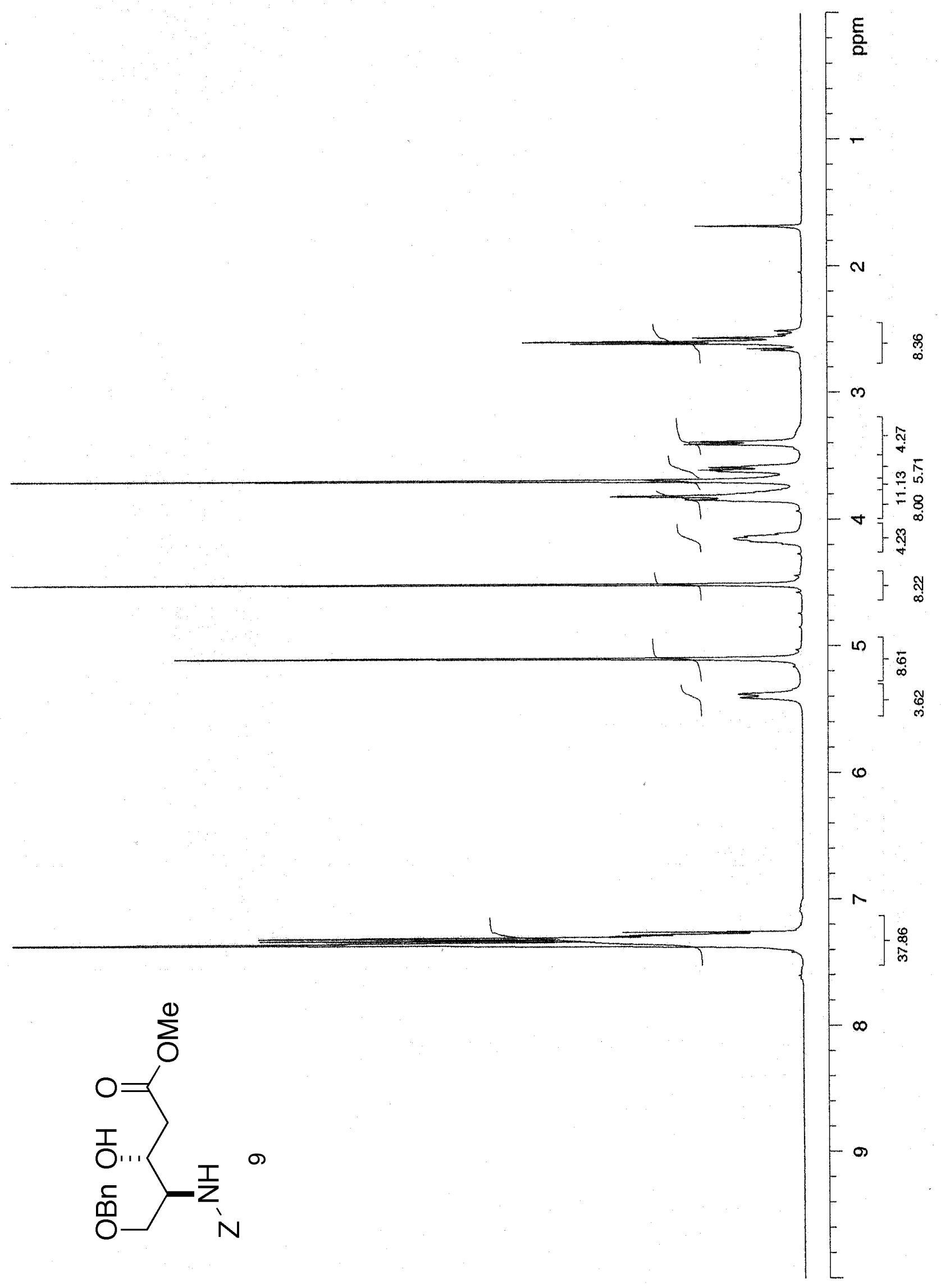




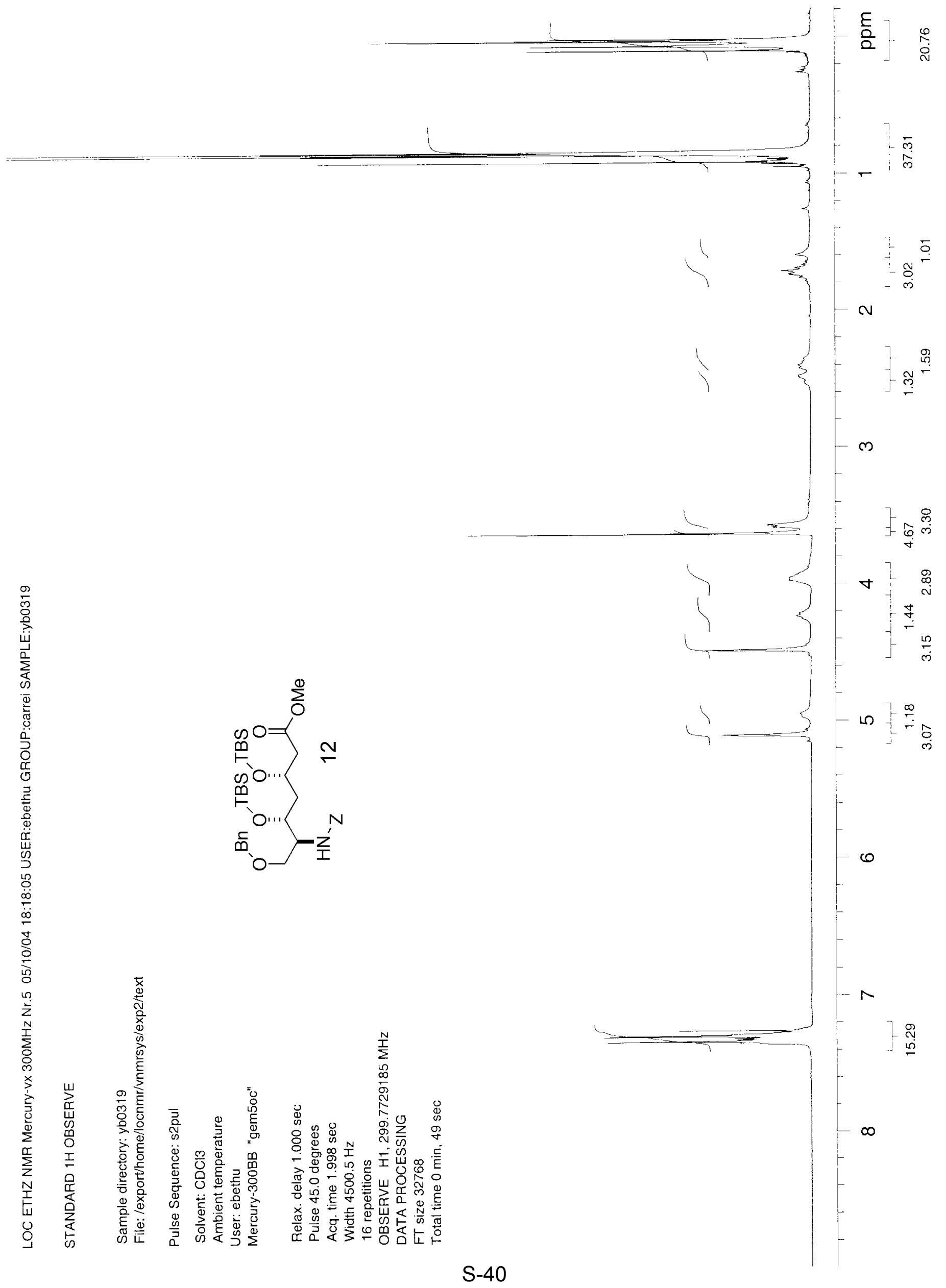




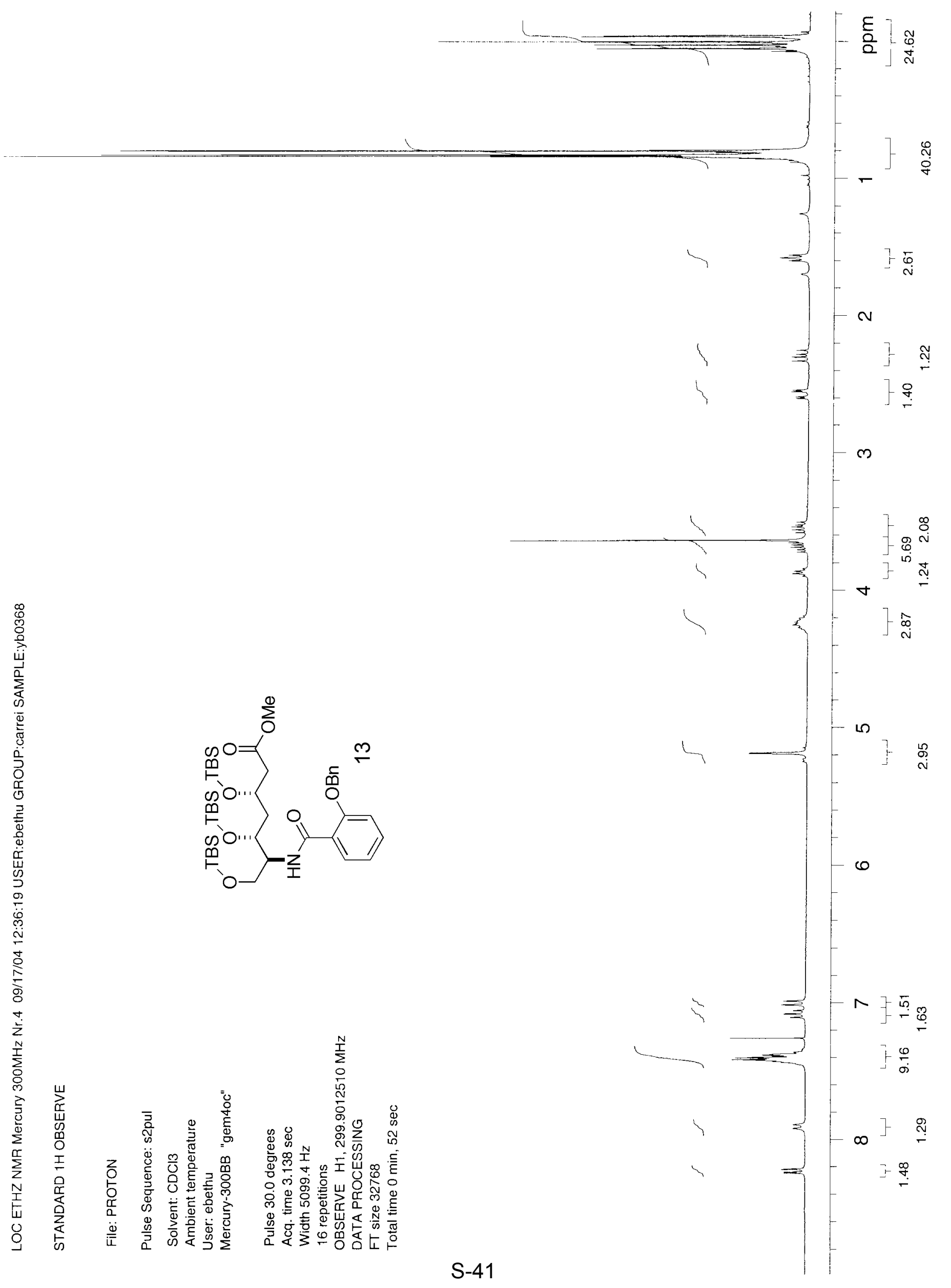




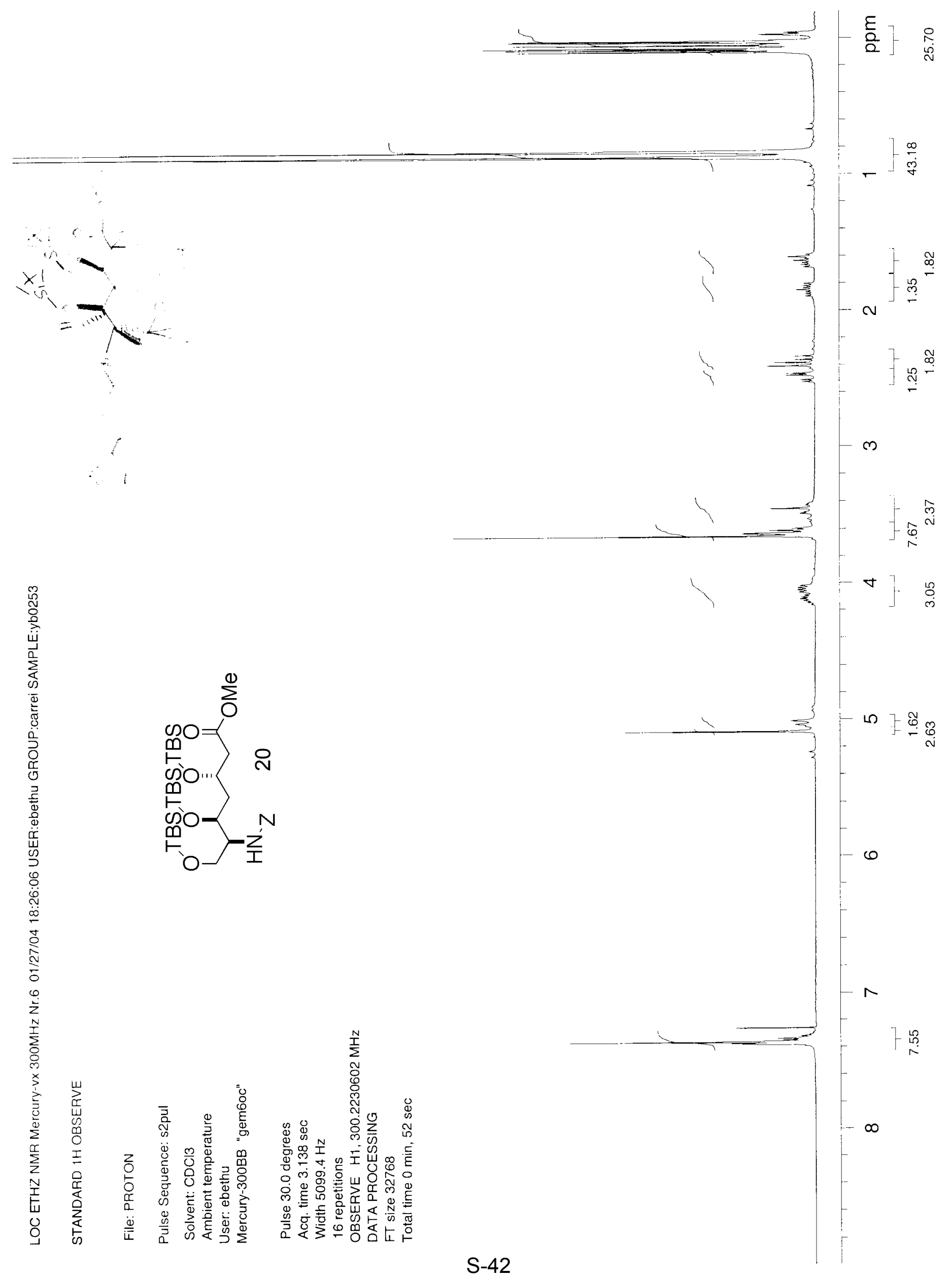




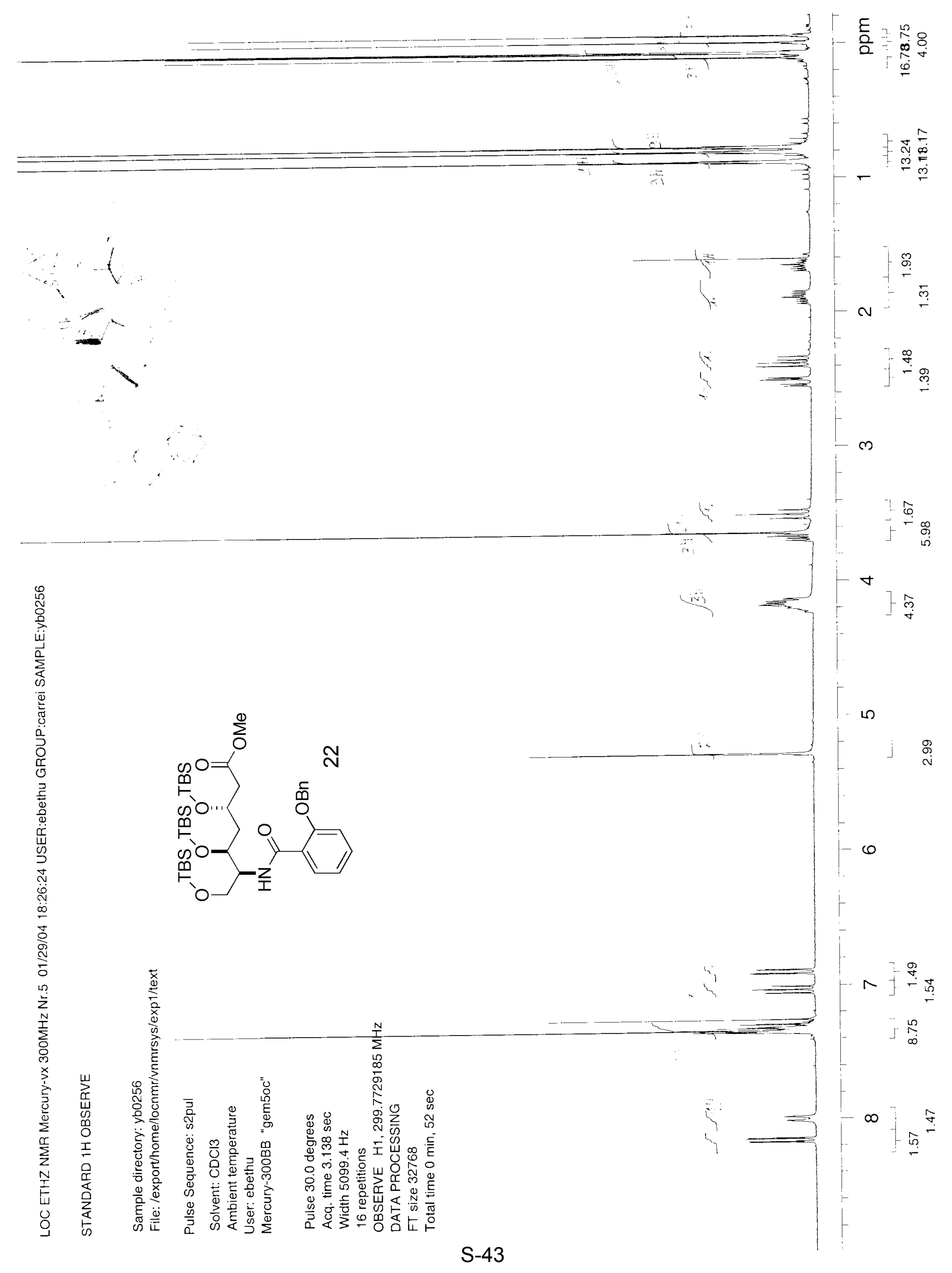




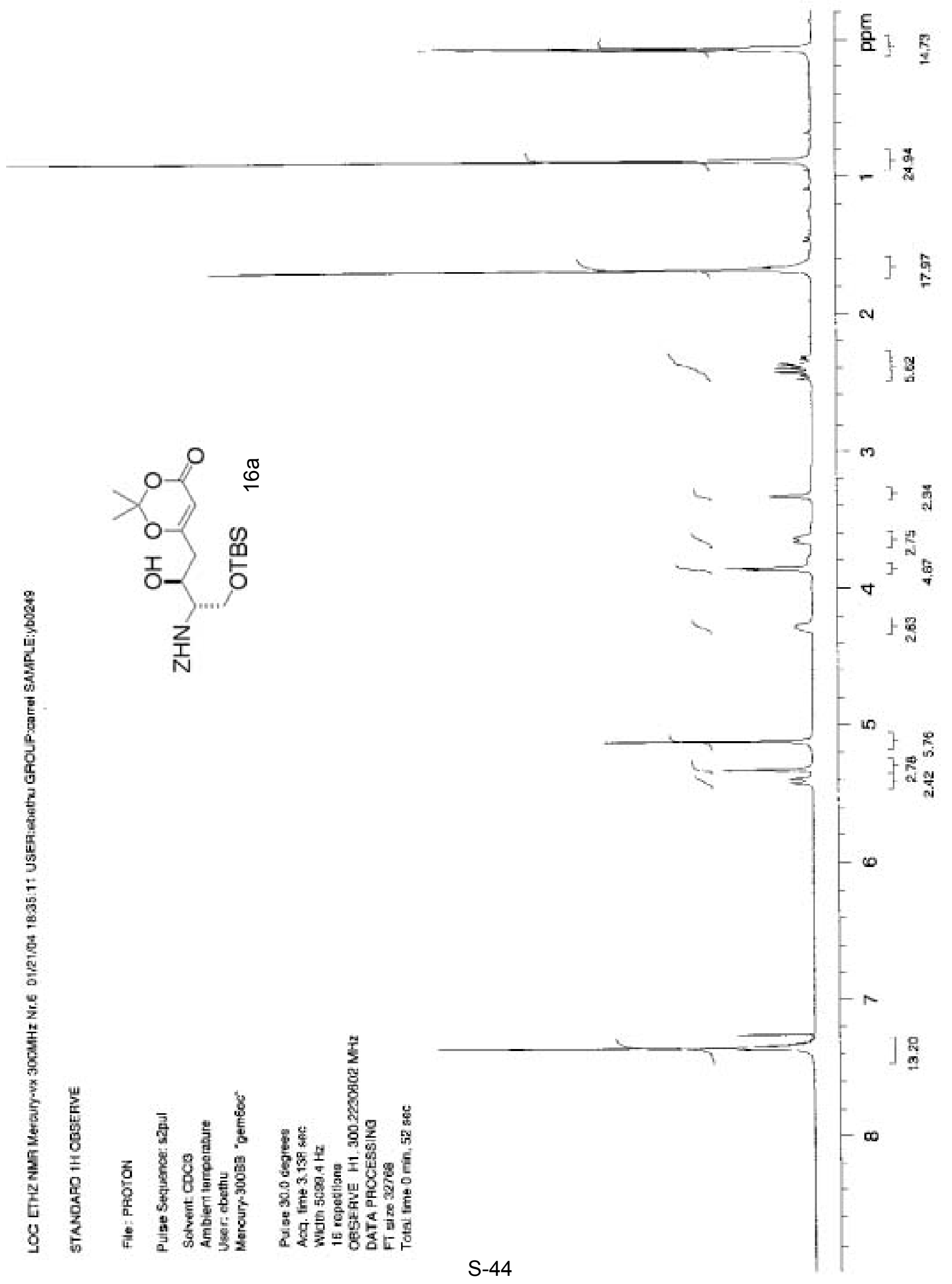




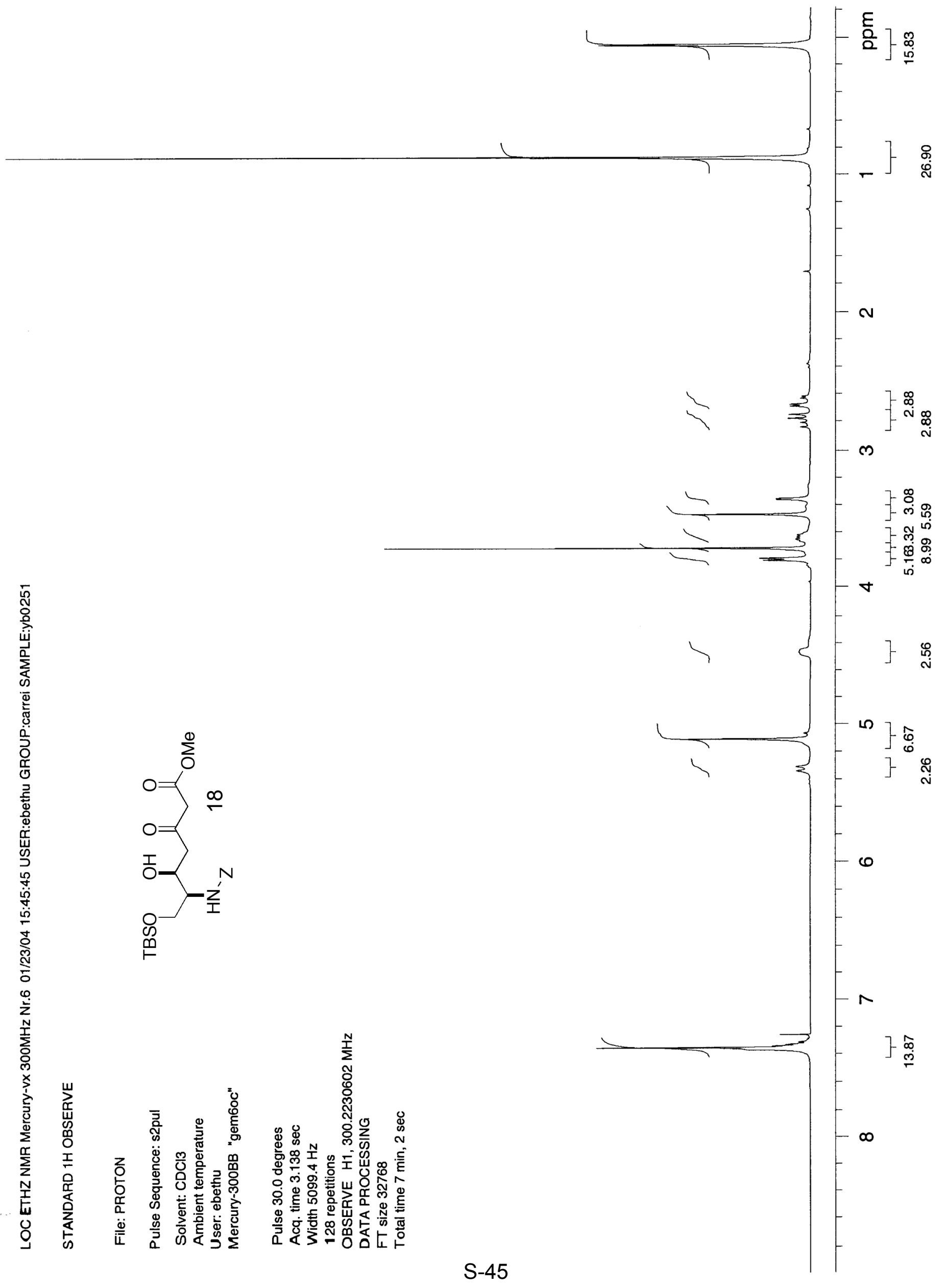




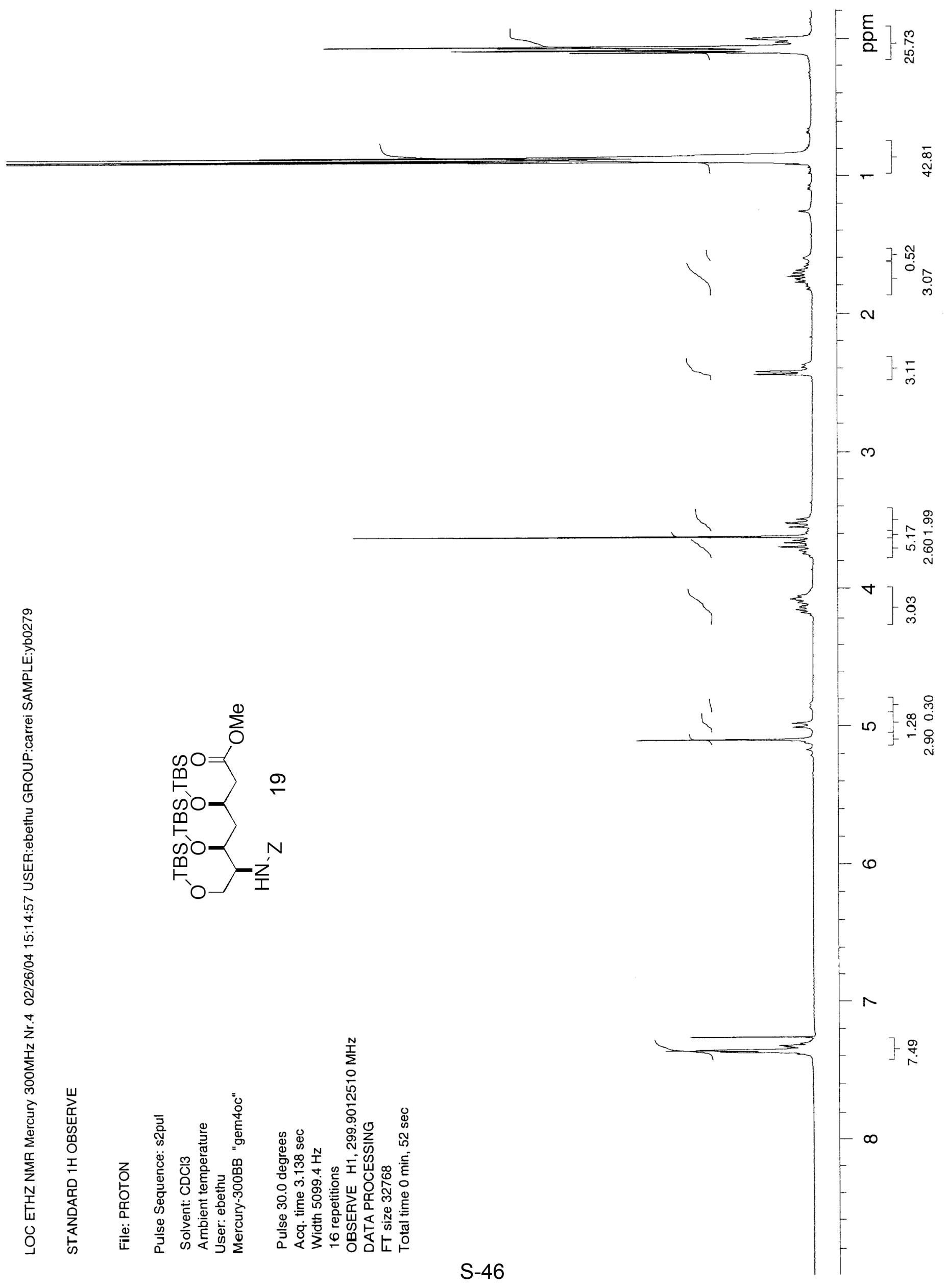




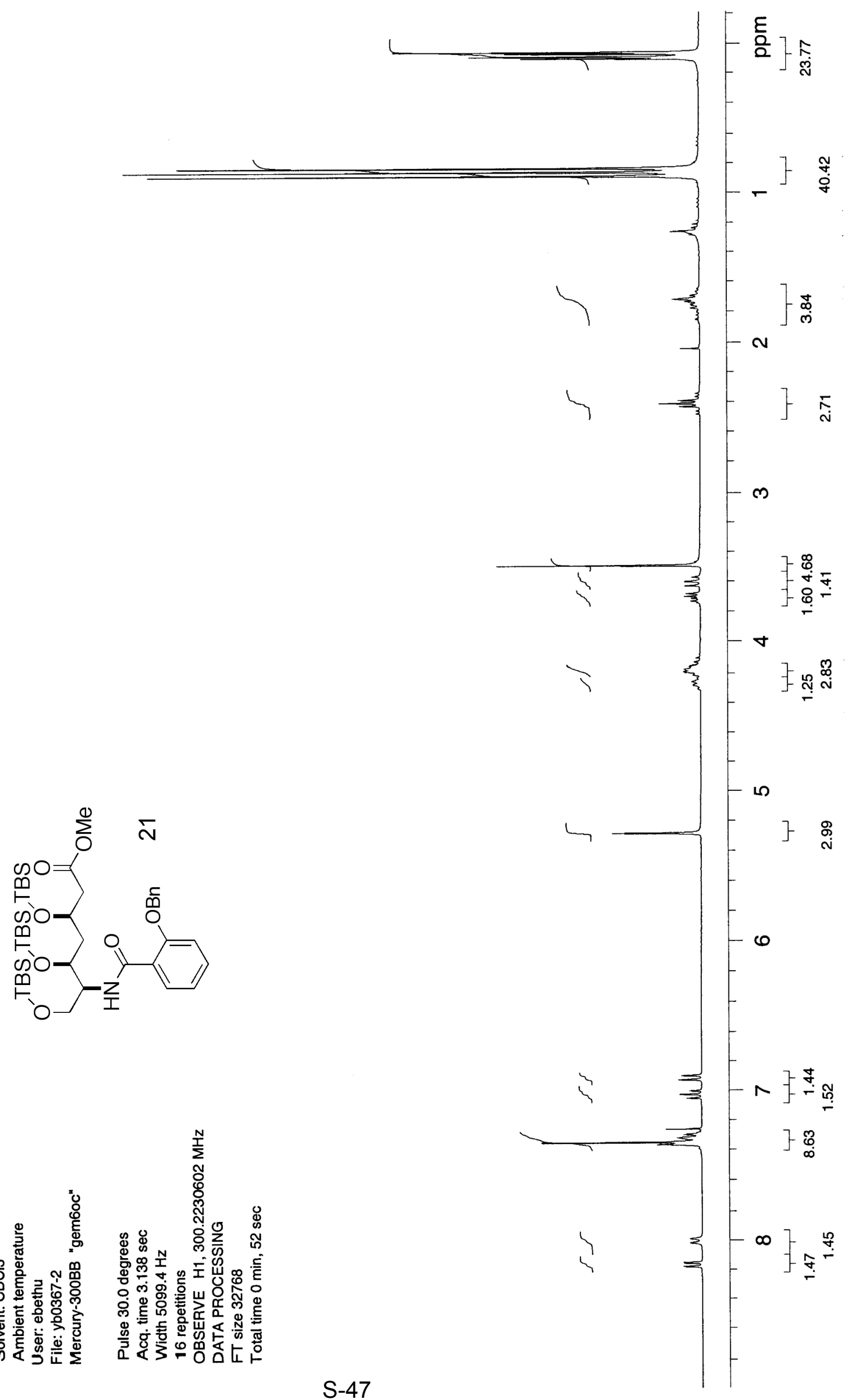




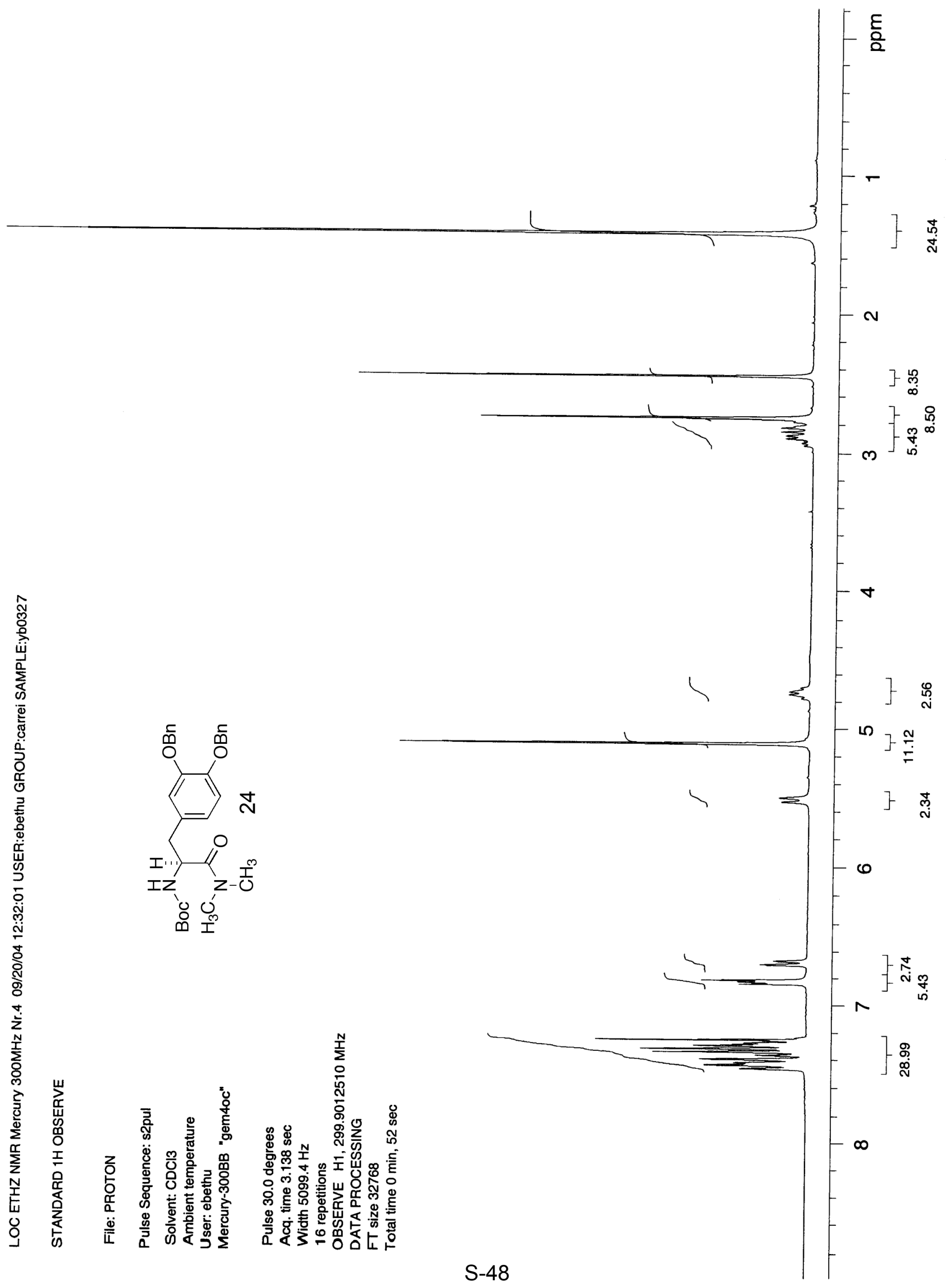




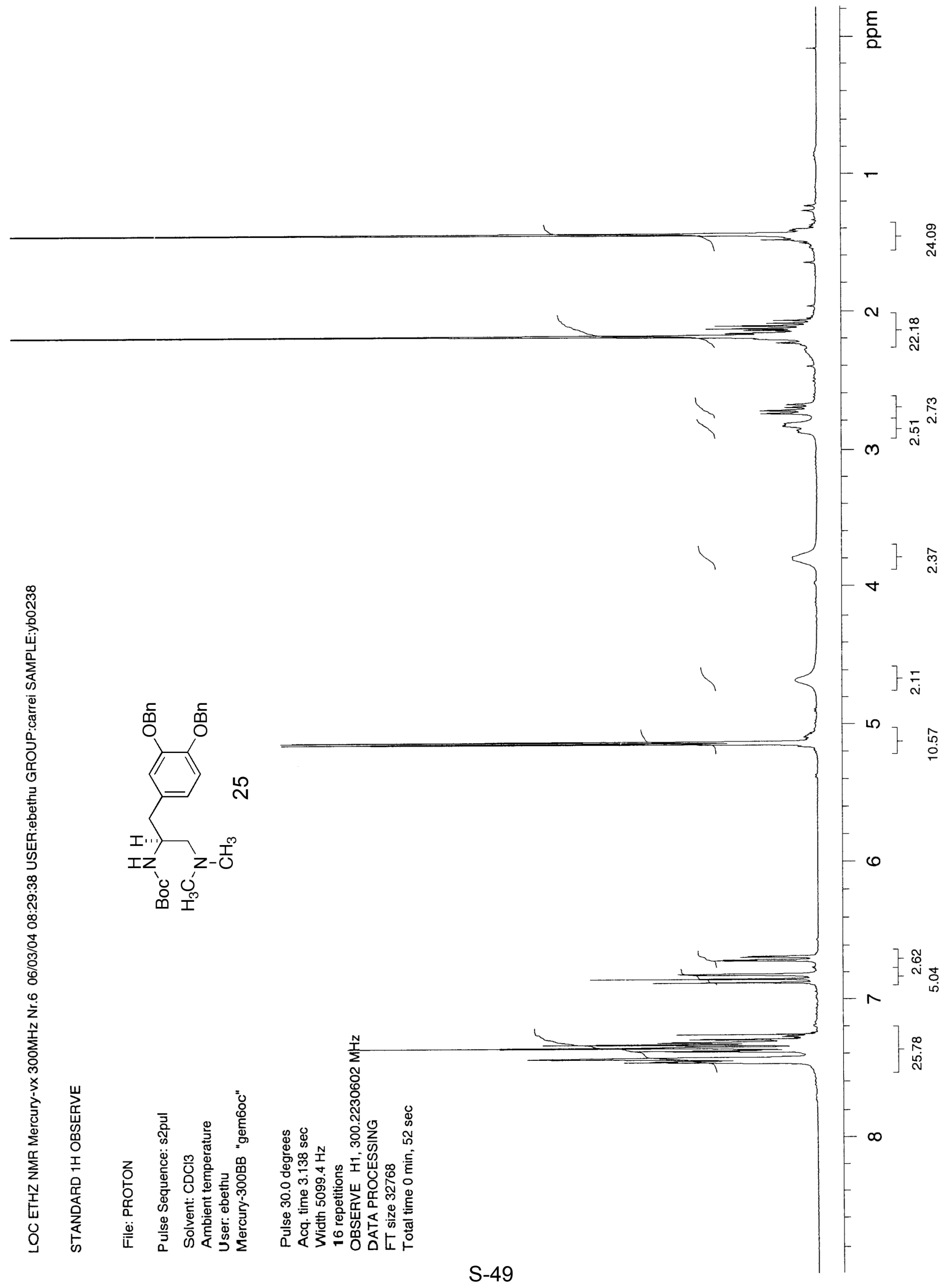



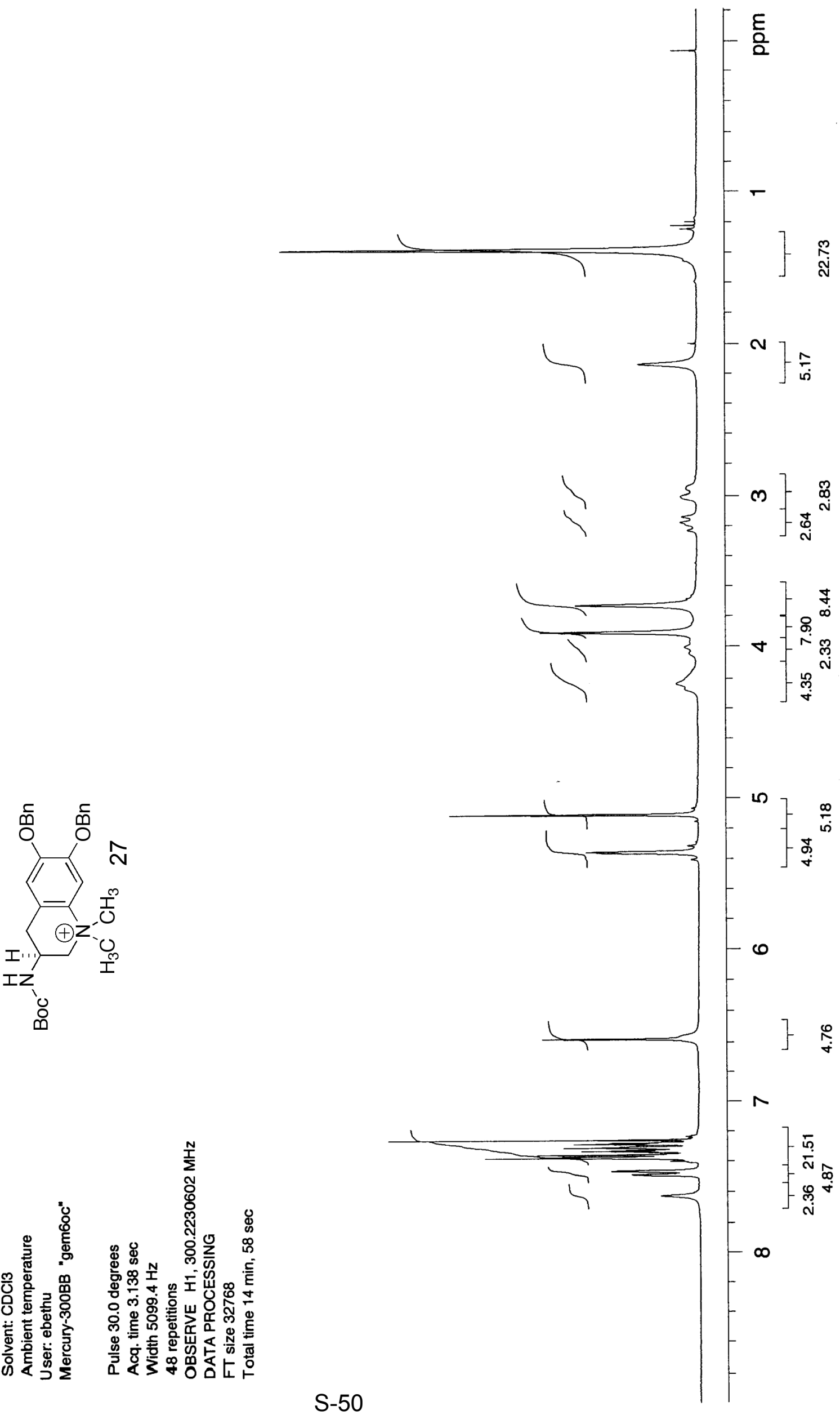


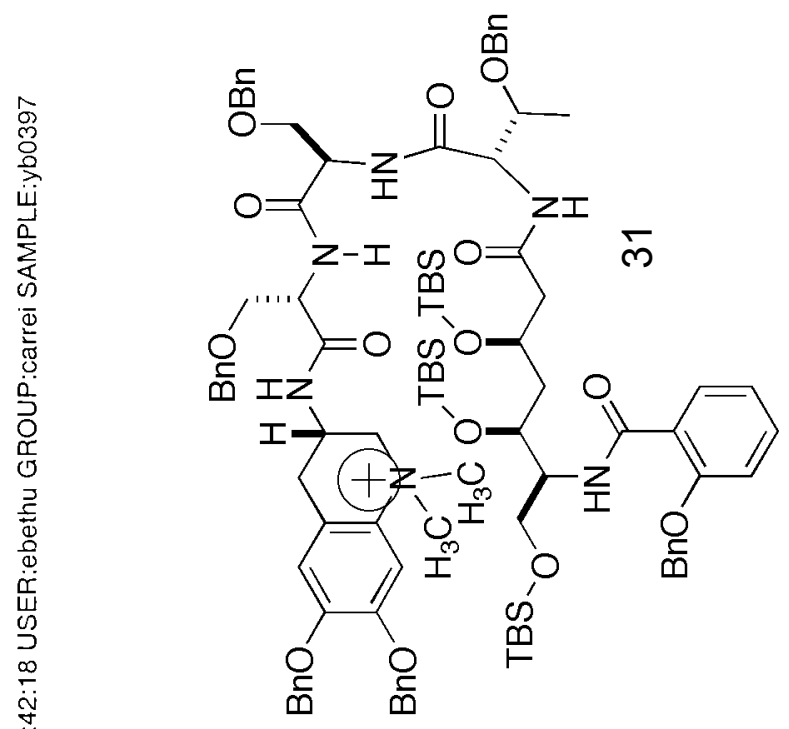

흘

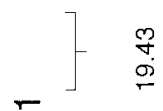
웅

] ํํำ

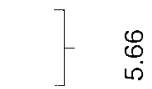

N 妾

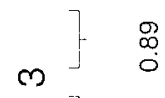
$-5$ $\stackrel{-\infty}{q}$

-

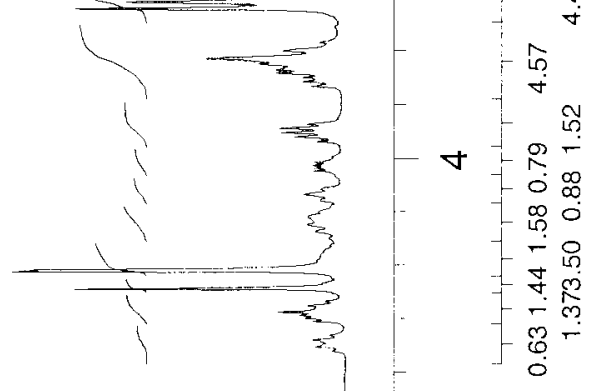

م

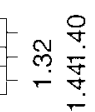

0

$5 \stackrel{9}{?}$

$\frac{\infty}{i}$

高

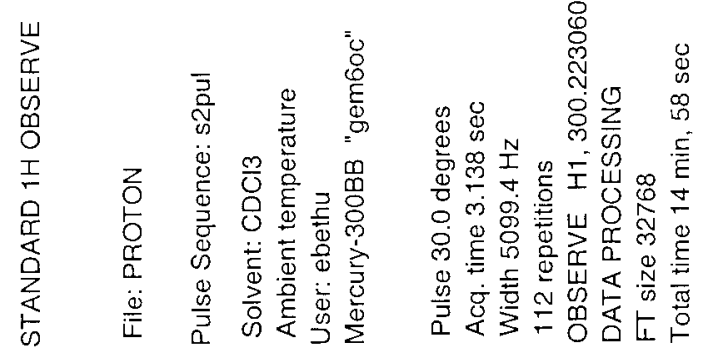




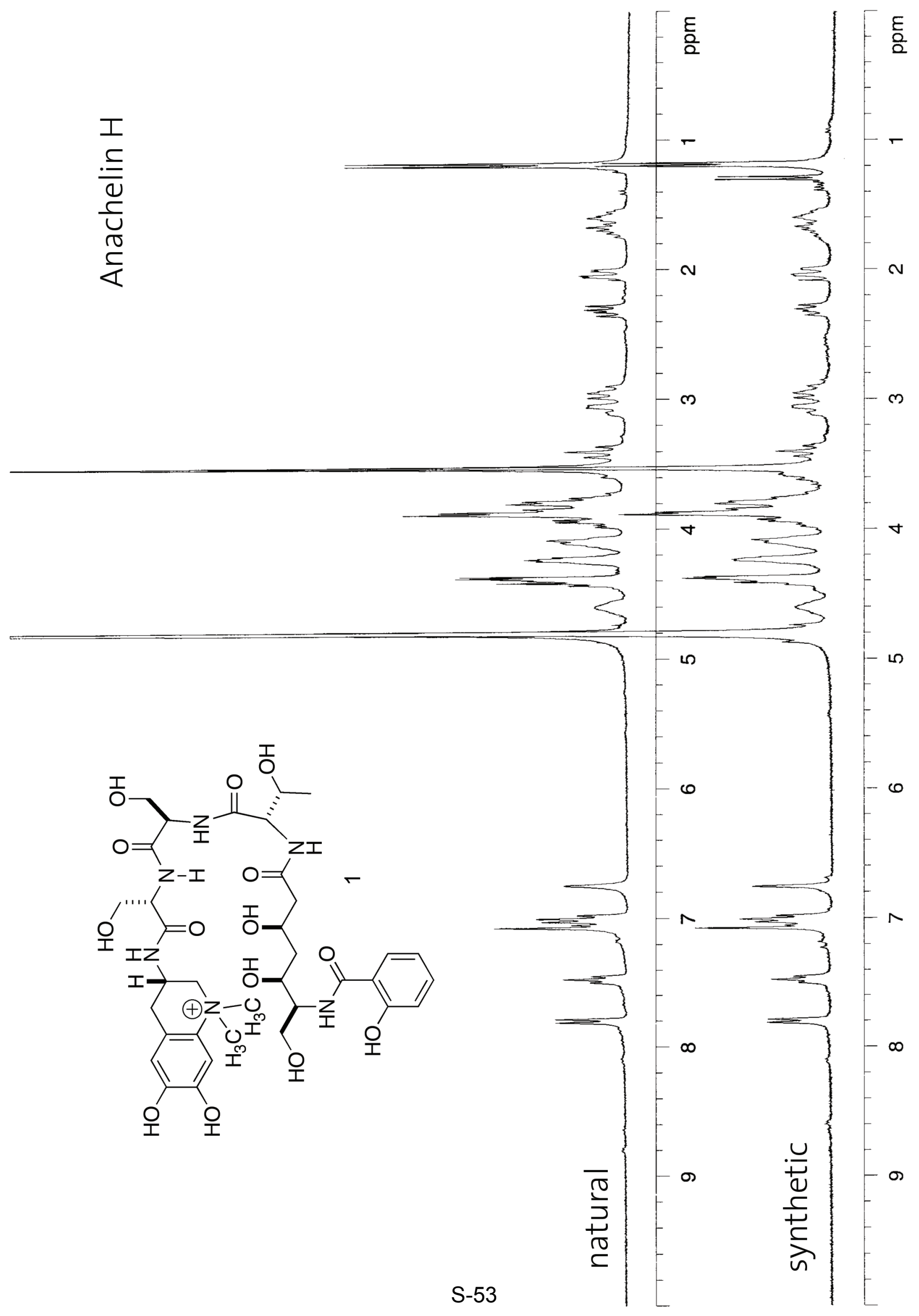




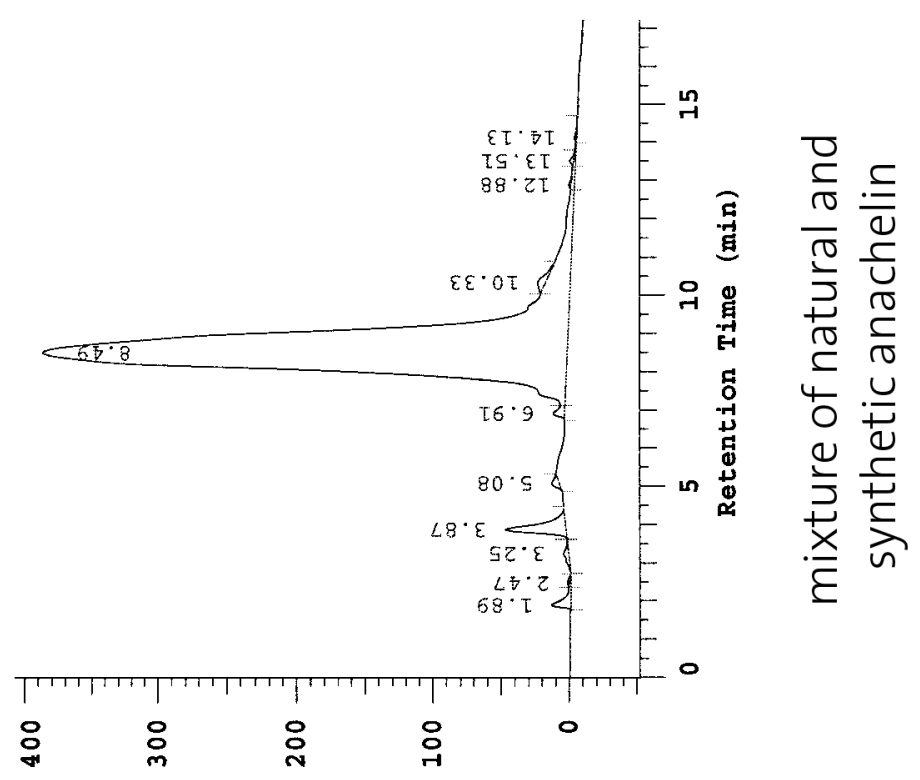

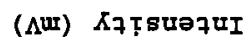
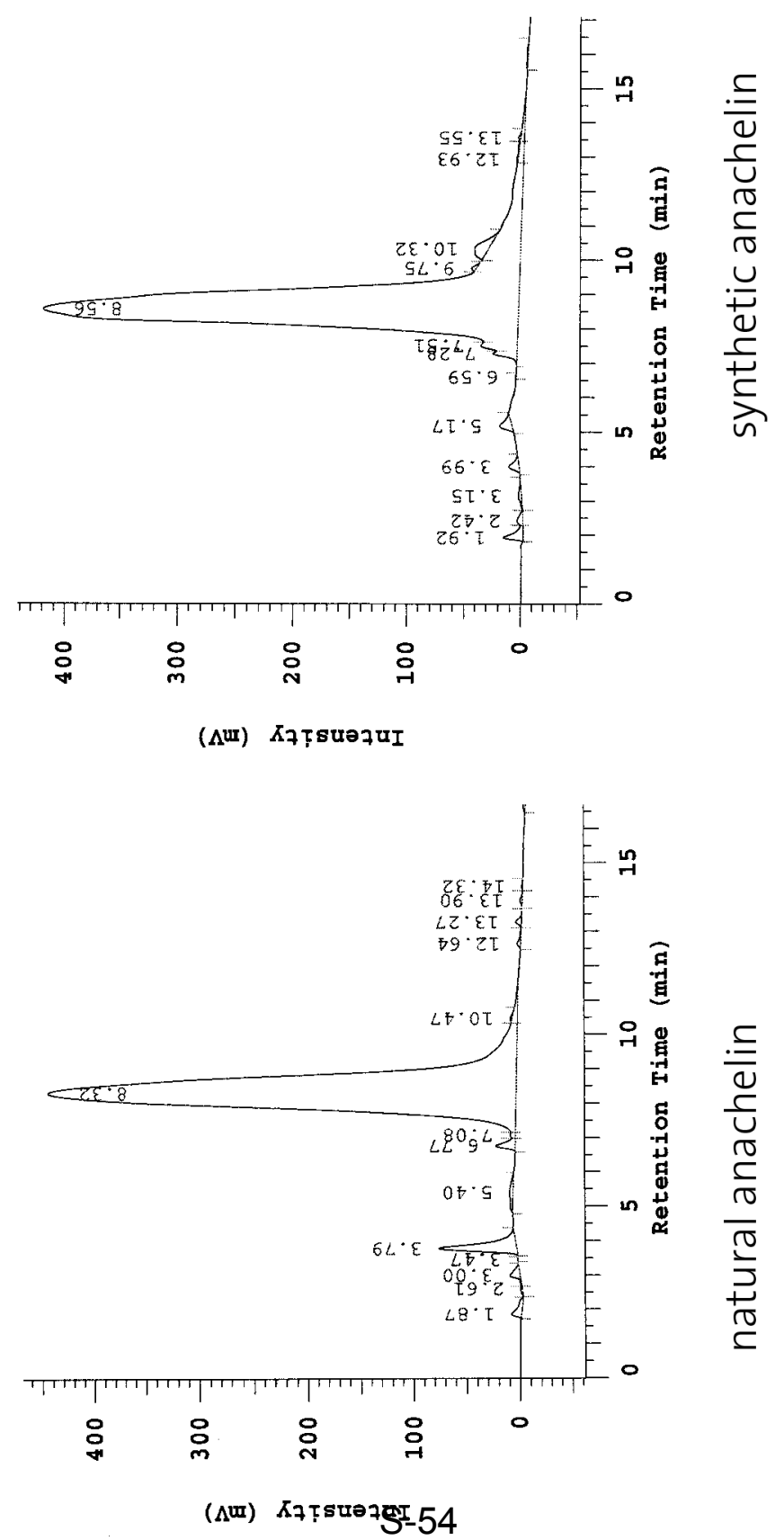


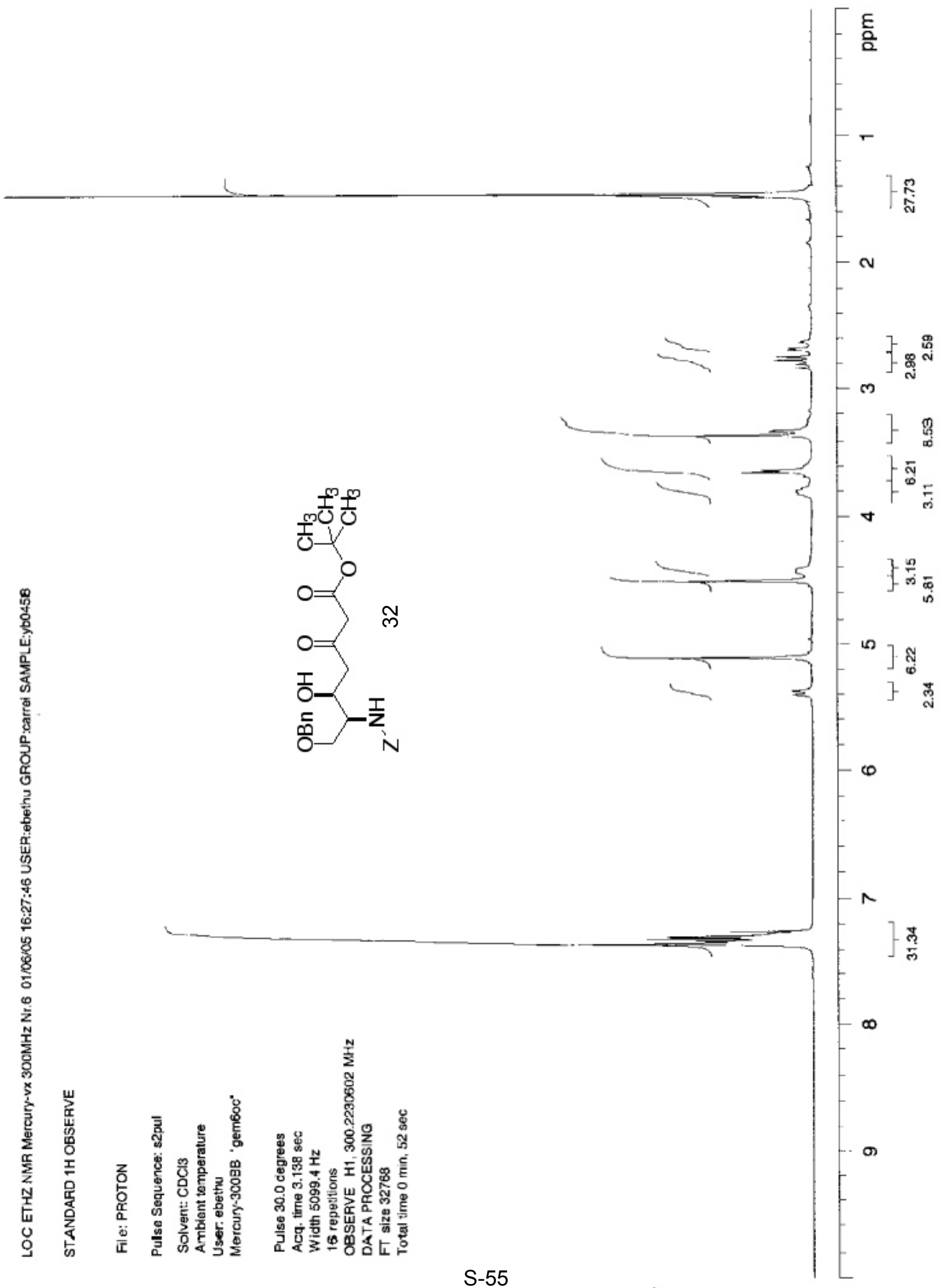




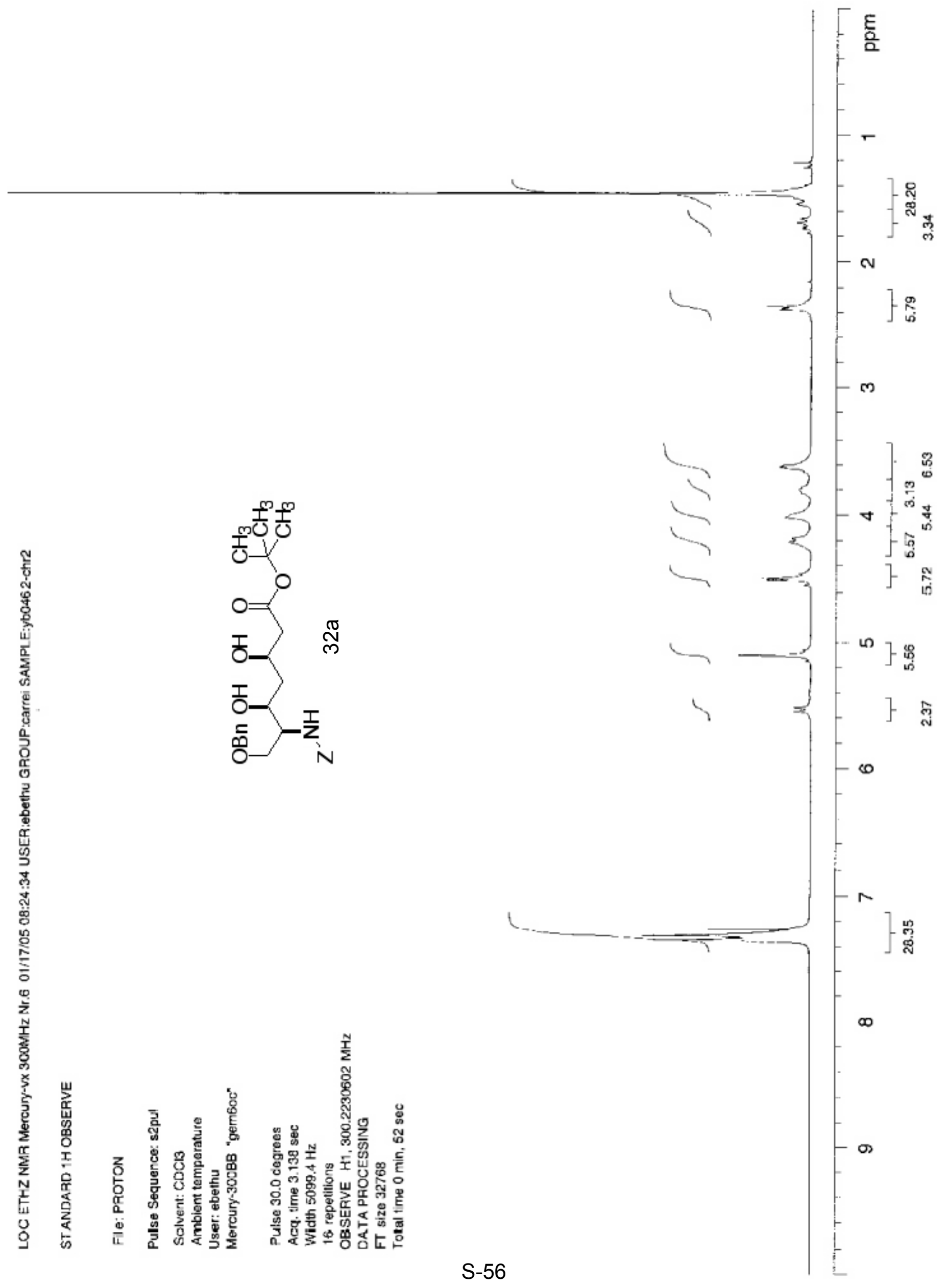




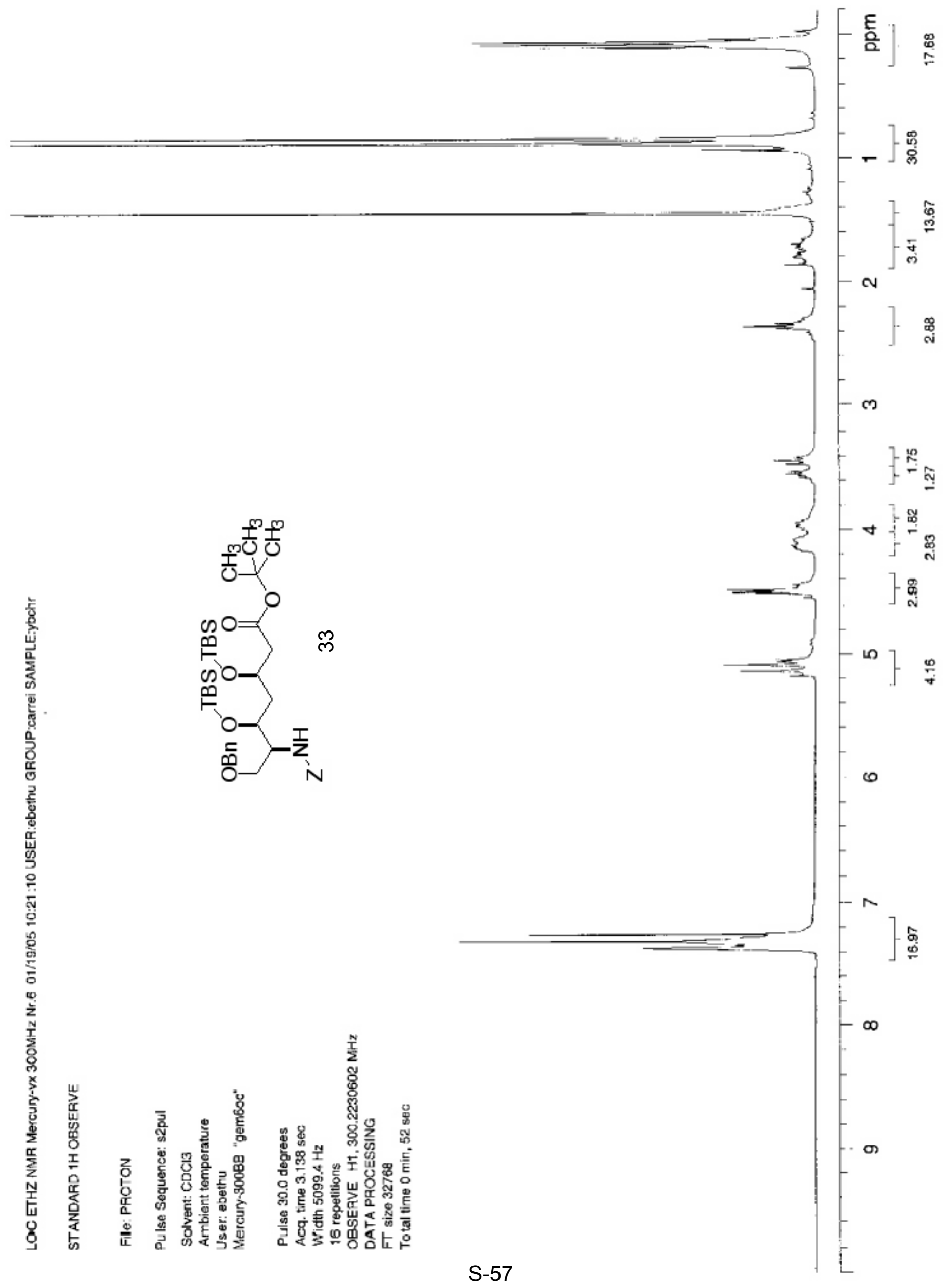




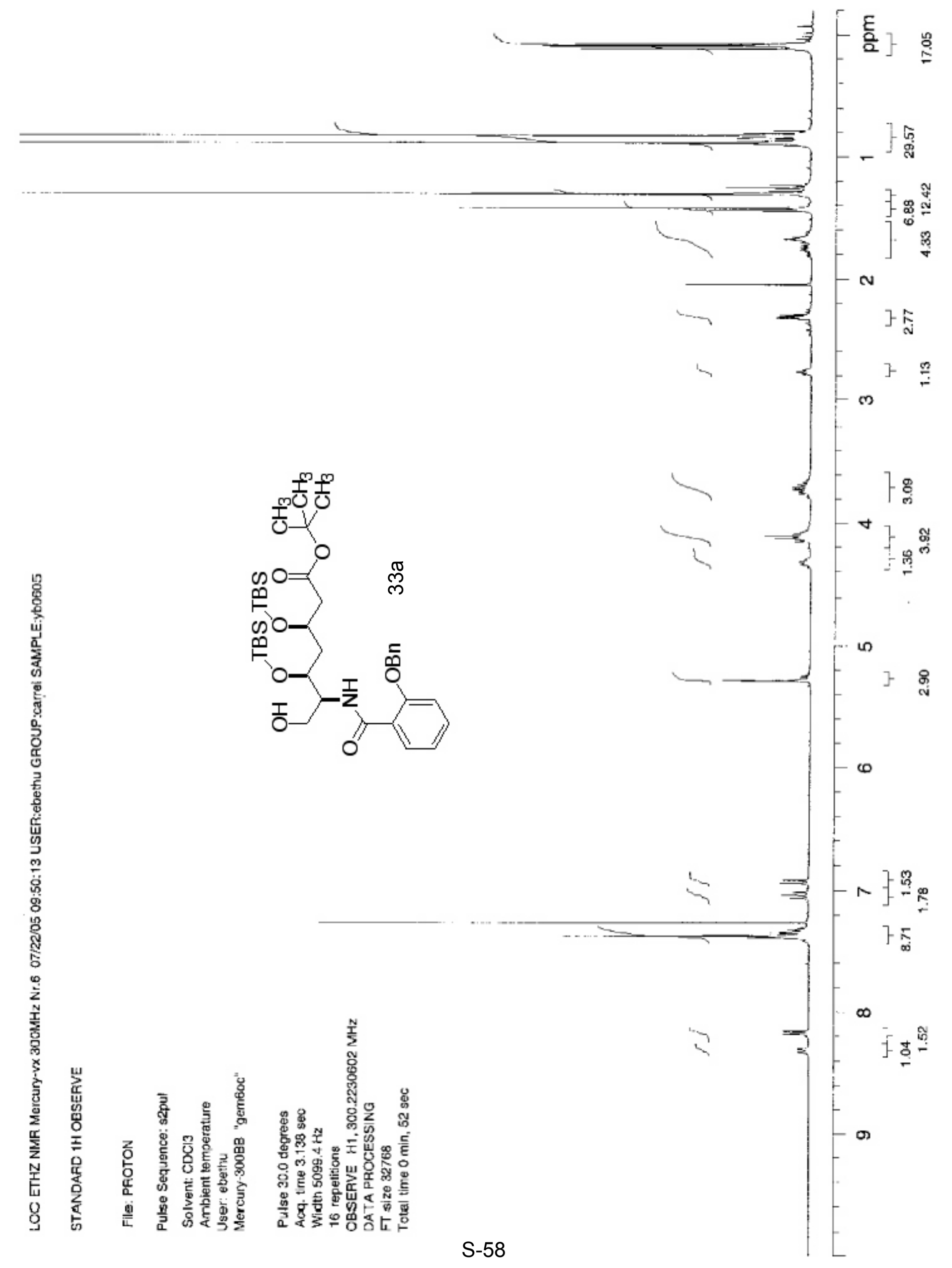




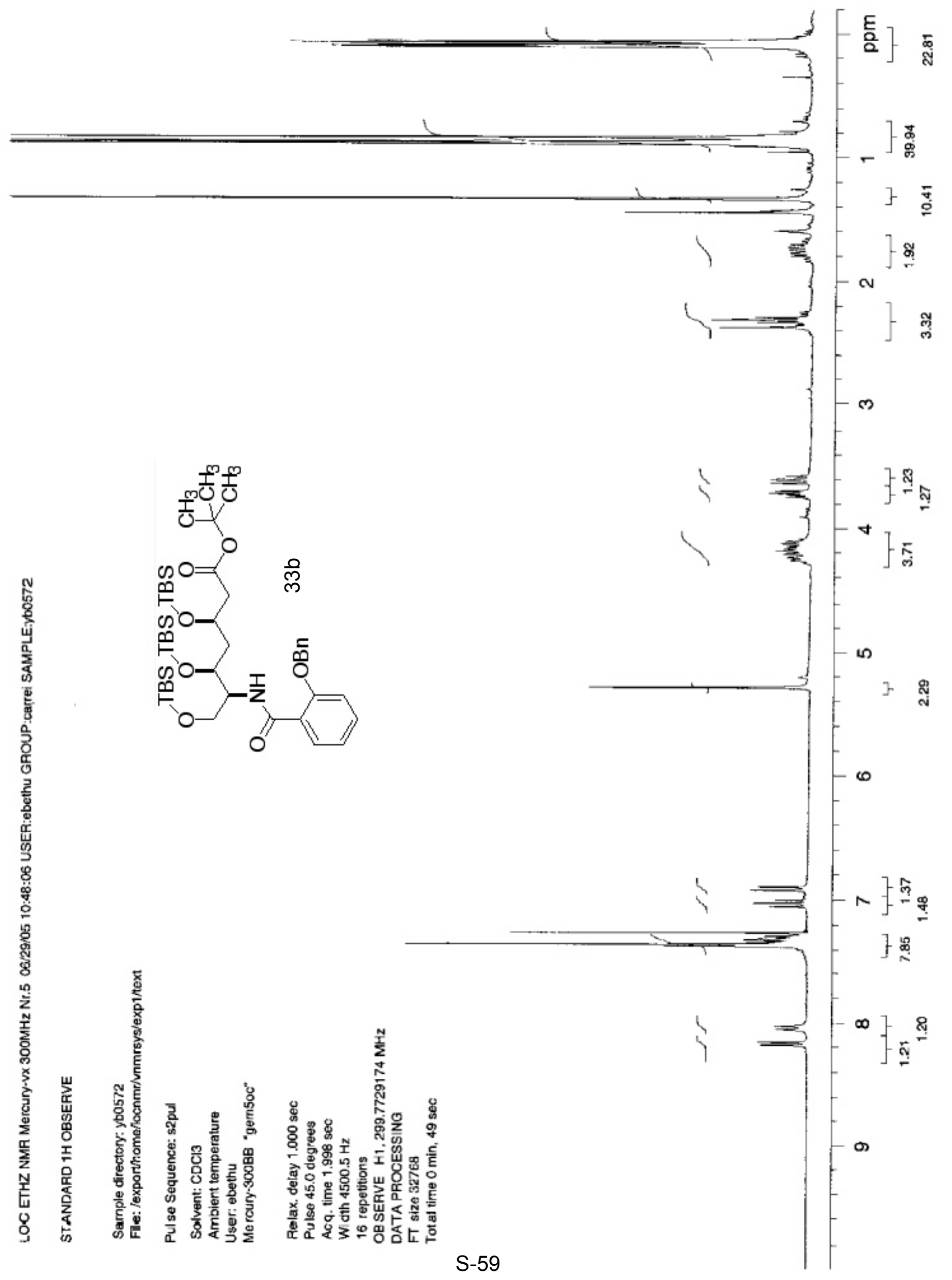




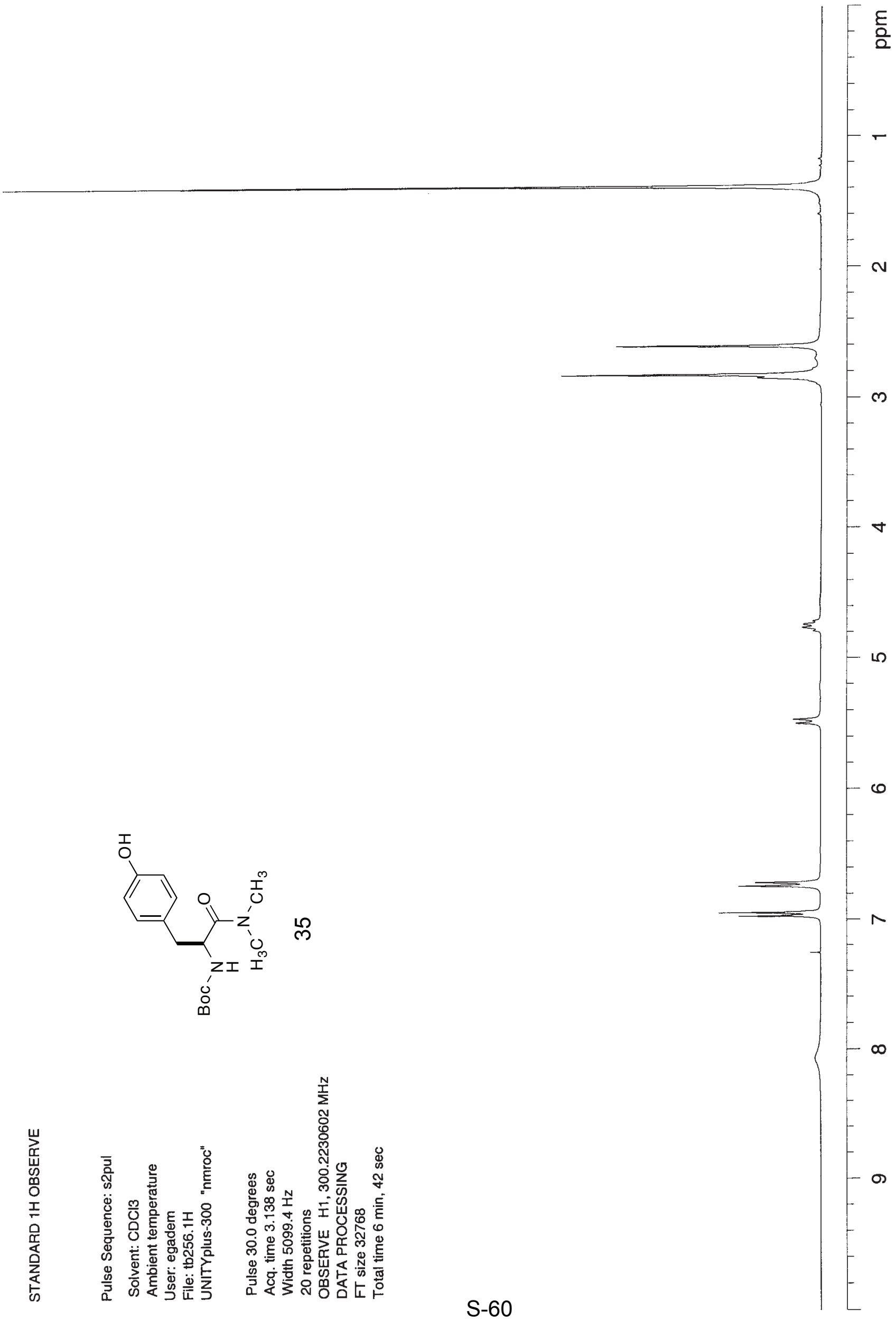




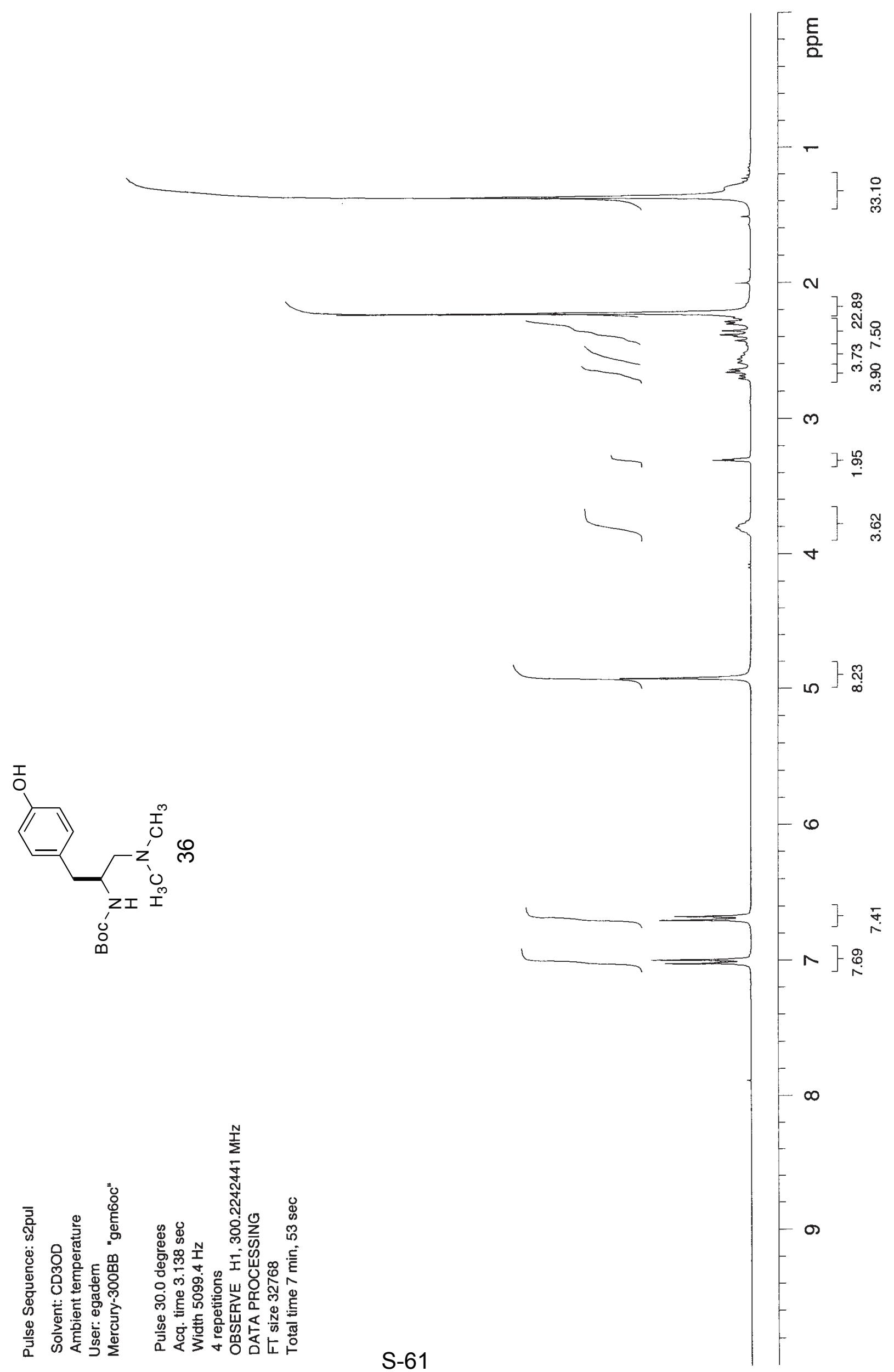

